\title{
WestVirginiaUniversity
}

THE RESEARCH REPOSITORY @ WVU

Graduate Theses, Dissertations, and Problem Reports

2014

\section{America's Lollipop Licking Tease: The Eroticization of the Female Child in 1930s Film}

Susan Jennings Lantz

West Virginia University

Follow this and additional works at: https://researchrepository.wvu.edu/etd

\section{Recommended Citation}

Lantz, Susan Jennings, "America's Lollipop Licking Tease: The Eroticization of the Female Child in 1930s Film" (2014). Graduate Theses, Dissertations, and Problem Reports. 461.

https://researchrepository.wvu.edu/etd/461

This Dissertation is protected by copyright and/or related rights. It has been brought to you by the The Research Repository @ WVU with permission from the rights-holder(s). You are free to use this Dissertation in any way that is permitted by the copyright and related rights legislation that applies to your use. For other uses you must obtain permission from the rights-holder(s) directly, unless additional rights are indicated by a Creative Commons license in the record and/ or on the work itself. This Dissertation has been accepted for inclusion in WVU Graduate Theses, Dissertations, and Problem Reports collection by an authorized administrator of The Research Repository @ WVU.

For more information, please contact researchrepository@mail.wvu.edu. 
America's Lollipop Licking Tease:

The Eroticization of the Female Child in 1930s Film

Susan Jennings Lantz

Dissertation submitted to the Eberly College of Arts and Sciences

at West Virginia University

In partial fulfillment of the requirements for the degree of

Doctor of Philosophy in

English

Dennis Allen, Ph.D., Chair

Laura Brady, Ph.D.

Anna Elfenbein, Ph.D.

John Lamb, Ph.D.

Janice Spleth, Ph.D.

Department of English

Morgantown, West Virginia

2014

Keywords: 1930s film, children in film, feminist film criticism, Shirley Temple, Stella Dallas, Wizard of Oz, Gone With the Wind, eroticization of children, Great Depression and Film, Hays Code, Scarlett O'Hara, Dorothy Gale

Copyright 2014 Susan Jennings Lantz 


\section{ABSTRACT \\ America's Lollipop Licking Tease: The Eroticization of the Female Child in 1930s Film}

\section{Susan Jennings Lantz}

This dissertation examines the eroticization of female children in film during the 1930s as a mechanism for concealing troubling realities of the Great Depression in the United States. The repressed sexuality embedded in the plots of Post-Hays Code movies featuring Shirley Temple and characters such as Stella Dallas, Dorothy Gale, and Scarlett O'Hara serve to suture over a crisis of masculinity triggered by changing roles in gender, race, and class. By attempting to invoke the image of a "little girl" in place of that of a grown woman, some films (such as Gone With the Wind, and Bright Eyes) do a better job of masking these abruptions than do other others (such as Stella Dallas and The Wizard of $\mathrm{Oz}$ ). 


\section{DEDICATION}

\section{To Max and Murry.}

Someday when you set off to follow your own dreams,

I hope you are surrounded with as much love and support as I have been.

Besides, who knows?

You might just save the world! 


\section{ACKNOWLEDGEMENTS}

There are a number of people who helped me pull this off. I hope I have remembered to acknowledge every one of them, because I am indebted to so many people for so much support.

There were friends like Amie Langfitt Johnson, Tonya Paugh, Bobbie Brandt, the late Tim Martin, Anna Allen, and Charlotte Green who volunteered to babysit so I could go to class or write or relax for an evening.

There were other friends like Jennifer Cullison Stanford, Chelle Adams, Kelly Diamond, and Bernadette Jungblut who read chapters and gave me feedback and didn't find my obsessive interest with Shirley Temple weird at all. (Or at least they pretended not to.)

There was Laura Little who has pretty much read everything I have written since 1987 when we met at Arnold Hall, and who can still out-think me any day (and usually out-talk me, if she deems it necessary.)

There were my committee members who taught me things about film (Anna Elfenbein), genre (John Lamb), the origin of the flapper (Janice Spleth) and feminist criticism (Laura Brady). They also spent time reading drafts, and listening to me prattle on about little girls and the Great Depression far longer than they probably cared to.

There was my chair, Dennis Allen, who has been a mentor and coach during this project. Without him I would have thrown in the towel years ago. Instead, my life has blossomed into something about which I could only have dared dream. I don't know what I am going to do next summer when I don't have "discussing Shirley Temple" as an excuse to sit on his front porch, drink coffee, and think out loud.

There was my mother, who from my very first book report on Harriet the Spy (in the fifth grade) until now has served as a sounding board, a critic, and my biggest fan. I have never known her to be without a good book or a witty comment, and she continually serves as an inspiration to me and my life. She was also the first person to point out the obvious eroticization of Shirley Temple and her suggestive short dresses. To paraphrase E.B. White, "It is not often that someone comes along who is a true friend and a good writer." Iris is both.

Then of course, there is the man who said the sexiest words anyone could possibly say when I started this project: "I'll do whatever I can to help you make this happen." Craig Collins Lantz, you are my partner, my Mr. Incredible, and my co-conspirator. Thank you for encouraging, supporting, complimenting, and taking care of me and our family. You. Freaking. Rock.

And finally, there are my muses. Max and Murry, your humor, wisdom, and affection brings joy, perspective, and balance to my life. I wish I could say, "Never change." But in light of my dissertation topic, that would be way too creepy. Just always know that Mommy loves you more than life itself. 


\section{TABLE OF CONTENTS}

Chapter 1:

"A Babylon Revisited": The Women and Girls Carried out Screaming....................................

Chapter 2:

Shirley Temple: Bright Eyes and Dark Men

Chapter 3:

Stella Dallas: I Don't Believe there is a Man in the World Who Can Get Me Going Again........71

Chapter 4:

The Wizard of Oz: Are You a Good Witch or a Bad Witch?

Chapter 5:

Gone With the Wind: Before War and Poverty Had Done Things to You..... 


\section{Introduction}

He would come back again some day; they couldn't make him pay forever.

But he wanted his child and nothing much was good now, besides that fact.

He wasn't young anymore with a lot of nice thoughts and dreams to have by himself (Fitzgerald 230).

Published in 1931, F. Scott Fitzgerald's short story Babylon Revisited would serve as a prophetic metaphor for the image of film in the United States for the next decade. The story concerns a man seeking atonement and respectability in order to gain custody of his daughter; meanwhile Jazz Age ghosts of the 1929 Stock Market Crash haunt his days. For Charlie, attainment of his child represents reconciliation with past dalliances into a world of excess, and a world in which individual lives aren't nearly as important as the party. But Charlie Wales, the protagonist, discovers, or probably already knows, that expiation isn't so easily achieved, and that children tend to be elusive prizes to catch at best. Keeping them, of course, is impossible. Charlie has lost his innocence, so has America, and soon his daughter will, too.

Influenced partly by the life of Fitzgerald, who like Charlie, had great success in the 1920 's, but whose life was damaged by drugs, a foundering marriage, and questionable parental fitness, Babylon Revisited's central theme indicates that Charlie's loss wasn't as much money he lost when the market crashed, but the moral corruption he witnessed and on which he was a willing participant during the preceding decade. At the end of the piece, Charlie tells the bartender that he lost everything important in the "boom" before the crash. The bartender suggests the cause to be "selling short." Charlie, ironically, replies that it was "something like 
that." While selling short in the world of finance may mean the investor will profit from the loss of value on his net asset, and such practices can yield high gains, doing so is risky and can also yield staggering losses. Ultimately, this sort of trading can bankrupt not only individuals, but entire banks and even countries. The practice of selling short was one of many factors that led to the stock market crash of 1929, and it was eventually banned for nearly eighty years in the United States. Charlie's behavior and life in Paris before the crash consisting of "champagne dinners and long luncheons that began at two and ended in a blurred and vague twilight" contrasts sharply with the life in the "warm" home of his sister-in-law who cares for his daughter and where "the children felt very safe and important: the mother and father were serious, watchful" (215 and 226). Just as investors in the United States had sold the country short by counting on a profit from loss of value before the crash, Charlie had sold himself short by not investing in the love, affection, and future of his wife and daughter. Charlie hadn't been "serious" and "watchful," and neither Charlie's daughter nor wife had felt "safe and important." Instead he had invested in the jocular, moneyed, and decadent lifestyle of the expatriates in Paris during the Roaring Twenties. Investors profited by a loss in value and Charlie traded on the values of his family's youth and innocence, and everyone lost.

It is a widely accepted interpretation that in Babylon Revisited, Charlie does not realize the value of the domestic sphere until after he has cheapened its importance and allowed it to slip through his fingers. I would further that argument by suggesting that Charlie doesn't realize the value of his relationship with women until he has allowed them to become cheapened and lost to tragedy. In the story, through flashbacks from various characters, we are given a glimpse of a philanderer who introduces his wife to a wealthy and raucous lifestyle and is happy to knock on 
a friendly flapper's door at 4 a.m. looking for a drink and a good time. However, when his wife exhibits some of the same sexual liberation that he enjoys, their subsequent fight sparks a near tragedy and is the beginning of the end for their relationship. In a drunken stupor he locks her out in the snow, and, as she is also incapacitated, she wanders the streets of Paris in the night nearly freezing. Although Charlie contends that this incident doesn't end in tragedy, it is impossible to dissuade her sister, the guardian of his daughter, that such cruelty wasn't commonplace. What was commonplace, though, was the devaluing and objectification of women in the degeneracy of his previous affluent world.

The little man Helen had consented to dance with at the ship's party who had insulted her ten feet from the table; the women and the girls carried screaming with drink or drugs out of public places--

--The men who locked their wives out in the snow because the snow of 29 wasn't real snow. If you didn't want it to be snow you just paid some money. (230)

In order to make up for the loss of a decade, the loss of his wife, the loss of a stable home and hard-working American values -- all of these the things that helped him make money and put him in a position of privilege where he was "a sort of royalty, almost infallible, with a sort of magic" around him, Charlie seeks to attain absolution by regaining possession of his daughter (213). The problem, for Charlie, anyway, is that his late wife's sister isn't convinced that he has changed, and is reluctant to allow him to take his daughter. She's right. Clearly, Charlie hasn't really changed, and it isn't Honoria that Charlie wants and misses. It is really the wealth, power, and 
near infallibility that she represents. Retaining custody of this little girl could, in fact, restore his damaged masculine pride.

In this introduction to my scholarly endeavors regarding popular images of eroticized female children in 1930s film, I hope to show not only how Charlie's desperation to restore his fractured family is analogous to America's desperation to restore its fractured and altered gendered identities, but also the rise and change of female identity in the decade immediately preceding the Crash of '29, the history of child idolatry in Western Culture, and a summary of how each of the following chapters further my argument. In the final analysis, the image of the American female that emerged in popular culture in the 1930s was constructed as a reaction and compensation to the utter economic devastation felt by the dominant image of American masculinity. The fashioning of a little girl as a gendered ideal was the by-product of the reconstruction of the American male as he adapted to issues of class mobility, familial disintegration, changing economic and domestic roles, and unresolved racial tensions. Popular films and child stars of the day were both influenced by, and helped influence the fixation on the containment of female eroticism in the body of a child. Films like Stella Dallas, The Wizard of $\mathrm{Oz}$, Gone With the Wind, and the oeuvre of Shirley Temple reflect different attempts at this containment, as well as the outcome and success of their intent. It is my aim that the following pages address the manner by which the cinematic physical image of a little girl becomes an eroticized and nostalgic image of womanhood and a lost decade in much the same way that Charlie's yearning for his daughter is really a yearning for the nostalgic past.

In the early 1930s, the solid economic, racial, and ideological ground upon which the tenants of white masculinity had been constructed began to shift dramatically. Traditional 
patterns of family life altered significantly as full-time work for men became scarce, and the roles of women and children began to change in regards to the economies inside and outside of the domestic space. In addition, the economic down-turn further illuminated the racial discord that continued to bubble to the societal surface from the failed emancipation of African American slaves in the American South some 70 years earlier. The films of the 1930s served to help reconstruct white American masculinity through fetishistic placement of little girls in popular films of the era. Shirley Temple films and features like The Wizard of $\mathrm{Oz}$, Stella Dallas, and Gone With the Wind all introduce very different types of female children who illuminate, deflect, and ultimately conceal the anxieties of the day. But in order to understand Charlie's pursuit (and America's pursuit) of a child, one must first understand what Charlie, F. Scott Fitzgerald, and American women had been up to during the previous decades.

\section{Part I}

During the end of the late 19th Century and the beginning of the 20th Century, images of women in popular culture moved away from the selfless Victorian "Angel in the House" and toward the independent, athletic, standard of American beauty, the Gibson Girl. Early movie serials in the 1910s such as The Perils of Pauline, the Exploits of Elaine, and The Hazards of Helen "featured athletic, adventurous girls, who rejected ladylike behavior and stay-at-home femininity" (Mintz 224). But by the 1920s, spurred by increased independence brought on by necessity during WWI, the ratification of women's right to the vote, and the continued industrialization of the middle class, even newer images of American womanhood, such as the suffragette and the flapper began to surface. 
Fashion and style among American women changed and quite literally lightened drastically during this time period. American girls bobbed their hair, shortened their skirts and never looked back. In the fifteen year time span between pre-WW I and 1928, the year before

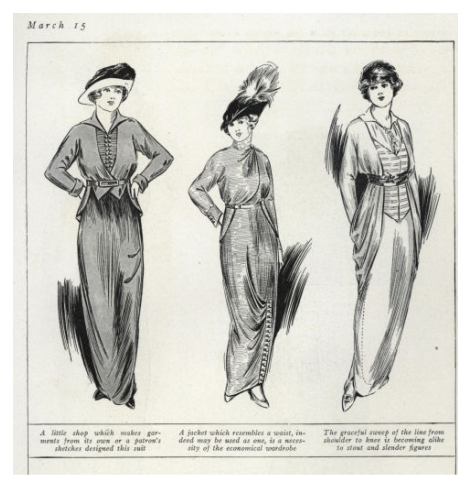

Figure 1: Fashionable women's clothing styles pictured in a 1913 issue of Vogue. Note the length, waistline and dependence on hand made clothing in PreWWI styles. the stock market crash, women stopped wearing corsets, multiple layers of petticoats, and skirts below the knees. Consequently, the sheer yardage of material required to make up the average women's complete outfit declined from $191 / 4$ yards to 7 yards and, due to availabilities of new sorts of textiles like silk and rayon, the actual fabric of women's clothing was becoming thinner and lighter (Only Yesterday Allen, 79). Even hair styles became easier to manage. The close-cropped bob, which began as a fad in the early part of the decade, and simply didn't go away, allowed women to lighten the weight upon their bodies even more. Because fashionable women's hair (for women of all generations, not just the young) had become so short, the "small cloche hat which fitted tightly on the bobbed head" became all the rage and, as Allen asserts, "the manufactures of milliner's materials joined the hair-net manufacturer, the hair-pin manufacturer, and the cotton goods and woolen goods and corset manufacturers, among the ranks of depressed industries" (Allen 80).

According to Rena Sanderson, both the Gibson Girl and Flapper images of female beauty managed to undermine the gender politics of maternal leadership present in the Nineteenth Century. But, she points out, in the Twenties, "various discourses of pop-culture co-opted the rhetoric of feminism" from the "activist feminism" of the suffragettes to "lifestyle feminism" 
embodied by the Flapper (146). It wasn't just lighter and less-restrictive clothing that changed for the women of this era. Their whole lifestyle was undergoing a great transition. Women were, according to Allen, growing independent from the "drudgeries of housekeeping" (73). People were moving into smaller, more manageable apartments, there was easier access to canned foods, and in urban areas there was more access to delicatessens. Not only was it easier to make meals, but commercial laundries were more available, and electric washing machines, electric irons, and vacuum cleaners made labor intensive housework lighter and faster. Off-the rack clothing was not only readily available to the average female consumer in America, but heavily marketed to her as well. The marketing of such freedoms were clearly directed towards the

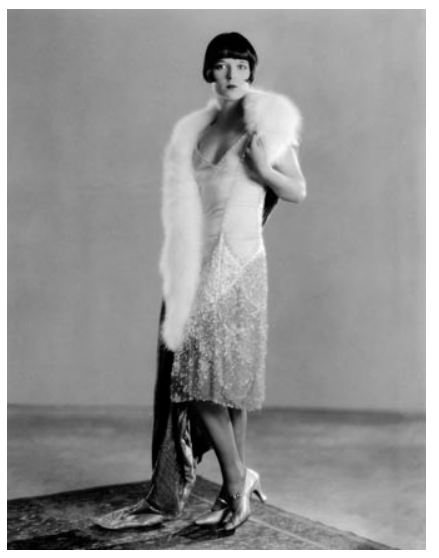

Figure 2: Photograph of 20 s Flapper Louise Brooks, replete with bobbed hair, knee length skirt, flat figure, and lowered waist. two dominant images of womanhood during this era, the Suffragette and the Flapper. But ultimately the Flapper became the symbol of 1920s femininity and also of the mass consumerism, moral anarchy, and lack of direction personified by the Lost Generation during the Jazz Age. Unlike the Victorian Angel in the House, her identity wasn't based on sacrifice. Unlike the Gibson Girl, she wasn't shortening skirts for athletic and wholesome activities (well, at least not wholesome activities). And unlike the Suffragette, she had sex appeal.

Fitzgerald is credited as having "invented" the flapper with much of his early published writing, and his wife, Zelda, is often heralded as the embodiment of the trope. Like Zelda Fitzgerald, "the flapper invited the public gaze," and groomed herself "appropriately" (Anderson 
150). In various stories written long before "Babylon Revisited," Fitzgerald taught his readers about the "rituals of 1920s youth behavior" (Zeitz 44). Fitzgerald's uncanny ability to market himself, his work, and his family as the true embodiment of the Jazz age not only helped narrate the script for the rise and fall of his own nuclear family, but helped manufacture the rise and fall of a cultural generational movement. While he described the generation of the world around him as he perceived its selfconstruction through the acquisition of money, things, property, sex, and booze, he was writing Flapper stories like "Bernice

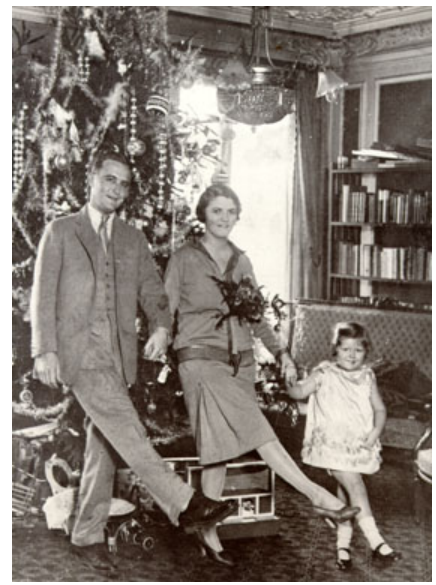
bobs her Hair" and putting together collections like Flappers and Philosophers and Tales of the Jazz Age. But he and Zelda were also participating in a constant state of raucous performativity for the popular press as they drank, partied, and ran through magazine royalties as fast as they could. They were good looking, charming, well-spoken, and often photographed. Years later, Scott himself pointed out that they had been "pushed" into Figure 3: F. Scott, Zelda, and Scottie Fitzgerald in 1925 Paris. Although the picture is seemingly that of a domestic family moment, ultimately it was used to illustrate a 1928 article published by College Humor penned by Scott and Zelda. Typical of the Fitzgeralds, the domestic familial sphere is juxtaposed into a public forum.

the role as "spokesman for a time. .. and product of that moment," and that they had spent the twenties being "quoted on a variety of subjects we knew nothing about" (Zietz 17).

In fact, it could be argued that both the image of the Zelda's Flapper in the 20s and Charlie's idealized/eroticized little girl of the 30s (whom we will be discussing in more detail soon) were male constructions of female identity and, by extension, sexuality. In Flapper, Joshua Zeitz points out that although the flapper "faithfully represented millions of young 
women" during the 20s, her "style, taste in clothing and music, the brand of cigarettes she smoked, and the kind of liquor she drank -- even the shape of her body and placement of her curves" was constructed not only by Fitzgerald but many other "artists, advertisers, writers, designers, film starlets and media gurus." Although young women willingly followed these trends, it is clear that most of the people Zeitz refers to as the "nations first merchants of cool" were, in fact, men.

Their power over the nation's increasingly centralized print and motion picture media, and their mastery of new developments in group psychology and the behavioral sciences, lent them unusual sway over millions of young women who were eager to assert their autonomy but still looked to cultural authorities for cues about consumption and body image. (Zeitz 8)

Writers of popular "confession" magazines offered phony lurid stories with "pious" endings recounting social and moral "mis-steps" that were often penned by professional hack writers who churned them out daily (Allen 76). Many women read more pedestrian periodicals like Ladies Home Journal while other young women took in films by the score. All of these media outlets had in common the ability to sell sex and consumerism, and the young, more socially independent women of the 20 s were eager to buy into it. Because of the plethora of visual aids provided by the magazines and film, they knew what they wanted to wear, how they wanted to look, and where to buy it. And, because of the lurid and sensationalistic film (remember, the Hays Code was years away at this point), they knew what to do with their bodies once they pulled it all together. 
Zeitz points out that while famous Flappers like Zelda Fitzgerald, Clara Bow, and Louise Brooks were part of the imaginary world invented by the media, their influence was felt by the common woman. Though Brooks and Fitzgerald were lavished with money and gifts and able to eat in the best restaurants and wear the best clothes, "the unspoken exchange of sex and romance for material satisfaction and financial security -- was being lived out on a lesser scale by millions of underpaid shop girls, garment workers, and office secretaries whose every date to Coney Island or to the movie theaters was fraught with subtext and negotiation" (Zeitz 253). The recent development and availability of closed automobiles allowed young people to easily get away from the family -- unchaperoned-- in what was basically a portable closed in room. It is no coincidence that whole new words like "necking" and "petting" were coined during this time period.

With their modern hair-cuts, their modern clothes, and their modern sense of independence, young women of the 1920s had, for the most part, tacitly agreed to produce a narrative about themselves and about sexuality. However, the gender performativity conducted by these slender, un-corsetted women didn't necessarily have much to do with the pleasure or perspective of women. In 1931, Fredrick Lewis Allen wrote of the 1920's: 
...the quest of slenderness, the flattening of the breasts, the vogue of short skirts (even when short skirts still suggested the appearance of a little girl), the juvenile effect of the long waist -- all were signs that, consciously or unconsciously, the women of this decade worshiped not merely youth, but unripened youth. They wanted to be -- or thought men wanted them to be -- men's causal and lighthearted companions: not broad-hipped mothers of the race, but irresponsible playmates. (Allen 81-82)

In other words, the Flapper represented to the post WWI world "the thrills of sex without fruition" (Allen 82).

Allen's point, that the dominant feminine styles of the 20s brought to mind girls (or even adolescent boys) becomes even more intriguing when one ponders the etymology of the word "Flapper." Many writers suggest that the term originally described women/girls who were so young that their pigtails would flap around their face as they ran or danced. The French word for what we call a Flapper in English is la garçonne: literally the feminized version of the word le garçon. Today the word would translate in "tomboy," but one could hardly argue a young woman dubbed la garçonne was truly a tomboy. I would assert more strongly Allen's 1931 suggestion that this unique image of the short-haired, slim-hipped girl as a sexual partner who promised fun without consequence in the form of a woman performing as a girl, or even a girl performing as a boy became a sort-of androgynous image of womanhood constructed by a post war male dominated media, and sold to the young women of the jazz age. 
But as most women know, irresponsible sexual behavior and (hetero) sexuality don't often co-exist without consequence for long. Despite the promise of sex without reproduction offered by the androgynous Flapper, the fact remained that the reproductive parts were still in working order. In his 1939 account of the 1930's Allen writes:

the rush of sentiment in favor of sex freedom -- had reached its peak in the years 1923-1927. . In the year 1930 the magazines expressed more approval of marriage and family life. [But] the most important reason for the change was the Depression. (131-132)

Allen goes on to explain that the Depression-Era rejection of the wild and inhibited lifestyle of the Jazz Age was complicated, and based in part on practicality. He points out that shocking behavior can only be considered shocking for a time before it becomes status quo. After all, "any idea palls after a time, any bright new revolution begets doubts and questions" (131). But mostly he suggests that the economic and emotional security of married and family life seemed much more intriguing and desirable once it was more difficult to attain. People simply didn't have the money to get married and have children. Allen states:

The song 'I can't give You Anything But Love, Baby' dated from 1928, but it might well have been the theme-song of the nineteen-thirties. The marriage rate per thousand population fell from 10.14 in 1929 to 7.87 in 1932. (132)

The party couldn't last forever, and if Flappers were, as I am suggesting, the female embodiment of the Jazz Era Boom Times, then all fun things must come to an end. 
Fitzgerald knew that the party he himself had fashioned was coming winding down. In his memoir "Echoes of the Jazz Age," he wrote "After two years the Jazz Age seems as far away as the days before the war . . as dead as were the Yellow Nineties in 1902." According to

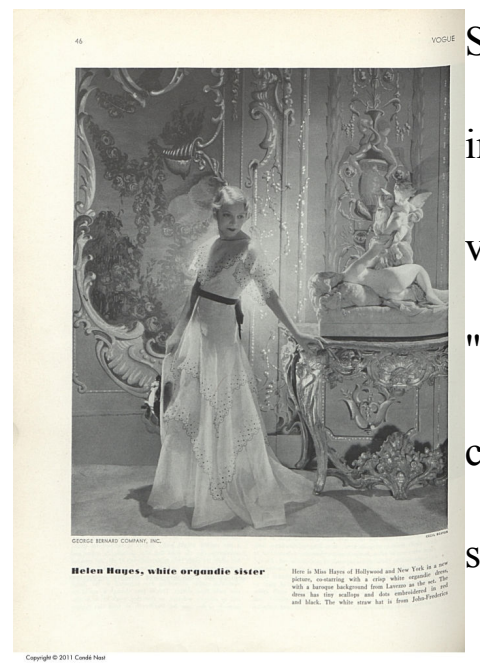

Figure 4: In the 1930's natural waists were back in style, as were bows, organdy, and ruffles.
Sanderson, by 1931 Fitzgerald came to realize his "lifelong investigation of female adolescence as inappropriate voyeurism" (Sanderson 159). Alianing itself to what she refers to as

"America's obsession, especially in popular film, with an erotically charged girl culture," Scott publishes a story of a "younger, purer, ... symbol of regained honor" in "Babylon Revisited" with Charlie's daughter, a 10 year old little girl named Honoria (158). By 1931, in other words, girls bobbing their hair and dancing the Charleston was out, and girls wearing gingham and singing The Good Ship Lollipop was on its way in.

In the "Evolution of the Language of Cinema," Andre Bazin states that, "The image is evaluated not according to what it adds to reality, but what it reveals of it" (47). In the 1930s the culturally constructed image of women began to change as their hemlines fell and their waistlines rose and hair was allowed to grow, loosen, and give way to a variety of hairstyles other than a severe bob (Ferrell-Beck 80). Ruffles, bows, and furbelows began to creep back into style. In 1939, Allen wrote:

Gone was the ... long-waisted effect: the waist returned where it belonged. . . The flat-breasted. . .girl of the nineteen-twenties had attained maturity and was proud of it; indeed so striking was the change 
between the ideal figure of 1929 and that of 1933 that one might almost have

thought a new anatomical species had come into being (Since Yesterday 137).

Eventually as the decade wore on, a different type of female image presented itself. Instead of world-weary flappers like Clara Bow who dressed in clothes that made their figures look like pubescent boys, the movie stars became more adorned with feminine styles. The flapper's cute boyish looks may have been all the rage in the 20 's, but when the pendulum stopped swinging in the other direction, femininity stopped short of nothing less than the broad hipped and chesty Mae West whose imposing figure reminded one not of a boy nor of a girl. Mae West's body was all WOMAN. In fact, West didn't even appear in her first film until she was 40 , and she was not coy or subtle about her interest in sex. She

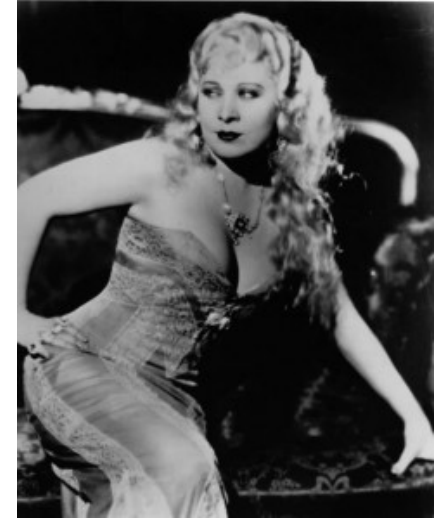

Figure 5: May West certainly did not represent sex without consequence. never resorted to "downcast eyes" or "shamed demeanor" to play a bad girl or fallen woman (Doherty 186). In her films she made it very clear through voice inflection, tone, and cadence she was neither bored by, or too virtuous to be interested in, sex. Her one-liners were full of innuendo, and are legendary: "Why don't you come up and see me some time?" and "Is that a gun in your pocket or are you just happy to see me?" continue to live on in popular culture synonymous with her name to this day. Molly Haskell describes her as not only someone who blurs the "lines between the biological and culturally constructed woman" but as someone who stretched "the ways in which we think about and define femininity" in the 1930s (Haskell, Mae West's Bawdy Spirit). 
As the cultural construction of femininity changed radically to exclude the boyish flapper and include the buxom West, it did something else, too. In 1939, Allen reports of the 30s that Maturity began to pall. Gradually the skirts became shorter and shorter (except in the evening); by 1939 they had retreated almost to the knees. "Little-girl costumes, "girlish ginghams," "swing" outfits "adapted from skating skirts " were bidding for attention, and the massive president of the woman's club was wondering whether she should try to insert herself into a bolero suit and put one of those bows in her hair. (139)

Eventually Allen points out that "apparently the old-fashioned little girl was becoming the standard type of the new day" (139). Mae West may have made more money than any other Hollywood star in 1934, and her body type marked a clear departure from the bored, boyish flapper. But it is important to note that another less mature body type was the top box office Hollywood draw between 1935 and 1938: it was the diapered, curled, dimpled body of Shirley Temple.

In the 1930s, the image of the eroticized little girl reveals an American culture grappling not only with Jazz Age ghosts, but the ghosts of a country which was aware of its complicity with slavery based on race and gender. It reveals a world in which women were taking control of their fertility and sexuality and using their intelligence and capabilities in new and untraditional roles. It reveals a new emphasis on class mobility in a time of economic uncertainly. And, ultimately, just like the work of F. Scott Fitzgerald, it represents "the loss of idealism and the grand romantic theme of recapturing the vanished past" (Berman 79). It is almost as if West and Temple each represent two ends of that spectrum. They become a nostalgic cinematic fantasy of 
a time when women were fertile sexual partners, not bored party animals. And nostalgic, I might add, for a time when little girls were innocent and wholesome and not consequence-free playthings. Ultimately, they possess nostalgia for a time when the Jazz Age hadn't happened, the party hadn't started, and America hadn't strayed so far from its Puritanical work ethic.

Films of the 1930s try to capture the essence (or maybe just the image) of a little girl in order to gain forgiveness and atonement for the sins of her older sister, the flapper. In the same way, in Fitzgerald's vision of "Babylon Revisited," possession of the little girl represents a sort of reparation for the Roaring Twenties. Sanderson points out that most of Fitzgerald's work (not just this particular short story) is noted for using "inspirational symbols" and exploiting "the male tendency to see women as such symbols, perhaps especially during a time of personal, familial, and national disintegration" (156).

Undoubtedly, the 1930s were a time of "national disintegration," but individuals and families were also overwhelmed as well. I hope to show here that Hollywood's use of little girls in film attempts to reconcile gaping societal wounds left by abrupt class transgressions, the disintegrations of the family, the changing roles of women, race relations, and, ultimately, of New Deal politics that accompanied personal and familial fragmentation in some of the most popular box office films of the decade. Ultimately, the popular films of the 1930's provide a window to the way a nation looked at itself during a turbulent and frightening time. Every group who was affected economically and ideologically by the party that was the Jazz Age, be it the investors who had gotten rich, the average families who had more money and more time to devote to leisure activities, the African Americans whose status had risen due to wartime military service and work in war industries, and even the artists who profited by migrations to the cities 
by a racially diverse population was forced to contend with the hangover that was the Crash of 1929. The morning after came as a complete shock to a nation that was riding high. And much like Charlie desperately trying to regain his daughter back, the American public set about trying to regain their own "Honoria" in the form of nostalgia for a cute little lass.

As a result of placing so much of the responsibility for helping flag the drooping spirits of a depressed nation on the shoulders of a little girl, it should come as no surprise that America's image of womanhood begins to shift from a picture of naiveté and innocence, to the image of a wise and seasoned temptress. Shirley Temple, who we will discuss at length in the next chapter, kicks off the decade with cartoonish imitations of adult stereotypes (in the same vein as her predecessor, 1920s star Baby Peggy) but soon morphs into a spunky, plucky orphan with the ability to flirt, cajole, and use her feminine charms to melt the hearts of the men around her to create her own version of a nuclear family.

In fact, if the flapper represented sex without family responsibility in the 1920 s, by the mid 1930s Temple began to represent family responsibility without sex. By the late 1930s, America's femme fatal had changed again as can-do and competent protagonists Dorothy Gale and Scarlett O'Hara were played by women nearly a decade older than the characters that they were portraying. At this point, the image of womanhood in this country begins to resemble an unruly woman/child. Such transformation is evidenced with Shirley Temple's characters in the early to mid 1930's, the fetishization of Lolly in Stella Dallas, the heroine's journey of Judy Garland in The Wizard of $\mathrm{Oz}$, and finally the late 1930s Scarlett/Bonnie duality in Gone with the Wind. In other words, in starting the decade with the plucky, spirited class transgressions of Shirley Temple, and ending it with the juxtaposition of a child in a woman's body like Scarlett 
O'Hara, Hollywood ends up creating "America's Femme Fatal" as the "Lollipop Licking Tease" described by Molly Haskell 1987's touchstone work on feminist film criticism, From Reverence to Rape (21). Ultimately, American Culture creates a new category of child/woman: the teenager. When the stock market crashed in 1929, many eras ended. The Great Depression signaled the end of an era for the independent sexually liberated flapper. In fact, it signaled the end of sex for everyone, as sexual activity and births seemed to hit an all-time low during the Great Depression. The advent of talking pictures and the end of silent films corresponded with the crash as well. The children of the Jazz Age entered into their adulthood during a decade marked by unemployment, poverty, and fear. Interest in fictional commentary and celebration of monied, vulgar, and immoral behavior of famous people wasn't nearly as fascinating during this new decade (Berman 81).

Between the Wall Street Crash, the Dust Bowl, and the subsequent economic depression that seized the country, the decade immediately preceding World War II inarguably changed the lives and lifestyle of every American for years to come. The year 1929 also signaled the introduction of the Motion Picture Production Code, also known as the Hays Code. Hays provided censorship guidelines where before there had been none, and although these guidelines weren't officially adhered to until the mid 1930s, their existence and appearance forever altered the course of motion picture production.

These enormous changes to United States popular and economic culture (the Hays Code, Black Tuesday, and the Dust Bowl) seem, metaphorically at least, to be a sort of retribution for the free and inhibited lifestyle enjoyed by the young adults who came of age in the 1920s. Popular culture certainly insinuated that like the "Good Time Charlie" in "Babylon Revisited," 
Americans of the 1920s had begun to stray from Puritanical ideals and American virtues like "temperance, hard work, and deferred gratification" (Dohorty 21). "Whereas the journey of life once symbolized a pilgrim's progress from innocence to experience, growing old during the Jazz Age came to represent planned obsolescence -- an unsolicited invitation to irrelevance. (Curnutt 30)

The sexually liberated young-adult Flapper symbolized all moral bankruptcy the Roaring Twenties had to offer. Just as fictional Charlie had sold short the importance of his family, his wife, and daughter, real investors had sold short stocks they did not own, and Americans began to suspect that they had sold short their values and ethics.

In Pre-Code Hollywood, Dohorty sums up the shift beautifully. "From sin to retribution, debauchery to convalescence, gaiety to gloom, the 'morning after' imagery and moral shadings of the historical shift settled over the atmospherics of Hollywood cinema." (23) He goes on to describe how the films made in the post-crash 1930s take on the preceding decade as a "wide eyed wonder and moral censure that was now the cultural consensus" (24). The 1931 Joan Crawford film Dance, Fools, Dance (famous for its pre-code underwear skinny-dipping scene) features Jazz Age babies partying before the crash, who are left ill-prepared to find honest work after the crash. In Barbara Stanwyck's 1937 film Stella Dallas, about an aspiring working class woman who sacrifices everything for her daughter, a main plot point centers itself around Stella's flapperish sense of style and behavior that reveal themselves to be undesirable by the $1930 \mathrm{~s}$ viewing audience's jaundiced eye, according to Anna Siomopoulos (8). The interest in the Roaring 20s and the spectacle of that decade's womanhood was considered by more cynical and wary Depression era audiences to be foolish, wasteful, and low-brow. 
American cinema was inspired in this respect by the events of the day and by the cultural reaction to them. In the 1920 's, the cultural perception of the eroticized flapper was that of shock and scintillation. But in the 1930's, former flappers with their sexually liberated ways were painted as fallen women and cheap villains who undermined families and corrupted the very lynch-pins of Western Civilization. In fact, the Louise Brooks silent melodrama, Pandora's Box (which, although German, was released in the United States in 1929) featured classic flapper Brooks as a mistress who uses her sexual wiles too many times and is ultimately reduced to becoming a prostitute who has the misfortune of being picked up by Jack the Ripper. Louise

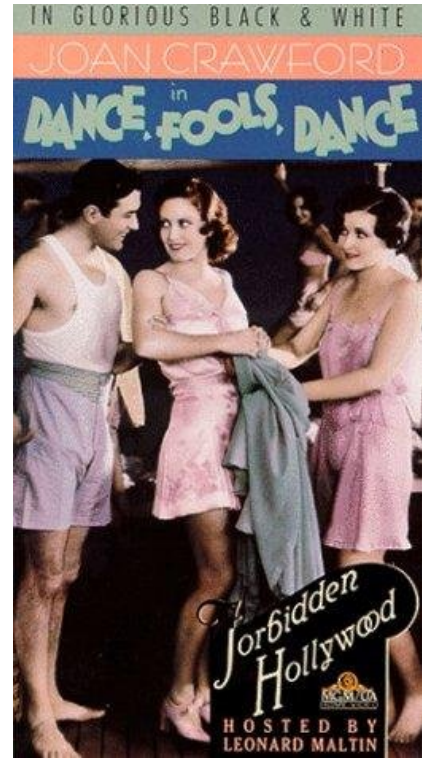

Figure 6: The cover of the VHS tape of 1931 Dance Fools Dance. The original film was in black and white. gets her just desserts for her sexually liberated ways as do other sexually liberated women in the public eye during this period.

The 1934 case of Gloria Morgan Vanderbilt who had married 42-year-old Reginald Claypoole Vanderbilt (heir to the Vanderbilt railroad fortune) at the age of seventeen lends itself well to this argument. Gloria Morgan's eroticism and sexuality was not called into societal question when she married a man twice her age as a young debutante trophy wife. Neither was the fact that she was believed to be underage when she married and when she gave birth to her daughter. But nine years later, upon his death, Gloria Morgan Vanderbilt's eroticism and sexuality was not only of great societal concern, but scorned, and quite literally called into court during the custody trial of her daughter, Gloria Vanderbilt in 1934. (I will discuss this case in more detail in Chapter 2.) During the trial, her sexual dalliances (and that of her twin sister) with 
European royalty (and others) were examined, questioned and reported in sensationalistic tabloid headlines in across the United States. Ultimately, newspapers of the day reported that the judge offered Gloria Morgan limited visitation and stated that her care of the child was "entirely and in every way unsuitable, unfit, improper, calculated to destroy her health and neglectful of her moral, spiritual, and mental education" (Gloria Vanderbilt, Ward of the Court 1).

Another former flapper's dalliance with a member of a European royal family ended up causing the most famous abdication in modern history and shook not only the constitution of England to its foundation, but made for one of the notorious romances of the decade and possibly the century for both England and the United States. The affair between Edward, Prince of Wales and Wallis Simpson, self-styled socialite of the 1920s' and American divorcee, was sordid, scandalous, and further fodder for American media.

Eventually, then-King Edward VIII chose to abdicate the throne of England for twice-divorced Simpson. (It is interesting to note that first, Wallis had to steal him away from his current girlfriend, Thelma Morgan Furness, the aforementioned Gloria Morgan Vanderbilt's identical twin

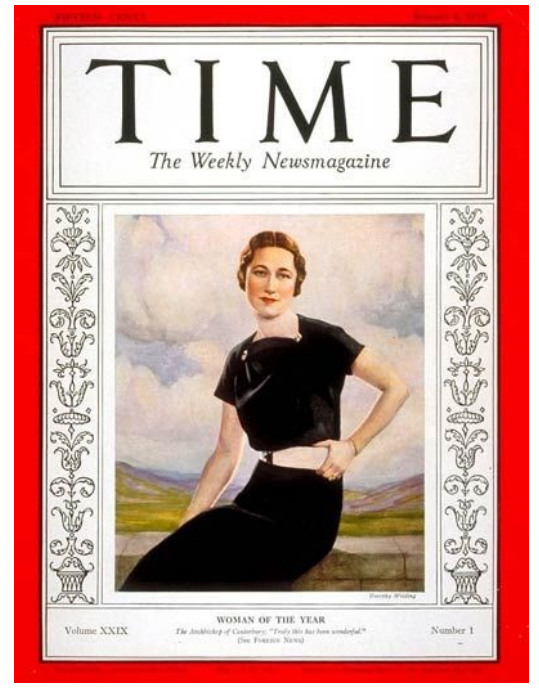

Figure 7: Sexually liberated Mrs. Wallis Simpson was Time's Woman of the Year in 1937. But she could never be Queen of England.

sister.) In an act of self-preservation, Simpson was literally forced to flee reporters by racing to the South of France as the abdication scandal broke. As an indication of how important this story was to the general American public and media at the time, one may note that Wallis Simpson was 
named Time Magazine's "Person of the Year" in 1936. The article declared Simpson to be "the most-talked about, written about, headlined and interest-compelling person of the year."

Anne Sebba's 2011 biography of Wallis Simpson, noted not only for being one of the only biographies that painted a sympathetic picture of the Duchess but also for being one of the only biographies about Wallis Simpson written by a woman, addresses the not-so-secret gossip that had been circulating throughout the English speaking World for over seventy years: that of Simpson's gender. Sebba makes the case, based on behavior, mannerisms, and physical attributes, that Simpson had a rare genetic disorder that caused her to have chromosomes (and partial genitalia) for both genders. Although no available DNA can confirm or deny this conjecture, circumstantial evidence does suggest that it was, indeed, possible that Simpson could have suffered from a lack of the estrogen which could explain much about Wallis' facial and bodily appearance, lack of children, and string of crumbling marriages. In a "bold statement of identity," Wallis (originally christened Bessiewallis) selected a name that was unique, and not traditionally feminine. Whatever the case, as Sebba writes: 
Every biographer of Wallis as well as courtiers who knew her, in trying to explain the inexplicable -- how could a middle aged, not especially beautiful, rather masculine looking woman have exerted such a powerful effect on a king that he gave up his throne in order to possess her? -- produces a different theory. What most argue on was that Wallis was the bad girl, the wicked temptress, the femme fatale who, in teaching a repressed prince satisfying techniques in bed, nearly destroyed a monarchy. (112)

It really doesn't matter what chromosomes Wallis Simpson did or did not possess in 1936. What mattered is that the King of England sacrificed his throne to be with someone who was painted by the media to be an American "temptress" who had been been married twice before.

But the very discussion of Wallis's chromosomes is a re-phrasing of the same argument that had been stated from the time that Wallis hit the public eye: because the twice divorced socialite was sexual, Simpson was an abhorrent creature who was underserving not only of social standing but of happiness and the attentions of the most eligible bachelor in the Western World. She isn't the only one. In Chapter 5, I will discuss how Margaret Mitchell's portrayal of sexuality and nonconformity made her undeserving of a place in Atlanta's junior league, until she managed to pen Gone with the Wind. Flappers were bad news

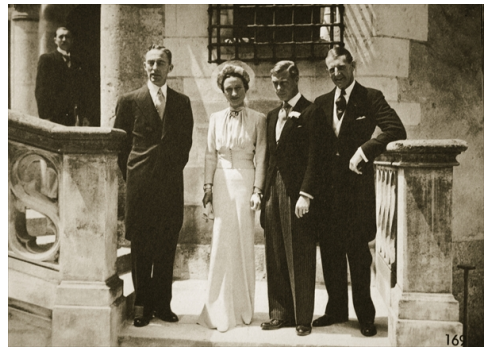

Figure 8: The Duke and Duchess of Windsor and other members of the wedding party after the ceremony. The marriage represented one of the greatest romances and constitutional crises of the twentieth century all rolled into one. for respectable women. The image of an androgynous, sophisticated, bored, sexually liberated 
socialite from the twenties began to seem less appealing and more disruptive to the sensibilities of the 1930s. The American Jazz Age, the Flapper, and what Charlie Wales refers to as "the boom before the crash" in "A Babylon Revisited" were all, culturally at least, rolled up together and to blame for the constitutional crisis in England. Sex without responsibility, it turned out, had consequence indeed.

\section{Part II}

But how does one get from the sexy, boyish, flapper to the innocent daughter of Charlie Wales, or even Shirley Temple? One must first examine the concept of childhood in Western Civilization to understand this connection. In her book The Case of Peter Pan, or the Impossibility of Children's Literature, Jacqueline Rose argues that the contemporary obsession with innocence and eternal childhood that exists reveals not something about children, but something about the investment that popular culture has with childhood itself. Notions of childhood innocence have been used since the inception of the concept for purposes of asserting popular cultural values, ideologies, and relationships, much to the advantage of wealthier children and to the disadvantage of children marginalized by race, class, and gender. To understand how notions of childhood work in constructing an ideology of innocence, one must first understand exactly how and when the concept of "childhood" came to exist. For the purposes here, I shall discuss the history of childhood as it relates to only Western Europe from the Middle Ages on, and the United States from its inception.

According to Phillip Aries, in his seminal work Centuries of Childhood, the concept of "child" didn't exist until sometime in the 16th or 17th century. Based on his study of Medieval 
and Renaissance art work and surviving texts, he deduces that since there are no pictures of children, there was no concept for the period of development which we currently refer to as "childhood." Admittedly, the pictures often depict small adult figures standing next to or in the arms of larger adult figures, but the musculature, dress, expressions, and mannerisms are no different from that of the representation of someone in their thirties. According to Aries, the concept of childhood simply did not exist. Once a being was capable of survival away from physical contact with its mother, it became, in dress and responsibility, part of the adult world. Most young people were apprenticed or worked in fields from a very young age, and the child mortality rate was so high, Aries theorizes, that it didn't make practical sense to invest time, money, emotion, or energy into a being that might not survive. Eventually, during the Renaissance, more and more children appear in art although they are usually as Christ, saints, or cherubs. It is his assertion that the concept of childhood began among the upper classes during the Sixteenth and Seventeenth Centuries, solidified in the Eighteenth and Nineteenth Centuries, and mushroomed in the Twentieth Century, Century, as both financial and emotional costs of elite childrearing were rising during these periods. Eventually, better economic and medical conditions led to higher investments in infant survival, declining infant mortality, and a rise in survivorship. Privileged families were forced to adopt fertility control in order to avoid the production of too many costly children. Aries' work, which was published in 1962, contextualizes most other work written later. Some of its ideas may seem a bit dated, and it falls short in its treatment of women and cultural influences other than Western Culture; however, it is certainly one of the best places to begin. 
Jackie Wullschlager, in Inventing Wonderland, James Kincaid in Child Loving, and Jacqueline Rose in The Case of Peter Pan assert that the Victorian Era pretty much fine-tuned the notion of childhood innocence in Western Culture. Wullschlager traces the inception and development in children's literature of the era among writers like Caroll, Barrie, Lear, Graham, and Milne. She feels that although it is clear that these writers are reflecting cult-of-thechild ideology of the time (artwork and advertisement actually show children - real ones, not little adults, or cherubs, or Christ this time - portrayed with halos over their heads), they were just as responsible for helping construct it. Peter Pan, the boy who would never grow up, was a character portrayed by James Barrie in a host of plays, short stories, and speeches. Pan was the very epitome of youth and innocence, and, according to Wullschlager, a Victorian society that valued youthfulness, innocence, and who simply didn't want to grow up. By the time the author of the Winnie the Pooh books, A. A. Milne, came along in the 1920s post WWI, Edwardian era, the cult of the child centered around youth for youthful pleasures' sake, and nostalgia for a society who wished it hadn't grown up. Rose asserts that children's fantasy pretty much begins during this era with James Barrie's work, although Wullschlager would argue that it began with
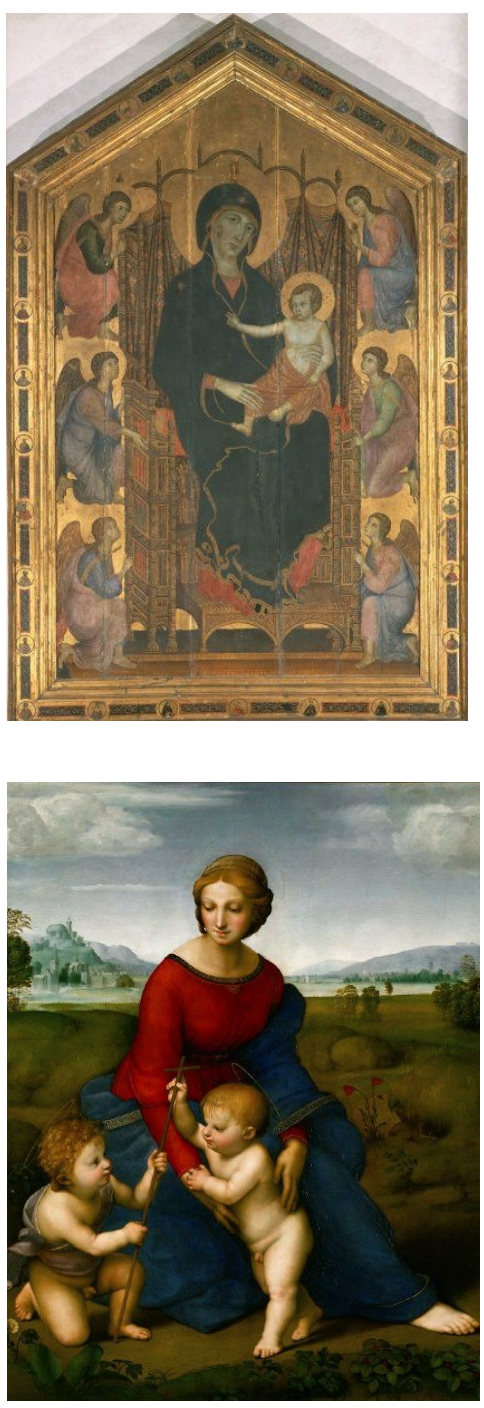

Figure 9: Panel from 1285 depicting Christ as a miniature adult.

Figure 10: Later Renaissance painting depicting Christ and John the Baptist with child body types and not miniature adult bodies. 
Lewis Caroll's adventures of Alice. Neither would argue that these books weren't really books (or plays, in the case of Barrie) for children until you get to Milne's Pooh bear, but they are simply about children, and that in fantasy, unconscious or repressed desires can be expressed. James Kincaid, in Child Loving, would agree. His argument states that myths about childhood innocence and concurrent vulnerability arose historically as we created a separate identity for children. This stoked a "quasi-erotic" love of children as innocents, and a hatred of those who act out of eroticism. In both Child Loving and Erotic Innocence, he discusses, at great length, the ways in which production of the monster known as the pedophile in many ways allows not only the Victorians, but members of our contemporary culture, to define ourselves. We reject pedophiliac monstrous activity with such automatic indignation that, as a group, the indignation begins to feel like pleasure. We open up a space for societal glee when we hear a convicted child molester has committed suicide, and we pretty much allow an approved ideological space for murderers in prison to torture, rape, and murder convicted child molesters. Kincaid asserts that by insisting that children are innocent, pure, and asexual, we have created a "subversive echo" that presents the child as experienced, corrupt, and erotic. We have set the trope of the innocent child to be fetishized, and the object of forbidden desire in popular culture. "What we think of as "the child" has been assembled in reference to desire, built up in erotic manufactories, and ... we have been laboring ever since, for at least two centuries, both to deny that horrible and lovely product to maintain it" (Child Loving 4).

Rose, Wullschlager, and Kincaid all agree that during a time when Victorian and Edwardian England was celebrating the innocence and purity of children in fiction and art, a 
great disparity was occurring at the same time. While children from the upper classes were glorified for their innocence, children from the lower classes were exploited for theirs. On one end of the spectrum were upper middle class Victorian children depicted spinning hoops and sailing toy boats in Kensington Gardens, attending Eton, and frolicking in Hundred Acre Wood with Pooh, Kanga, and Piglet. In the middle of the spectrum were the children working in factories, as apprentice domestic servants, chimney sweeps, or selling matches and flowers. At the other end of the spectrum of the era were the children sold into sexual slavery.

In 1885, English editor and rights activist W.T. Stead purchased a thirteen-year-old girl from her mother with the understanding that his intentions were to procure her "Maiden Tribute." Instead of raping the child, he wrote a series of articles for his paper The Pall Mall showing how easy it was to purchase a child sex slave which brought the issue to the public eye. His series was wildly popular and has been credited for changing legislation in regards to the legal age of consensual sex for children (Polhemus).

Across the sea in America things were similar. Poor children worked in factories and in coal mines, and really poor children were ripe for sexual exploitation, while the children of wealthier families were more protected and glorified. This glorification, on both sides of the Atlantic, began to lead to sentimentalized views of childhood in media and the popular press. The era after the American Civil War produced much art that evoked nostalgia of childhood. Artists such as Winslow Homer and Mark Twain glorified the world of the average child in their works to great aplomb. Children were no longer considered to be inherently evil, as the Puritans had suggested, and were no longer expendable in bloody wars. They were a treasure. 
Shortly after the dawn of the 20th century, the experiences of children began to change. Influenced by a shift away from agrarian and toward a more industrial and urbanized way of life, children were exposed to worlds that were very new to their parents. The Progressive Movement brought about Child Labor Laws that set limits on the hours that

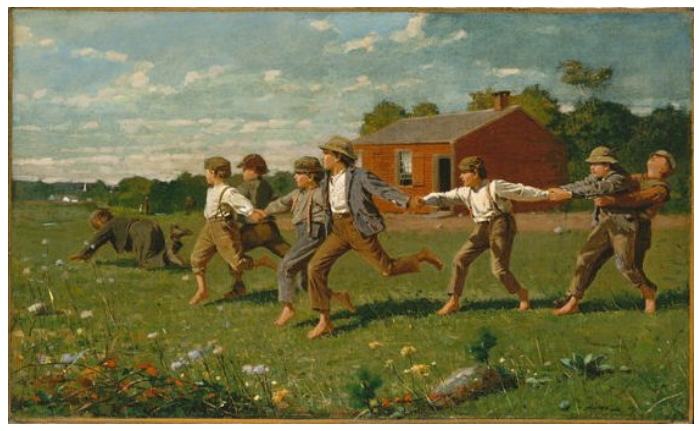
children could work and provided more opportunities to attend school. Children had access to store-bought toys, mass-produced clothing, and series of books actually written for children from authors like Beatrix Potter, Frank Baum, Figure 11: The children in Winslow Homer's nostalgic Snap the Whip nostalgically harken back to a more idealized and pure time for children, before the bloody American Civil War. and A.A. Milne.

Steven Mintz states that "Self-conscious modernity was the defining characteristic" of parenting children in the first few decades of the 20th Century (214). Many children and adolescents growing up in the mid-1920's had access to radios, cars, telephones, and movie theaters. Mintz goes on to state that "between 1880 and 1930, parent-child relations underwent a profound transformation" (215). Middle-class families became more private and child-centered, and the focus of children's lives became more influenced by peers. The radical change that went on in that 50-year span was even apparent in the vernacular. By the end of the 1930's, a new term was coined for the age-group of children like Judy Garland and Micky Rooney who sipped shakes at the soda fountain after school in the Andy Hardy movies: teenagers (Mintz 236).

Around the time that American children were spending less time in factories and more time in school and soda fountains, something else interesting was happening to which I have 
already alluded. Mass popular culture was reaching more and more people every day. Mintz points out that "modern adolescence grew up hand in hand with the rise of commercial amusements" (229). Commercial radio began broadcasting in the early 1920's, and, after 1910, single reel films became more and more commonly available. Movies provided not only a reflection of cultural mores, but also influenced and, according to many critics, reshaped behavior in regards to dress, sexuality, and "ideals of beauty" (Mintz 229). In 1927, The Jazz Singer, the first film to feature articulate sound was released and by 1930, silent films were no longer being made. From 1929 until 1934, a "ferocious debate" ensued regarding the levels of censorship that should be enacted in films being distributed throughout the country (Dohorty 19). Because there was not a consensus, films were censored by local boards and municipalities, which ensured a somewhat fragmented viewership: a film that was seen in New York City may well have been censored and spliced completely differently than the release of the same film in Richmond, Virginia.

Eventually, fueled in part by Maureen O'Sullivan's nude body double's famous swim with Johnny Weissmuller in Tarzan and His Mate, a rather lengthy and very specific Production Code (also known as the Hays Code) was enacted in 1934, thus effectively resolving the issue of local censor boards fragmenting the body of work observed by audiences around the country. It is my conjecture that this skinny dipping scene (and the uproar it preceded) effectively set the stage for images of eroticized female children in film for the next decade of American film. As we shall discuss in the next chapter, with the advent of enforcement of the Hays Code came the inability for directors to overtly represent women's sexuality. Several films opted to feature children who were sweet, and innocent. But, as James Kincaid points out, "By insisting so loudly on the 
innocence, purity, and asexuality of the child, [they] created a subversive echo: experience, corruption, eroticism" (Child Loving, 4).

Between the years of 1929-1934, three catalysts triggered a change in the use of child images in film and forever shaped them into what Molly Haskell has referred to as the "natural idiom of American eroticism" (From Reverence 21). The Stock Market Crash of 1929, the election of Franklin Roosevelt, and new adherence to the Hays Code in Hollywood all changed the ways in which children were represented and metaphorically exploited.

\section{Part III}

In the chapters to follow, I intend to discuss how the rise of the eroticized child star was not only a backlash against the country's gaze upon the Flapper, but also effectively sutured over the anxiety regarding the disintegration of the family, the changing economic and domestic roles of women in the United States, class mobility, strained race relations, and the reconstruction of white middle-class masculinity. For the purposes of this dissertation, I hope to examine these sublimated concerns by looking at the cult of the child star in the sexualized/infantilized body of Shirley Temple, the issue of familial relations in the 1937 remake of Stella Dallas, the adolescent Oedipal journey in The Wizard of $\mathrm{Oz}$, and the effect of race and gender on the definition of childhood in Gone with the Wind.

Chapter 2 will explore the ways in which New Deal policies generated angst regarding the transgression of class boundaries, and how it is reflected in many early films starring Shirley Temple. As Franklin Roosevelt's smiling baby, Shirley Temple shifted the locus of desire from woman to child, dimples and short dresses quietly concealed the ever-widening economic fault 
lines at play. Weighing heavily on everyone's mind was, of course, the horrifying economic picture looming before the country, the concern over whether Roosevelt's New Deal would work, and how it would affect everyone's way of life. Roosevelt's policies promised a handout and a hand up to people who worked hard and persevered. Such options, however, threatened to allow lower classes the opportunity to transcend class and economic boundaries.

In many of Temple's films, this disquiet is inscribed upon the body of youthful innocence, as a pretty little girl tap dances and croons through film after film in which lowerclass orphans are adored and adopted and find financial security at long last, thus glossing over the anxiety of economic class maintenance and transgression. In Daddy's Girls, Walkerdine points out that Temple's characters often capture everyone's gaze, choose a middle-class family over other economic options, subsequently put the country back onto the road to prosperity, and posit themselves back into the symbolic order.

Although the other chapters in this work tend to focus strictly on one film, for the purposes of this study, I will discuss several of Temple's films. The body of work represented by Shirley Temple tends to center around very similar themes. Arguably, until adolescence (which roughly coincides with the end of the 1930's, the Great Depression, and the United States entry into World War II), Temple pretty much plays the same spunky, adorable, innocent character, albeit with different settings and costuming. In most cases she ends up as an orphan (or separated from her parents/guardians) who must pull things together. Therefore, I have chosen to do not only a close reading of a specific Temple film, Bright Eyes, but discuss scenes, themes, and plot twists in a few of her other Depression Era films as well, especially the loose "Trilogy of Civil War films" comprised of Dimples, The Little Colonel, and the Littlest Rebel (Knight 105). 
When all is said and done, the celebration of the relationship between a pretty little white girl and her desexualized (sort of) black male companion overtly illuminates certain remaining qualities of American male identity. These were the same qualities being championed by federal and legislative policies of the 1930s, and the same qualities that have informed popular and sociological culture throughout the following several decades.

Chapter 3 will investigate ways in which cultural apprehension regarding images of disintegrating traditional families (including film clips of the Lindbergh baby kidnapping and the Dionne Quintuplets being raised in the sterility of a hospital) are allegorized in the ' $30 \mathrm{~s}$ melodrama Stella Dallas.

Steven Mintz points out that the Great Depression had a terribly destructive impact on family life. Divorces did indeed decline, because no one could afford them. However, by 1940, more than 1.5 million married women lived apart from their husbands, most of whom had deserted the family. There was a fifty percent increase in placements of children in custodial institutions during the early years of the Depression, and for the first time in history, the American birthrate dropped "below the replacement level: Americans had nearly three million fewer babies during the 1930s than they would have had at the 1929 rate" (Mintz 236-37). Barbara Stanwyck's over-the-top portrayal of Stella provided female spectators with some distance between themselves and the character and therefore provided some subversive commentary on the societal roles predicated on their gender and social class. As Mary Anne Doane notes, Stanwyck's Stella actually demonstrates that societal redefinition was happening well before the United States' entry into World War II. 
Ultimately the film relies on multiple levels of self-reflexivity and the ability of the title character to reintegrate herself into a patriarchal system and back into the symbolic order in order to achieve happiness. The film Stella Dallas can be read as a discourse on the importance of children in 1930s America, as a critique of the role of modern motherhood, or as an appraisal of the modern, urban family. Whatever the angle, though, it effectively navigates these issues by providing a pat melodrama indicating, on the surface at least, that mother's role is to sacrifice all for her children.

Chapter 4 will include a close feminist psychoanalytic reading of the film The Wizard of $O z$ that will help illuminate nervousness surrounding the redefinition of women's roles as portrayed by public figures such as Amelia Earhart, and Frances Perkins. During the Depression women were increasingly forced to rely on themselves to provide for their families economically. In light of cultural developments signaled by the achievements of the women mentioned above, I hope to explain the Technicolor Oedipal journey of Judy Garland's Dorothy Gale in the film The Wizard of $\mathrm{Oz}$ as she discovers what it means to be a woman on a farm in Kansas. Made during an era when women like Earhart and Anne Marrow Lindbergh could quite literally and independently "fly over the rainbow," this film's general obsession with the form and construction of a child's body leads to a perversion of desire that becomes downright freakish. Literal bodily inscription is at play with Judy Garland's heavily corseted and bound seventeenyear-old body stuffed into a gingham dress, ankle socks, and symbolically red ruby slippers providing a contrast to bodily proportionate adult dwarfs wearing bright colors, odd hairstyles, and props indicating whimsy. (The Lollipop Guild, indeed!) Doherty points out that the "disorder and disintegration in American culture" during the 1930s influenced the inception of 
the horror genre. Dorothy Gale's horrifying personal and psychological journey to and from $\mathrm{Oz}$ functions as a metaphor for a young women's Oedipal journey and completely whitewashes controversies regarding the redefinition of women's roles.

Teresa de Lauretis, in sketching her concept of a woman's Oedipal Journey, indicates that, because of societal pressure, girls must let go of their desire for their mothers. However, doing so is often quite traumatic and difficult, so they adopt a sort of "bisexual" identification that fluctuates between men and women throughout life. This fluctuation makes "passive" femininity difficult to achieve (Altman). So in film not only is there active male identification with the gaze, the passive female identification with the "image," but also a "double identification" with the narrative image that allows female spectators to be "desired by others" and then "desire to be desired." In The Wizard of $\mathrm{Oz}$, Dorothy, who wants to be seen as a grownup by the people around her (Uncle Henry, Auntie Em, Professor Marvel, and the field hands) goes to Oz, kills her mother (Miss Gulch/the Wicked Witch of the West), conspires with the Wizard/Professor Marvel (it would be inappropriate for her character to have a romantic relationship with the Wizard, so according to Rick Altman, they should be "conspirators"), and comes home to see that all of the adults (mostly men) who didn't have time for her as a child were worried that she had gotten badly hurt. Auntie Em, Uncle Henry, Professor Marvel, and the field hands are no longer too busy or distracted by the impending storm to pay attention to her. In other words, she desires to be desired, and by the end of the film she is desired.

The coming of age journey that occurs in her own subconscious proves to be exciting and interesting. First, she is mistaken for a witch with powerful magic, and then she helps the Tin Man, Lion, and Scarecrow (the convenient doubles of the field hands who didn't have time for 
her at the beginning of the film) and subsequently wins their friendship and their attention (and their desire, albeit innocent). By the end of the film, Dorothy is waking from her dream, and all of the people who were too busy earlier are gathered around and desperate for her safe awakening. It was 1939 and the Hays Act was in full force, so although the men aren't permitted to recognize her sexuality (um, castration), she manages to fit right back into the symbolic order [remember, "Oedipus always wins in cinema" (De Lauretis)]. In the final scene, she states that "If I ever go looking for my heart's desire again, I won't look any further than my own back yard." As all of the male characters in Kansas (and in Oz, too) are inept, clearly Dorothy has learned that if anyone is to get the work done on that farm in Kansas, it will be left up to her and Auntie Em (and the women of the 1930s in general) to make it happen. The dirty secret of the patriarchy is then laid bare: women are doing all of the work.

The previous chapters of this dissertation will deal with cultural issues surrounding class transgression, the capitalist influence on the role of the family, gender role redefinition, and how the fears produced by these issues are mediated through film and the use of child stars in the 1930s. The Scottsboro Boys case illustrates that race and gender and the definition of childhood were issues very much at the forefront of the cultural consciousness of 1930s America. With that in mind, Chapter 5 will closely examine the ways in which the film Gone With the Wind not only addresses the issue of race and the cultural anxieties regarding miscegenation, but also the ways in which the boundaries of childhood and adulthood become somewhat blurred and dependent upon qualifiers such as race and gender for practical purposes. Among the multitude of questions raised by the narrative of the film is the issue of which characters are children in the film. Is 16year-old Scarlett a child when she stamps her feet and refuses to take a nap? What about 14-year- 
old Prissy who knows nothing about birthing babies? Virginal Aunt Pittypat (with her ShirleyTemple-like locks), Melanie, and of course Bonnie Blue Butler could all be considered children, or at least child-like.

It is my assertion that class projections about sexuality and race that seem to be somewhat muted early on in Shirley Temple films (like the Littlest Rebel, Dimples, and The Little Colonel) in which the moppet tap dances down the stairs with Bill Bojangles Robinson in chaste and wholesome fashion, emerge again with a vengeance in Selznick's epic film. The economic devastation of the early 1930s made the injustices of race relations in this country more and more difficult to ignore. How better, then, to patch up the abrupt breaks regularly bubbling to the surface of the American consciousness regarding race, sexuality, and upward mobility than to recall the horrors and hunger of the American Civil War and Reconstruction?

To be sure, there were plenty of poor people before the Great Depression, but suddenly the issues of why they were poor and how best to handle it came to the forefront of the collective cultural consciousness. In Babylon Revisited the story, in the 1930s, redemption seems to rest on the shoulders of a little girl. As the decade begins, that little girl is a curly-haired moppet. By the end of the decade, the little girl is a full-grown woman who represents the American Dream... at once the eternal adolescent with an irrepressible spirit who can get away with ignoring the rules of decorum as it suits her whims, but who can also reap the benefits of her class, her race, and her gender. However, in the end, the one thing that she desires (Rhett) rejects her because she is no longer a child like Bonnie "before war and poverty had done things to her." Scarlett can no longer go back to the innocence of being a child, and the United States can't quite go back to the innocence of a time before slavery and before the perceived moral corruption of the $1920 \mathrm{~s}$ 
had done things to it. Like Scarlett, though, the eternal optimist, there is always tomorrow. "Tomorrow is another day!"

In Frankly My Dear, Molly Haskell suggests that much of the film's appeal has to do with the basic duality between protagonist Scarlett and her foil, Melanie. Haskell also suggests that Scarlett's assertiveness, impulsiveness, and rebelliousness are not unlike those of the original book's author, noted rebel and Jazz Age flapper, Margaret Mitchell (88). In many ways, Scarlett really becomes the mixed-up, repressed, yet aggressive American Dream personified in the body of a child/woman. Ultimately, it is my hope that this body of work establishes that Scarlett, and all the child/women film characters that represent American femmes fatales of the 1930s serve as a reflection of a censored and restricted representation of the turbulent and changing roles of American women during the 1930s.

\section{Conclusion}

When all is said and done, the films that I have selected for this study share not only a decade and protagonists that are female and young, but also an underlying theme of feminine control. Shirley Temple as moppet isn't easily controlled, but she is charming because she has no

officially sanctioned power. She may be able to hitchhike to the airport to find Loop because she is cute, and she might be able to sit on Abraham Lincoln's lap and and convince him to release a POW because she is so adorable and innocent, but at the end of the day she has no economic agency. She is subject to state control in the form of social workers, police, and inheritance laws, and she isn't going to be cute, adorable, or innocent for more than five or six years when she becomes an adolescent and her charms wane. The trials of Stella and Laurel send the overt 
message that women must sacrifice everything for the their children and that girls have a duty to follow prescribed patriarchal roles set forth by their culture. The melodramatic structure of the film hamstrings this theme enough to see the cracks of feminine resistance shining through, though. Dorothy Gale certainly seems to be posited firmly into an obvious gendered role on the farm in Kansas, but no one who watches the film really thinks she will stay after having seen the wonders of Oz. And Scarlett manages to buck the whole system by having agency, making money, and saving everything while being overtly and obviously sexual. But at the end of the day she can't have it all and have her man. Having it all and having sex appeal would be a right reserved for adolescence, not for adult women. It is my supposition, that these films offered an opportunity for American viewers of the 1930s to culturally prepare themselves for a time when the attention of the nation

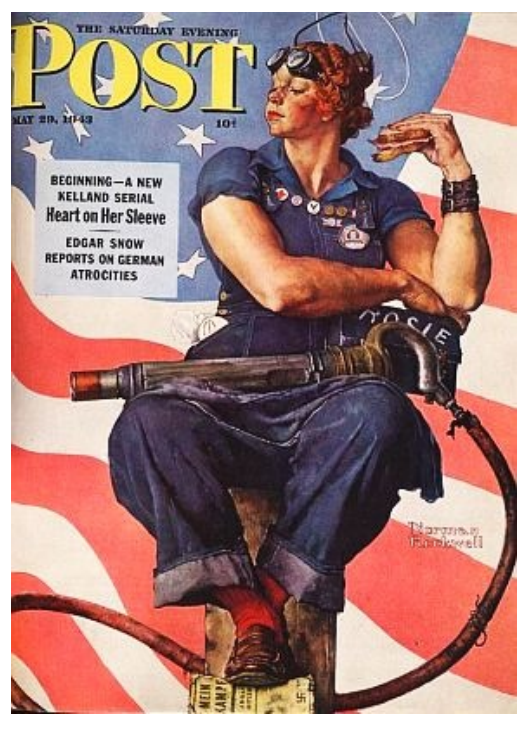

Figure 12: Norman Rockwell is generally attributed as the creator of the Rosie the Riveter image that encouraged women to go to work in factories during World War II. This was the cover of a 1943 Saturday Evening Post, which had a circulation of around 3 million people per week. would be turned towards a world war, and patriarchal cultural artifacts would be forced to reflect the competencies and abilities of both genders, at least for a short time. 


\section{Chapter 2 Shirley Temple: Bright Eyes, Dark Men}

In October 1934, one of the most famous custody battles of the 20th Century went to court. The subject of the dispute was ten-year old heiress, Gloria Vanderbilt. Gloria's paternal aunt sued for custody in order to remove Gloria from the care of her socialite mother, whose scandalous widowhood made for good press. The story was infused with tales of deliciously unsavory behavior, and the American public followed the papers closely for juicy details regarding the whole, sordid affair

Gloria's mother and the mother's twin sister were rumored to have had "intimate" relations with European royalty; consequently, Gloria's mother was accused of being an "unfit" guardian. The fascinating events put forth by the press proved that money, in this case, did not guarantee happiness. The public listened to the tales of unwholesome socialite parties and child neglect with fascination, as the courts tried to figure out who the poor little rich girl's family should be. The draw of the story for the public became, after time, not so much about which adult would provide the best home environment for the child. It was really about who had engaged with "intimate relations" with whom, and the Schadenfraude experienced by the general public when people of wealth and social standing get embroiled in sexual scandal.

A few months after the trial, a film called Bright Eyes starring Shirley Temple as an orphan caught up in a custody battle between a wealthy family and her young, upwardly mobile 
(literally and figuratively) airplane pilot godfather, hit the silver screen. Although Vanderbilt was worth millions and the character portrayed by Temple was a destitute orphan, the issue of a child's custodial arrangements in regards to parental class standing was lodged in the collective consciousness of the country.

But, other things were also lodged in the cultural consciousness of the country, too. Under the direction of Herbert Hoover, the President's Research Committee on Social Trends commissioned a series of monographs to report on the instability and stability of current social issues in the United States. One part of the publication included a study by Hornell Hart of Bryn Mawr College that launched a statistical analysis regarding attitudes towards sex and sexuality in magazine stories and articles from the early 1920s until the committee report was published in 1933. Hart concluded that interest in sexual freedom had reached its peak in the time between 1923 and 1927, and that by 1930 these magazines had become much more conservative and championed marriage and family life much more than it did a decade earlier. Another study, this time of college students, was conducted by Fortune Magazine. It concluded that sexual promiscuity was no longer in vogue among young adults, and that "reasonable restraint, particularly on the part of the girl" before marriage as well as "fidelity" on the part of both partners after marriage, was desirable. The only exception to this new code of college student morality seemed to be among students on the West Coast, where the "jazz age experimental attitude" continued to persist ("A New Kind of College Graduate"). This study received a great deal of popular press. The opening lines of an article describing the study in the Milwaukee Journal asserts: 
Flaming Youth died somewhere in the dark depression years and the American college student of today -- boy or girl -- represents a "cautious, subdued and unadventurous generation unwilling to storm Heaven, afraid to make a fool of itself, unable to dramatize its predicament." (A New Kind of College Graduate

Cautious and subdued? Unadventurous? A rejection of the "jazz age experimental attitude" towards sex? Clearly there was a shift in the cultural frame of mind towards sexuality and socializing that so epitomized Fitzgerald's youth culture of the 1920s. The pendulum was swinging back towards a more conservative view of sexuality, family life, and marriage. According to the Fortune study, "... the general idea seems to be that promiscuity isn't very pretty" ("A New Kind of College Graduate" 23).

Based on this reversal of cultural thought from the "jazz age experimental attitude" to the rejection of promiscuity reported by 1930s young people, I would propose that the public fascination with the Gloria Morgan Vanderbilt case was more than just a lurid interest into the unfortunate lives of the rich and famous. In fact, it was an outright rejection of the implied casual and consequence-free sexuality that the flapper had come to represent. If the Great Depression was, at least metaphorically, penance for the sins of the Jazz Age, it follows that more traditional views of marriage and family life would be the resolution to the anxiety caused by the flapper's brazen sexual autonomy. In the process, though, female eroticism is shifted to the body of a little girl who was so talented that she could, in turn, conceal and illuminate cultural anxieties regarding female sexuality and who was controlling it. Through this 
simultaneous signaling and denying, her eroticism is manipulated into cute as opposed to sexy. And at the end of the day, "cute" becomes fetishistic.

In the following pages, I will discuss ways in which the subtle and (not-so-subtle) eroticization in the Shirley Temple films of the Great Depression reflected the American aspiration towards economic and social mobility, distracted the audience from the horrors of the economic collapse, and ultimately served to redirect the attention of its audience from the problems of a deteriorating white middle class masculinity to that of the flirtations of a destitute, lovable, and safe little girl. In doing so, however, Temple's body of work (to say nothing of her corporal body) began the subtle process of deconstructing the image of an asexual innocent childhood and building the underpinning for a cultural image of womanhood and sexuality that was decidedly infantile in nature. In other words, Temple was the first step towards creating what Molly Haskell refers to in From Reverence to Rape as "the natural idiom of American eroticism. .. [America's] Lollipop Licking Tease" (21). She was, in effect, the neutralizer for the ultra-sophisticated and sexually indulgent cultural creation of women from the previous decade.

The Gloria Vanderbilt custody battle showed a decided rejection of the agency represented by the flappers who took control not just of the length of their hair or the rigidity of their undergarments, but of their sexuality as well. The trial made evident the one hitch to the whole issue of a flapper's ability to represent sex without responsibility; it doesn't work very well. If someone gets pregnant, responsibility is unavoidable. Vanderbilt's mother, Gloria Morgan Vanderbilt, was a minor (17) when she married Gloria's older father (42). Due to his untimely death, (Morgan was believed to be under the age of 21 , and consequently needed a legal guardian for her daughter) the legality of Little Gloria's custodial arrangements was in 
question. During the trial, Gloria Morgan Vanderbilt (the mother) was painted as an uncontrolled party-girl with loose morals, which is how Little Gloria ultimately became (like Shirley) a fetish that both concealed and signaled anxieties at play in the greater cultural narrative.

As Fitzgerald's Honoraria reminds us, little girls can only remain little girls for a very short time; so turning something as ephemeral as a young child-actress into the ultimate representation of womanhood in order to assuage the unrest caused by financial panic would serve to contort the original intent of her cultural role. In other words, using Shirley Temple's "cuteness" as a distraction to help people regain a sense of nostalgia and good will regarding the state of femininity (before America had gone astray during the Jazz Age) forced the image of women to evolve as the child began to mature. So, although Shirley starts out fulfilling the role of the innocent infant orphan, as the 1930s progressed and she grew towards womanhood, the image of 1930s "woman" begins to shift towards the not-so-infantalized (Dorothy Gale), the notso-innocent (Scarlett O'Hara), and the not-so-motherless (Laurel Dallas). In using Temple as the antidote for women like Gloria Morgan Vanderbilt, Wallis Simpson, Zelda Fitzgerald, and Louise Brooks, America eventually ends up creating a permanent, yet controlled, space for adolescent sexuality that continues to influence the image of female sexuality into the Twenty-First Century. This chapter will explore the ways in which the angst regarding greater class mobility produced by New Deal Policies is reflected in many films starring Shirley Temple, and how her gender, eroticism, and race are used to diffuse and distract from potentially troubling realities.

It is especially provocative to trace the trajectory of Temple's film career in light of political activities in the 1930 's. Her early films feature exploitation on a pre-code level that functions to make contemporary adult viewers squirm with discomfort. After 1934 (and the 
unilateral acceptance of the Hays Code), she still wore short skirts and coquettish smiles. But her on-screen charms were reserved for adoptive daddies, rather than sugar-daddies, and her image became (on the surface, at least) a more wholesome metaphor used to conceal deep-seated economic anxieties. She seemed less of a baby vamp used for cheap laughs in exploitative film shorts of toddlers acting out adult roles.

James Kincaid's work on the more recent fetishization of American children in popular culture in his book Erotic Innocence and earlier eroticization of children that occurred in Victorian England in Child Loving, suggests that the concept of the myth of the "innocent and pure" child was constructed as a smokescreen and diversion to real social problems regarding children in Victorian England. He further suggests that the contemporary cultural scapegoat/ monster "child molestor" is a creation based on the reaction to the adoration of the ultrainnocent, quasi-erotic child star. He points out that there were other familiar actors and characters before the 1930s who also furthered the diversion. Lillian Gish, Mary Pickford, Jackie Coogan, Peter Pan, and Alice Liddell (the real-life inspiration for Lewis Caroll) all blurred the lines and boundaries between childhood and adulthood. But without a doubt, Shirley Temple best personifies the creation of the "sexualized child we are pretending to sanitize" (Erotic Innocence 21).

Undoubtedly, she was the "it" girl of 1930s. She was the top grossing box office star for Hollywood from 1935-1938, and she managed to beat out famed entertainers like Clark Gable, Bing Crosby, Gary Cooper, and Joan Crawford for that spot. Shirley provided to the American Public what they were longing for. In a world besought by stock market crashes, orphan trains, crumbling family units, and the distinct sneaking suspicion that somehow the public may have 
brought the whole thing upon themselves by not working hard enough and enjoying the sinful pleasures of the Jazz Age a little too much; Innocent nostalgia was a welcome relief. A child who needed to be cared for, but who was pleasant, attractive, and didn't seem to have too much emotional baggage, could provide the average middle class viewer with the nostalgic stasis they so desperately craved. As long as the little destitute orphan was on the screen using virtue, gumption and fortitude to get by, the audience was encouraged that they, too, could work hard and use backbone and perseverance to make it through tough economic times.

Although the general public was willing to enjoy her charms, Temple was not without her critics. Noted Catholic novelist Graham Greene called attention to Temple's "well-developed rump" and her eyes' "sidelong search coquetry" in a 1937 review of Wee Willie Winkie. His words nearly destroyed him financially and professionally:

Her admirers -- middle-aged men and clergymen -- respond to her dubious coquetry, to the sight of her well-shaped and desirable little body, packed with enormous vitality, only because the safety curtain of story and dialogue drops between their intelligence and their desire.

(Greene 37)

Twentieth Century Fox and Temple's attorneys successfully sued Greene and the magazine that printed the review. The public was outraged, and Greene was financially ruined and forced to flee England in order to avoid possible imprisonment.

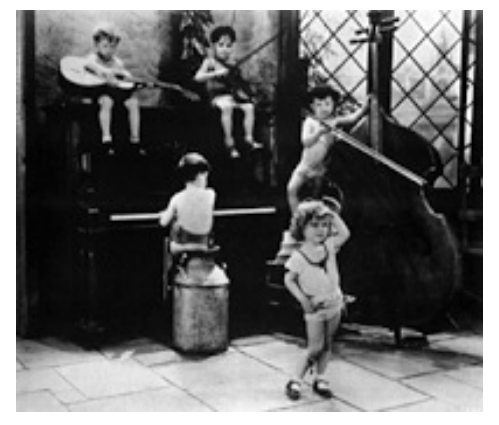

Figure 1: Shirley Temple dances for the troops and for lollipops 1932's War Babies. 
Ironically, just a few years earlier, before widespread enforcement of the Hays Code became the law of the land, it was not uncommon for exploitative sexuality to be common practice for most films, and Shirley was no exception. The "Baby Burlesks" shorts, filmed when Temple was just three and the Hays Code was not yet enforced, feature Shirley and a gang of little boys in diapers with oversized safety pins and minimal props acting out story genres familiar to the audience. They were, in Temple's words, “a cynical exploitation of our childish innocence, and occasionally were racist or sexist" (Black 14). In War Babies the incongruity of children playing G.I.s in a French watering hole, drinking bottles of milk (as opposed to beer), exchanging large lollipops for currency, and engaging in a sort of dumbed down manage a trois with Temple's French prostitute character provided Pre-Code audiences with a good chuckle. In Polly-Tix in Washington, Shirley portrays a black lingerie-clad vamp whose greatest thespian moment occurs when she announces that the country Senator that she has been employed to seduce can, indeed, "be had." But in 1934 when the League of Decency insisted that:

No picture shall be produced that will lower the moral standards of those who see it. Hence the sympathy of the audience should never be thrown to the side of crime, wrongdoing, evil or sin (Hays qtd. in Doherty 361).

Consequently, Shirley put on more clothes, dropped the Mae West act, and became less of a femme fatal and more of a wholesome moppet who inadvertently put herself in the way of male attention repeatedly. Hays specifically banned "excessive and . . lustful embraces," thereby prohibiting a repeat of Shirley's three way hug and kiss in War Babies. In addition, "Dances suggesting or representing sexual actions or indecent passions [were] forbidden," thereby nixing any urge to force a toddler to dance by "accidentally" placing ice cream in the child's diaper for 
the audience's delight and amusement. In addition, the Hays Code deemed that sex "must not be the subject of comedy or farce, or treated as material for laughter," and that "evil [not be] presented alluringly. . . [and] not be allowed to appear so attractive that the audience's emotions are drawn to desire or approve so strongly that the condemnation is forgotten and only the apparent joy of sin is remembered" (Hays qtd. Doherty 351).

In other words, the fact that the audience's emotions would be drawn towards Shirley's roles as fallen women in Polly-Tix and the dance girl in War Babies, and that her apparent sin would be the dominant memory for the audience, would pretty much end the production of this sort of farce after 1934.

But it would be simplistic to blame all of Temple's professional transformation on the Hays Code. In fact, the Hays Code, like Temple's films and even Graham Greene's legal troubles were all symptomatic of the changing climate in regards to marriage and family. The reason that Greene found himself under so much fire from the public and MGM was not really because he slandered Ms. Temple, it was because he was exposing the truth about sexuality in her movies; no one likes having an uncomfortable social hypocrisy in which they are complicit pointed out to them, especially the public.

Frederic Allen bluntly states in Since Yesterday that in the 1930s, "marriage seemed to be more highly prized as an institution than in the 1920s [and that] the family seemed to have become highly prized" as well (137). Not only did the flapper not fit in with these attitudes regarding marriage, but her partying and unbridled sexuality could break up families, and in the case of Wallace Simpson, they nearly broke up a whole country. In the case of Gloria Morgan Vanderbilt, the mother's sins were not just about her indiscretions after her husband died. They 
were about her inability to provide a safe family unit for his daughter where the adults were, as Fitzgerald describes it, "serious" and "watchful." Although the sexy sophisticated flapper couldn't produce a nice nuclear family for her daughter, the daughter (in the form of Shirley Temple) could re-frame the sexuality into "cuteness" and form one for herself.

In one of her most famous scenes from Bright Eyes Temple innocently dances up and down the aisle of a taxiing airplane singing about the "Good Ship Lollipop" to a group of pilots (rumored to be played by the University of Southern California football team), bewitching them

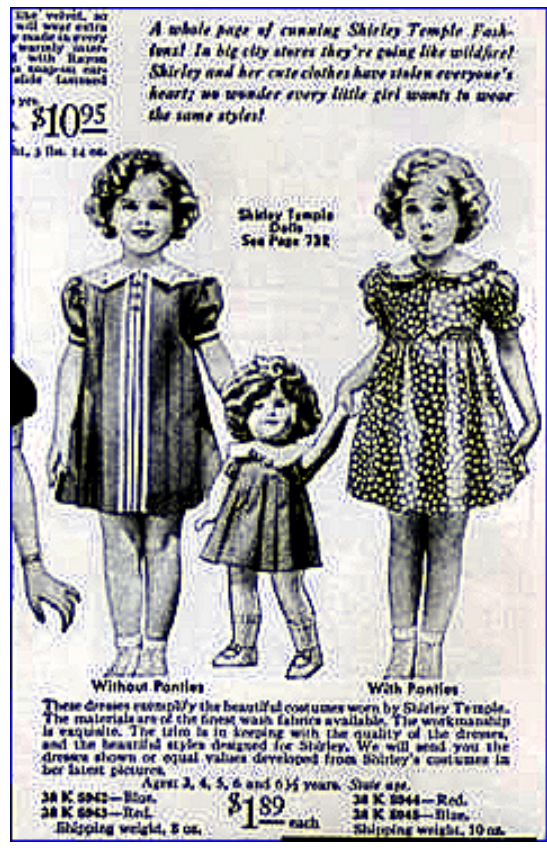

Figure 2: The 1935 Sears and Robucks catalogue actually featured a page of Shirley Temple fashions for little girls, featuring "panty dresses" that afforded little girls matching dresses and panties in coordinating prints (Blum 77). with her bright eyes, short dress, dimples, and enthusiasm. At no point does she indicate that she has interest in sexual folly. However, she is passed through the cabin by various men as she dances, staged not unlike Marilyn Monroe's dance of sexual greed in Diamonds are a Girl's Best Friend over twenty years later, and Madonna's similar re-framed kitschy Material Girl video over forty years after Monroe. In fact, unlike Monroe and Madonna, instead of collecting diamonds and other riches from her gaggle of male admirers, Shirley

collects a commodity more valuable to children (and the 1930's, jobless, penniless and hungry American proletariat): sweets. In addition, though she isn’t dressed to necessarily resemble a prostitute, as in the "Baby Burlesks" shorts, she still isn't wearing very many clothes. She is featured wearing a plaid dress that doesn't quite cover her bottom, and short pants that offer no more coverage 
than the diaper she wears with her French dance hall costume in War Babies. Incidentally, although the Hays Code specifically prohibits showing a child's genitals, it didn't prohibit using costuming that emphasized a child's bottom and underwear. Nor did it prohibit the camera angles that revealed a child's covered pubis, undressing a child on screen, or general tomfoolery regarding the child's body. Many Shirley Temple films, as Graham Green points out, go to great lengths to emphasize Shirley's "bewitching bottom" and "short dresses." (Green qtd. in Parkinson 234)

In that same film, Shirley's co-star, Jane Withers (who plays Shirley's foil, the brat) rides an oversized tricycle around and generally terrorizes elderly Uncle Ned (and the audience) by making police siren noises. Although she is very obviously costumed and cast as the "AntiShirley" (she was richer, was taller, had darker hair, spouted dialogue about her psychoanalyst, and had a propensity for breaking toys), she also wears a short dress, and hers reveals the crotch of her (plain white, not coordinated) panties. Because it is so obvious, the scene is clearly not meant to illicit titillation from the audience. But the incidental and seemingly "innocent" view of Wither's nether region easily conceals a more subtle eroticization of Shirley's flirtation with Uncle Ned.

Uncle Ned encourages his family to enter into a custody battle with Shirley's woefully middle class godfather, the pilot "Loop," once Shirley's mother is conveniently eliminated from the plot in a fatal car accident. Custody battles were very much in style in the 1930s, but unlike the scintillating tale of Gloria Vanderbilt's mother and aunt bedding princes and partying across Europe while battling a wealthy family, the fight over Shirley had more to do with an upwardly mobile middle class pilot battling a wealthy controlling family for custody of a domestic 
servant's orphaned daughter. Hayes restrictions limited the amount of licentiousness to be used in the plot. However, the chemistry between Shirley and the men around her is unmistakable as she croons, mugs, and preens for Loop, Ned, and an entire plane of young men. At the end of the film, Shirley manages to champion the middle class nuclear family by going to live with her Godfather and his fiancé Adele. In doing so, she sutures over any anxiety felt by the monied upper class by this economic transgression by bringing crotchety (and wealthy) Uncle Ned to live with them, too. At the end of the day in Bright Eyes, the charity case has, much like recipients of WPA programs, managed to create her own good fortune and looks to a bright future with her own nuclear family (with Uncle Ned as the bonus patriarch). One suspects that Little Gloria Vanderbilt would much rather have had such a simple, positive, and conclusive outcome to her story.

Shirley's precocious flirtations with men weren't limited to Bright Eyes. Many of the plots of her post code films revolve around her ability to charm the opposite sex. In Captain January, Heidi, The Little Princess, and Little Miss Marker, the plot hinges on her relationship with her father (or an older man substitute) and the complications as a result of a missing mother. In Captain January, she's an orphan who has taken up residence with a gruff lighthouse keeper. In Bright Eyes she's an orphan who wishes to be adopted by an airline pilot. In Little Miss Marker her father forfeits her to a bookmaker as collateral on a debt, and she is left in the care of other older men. In Heidi she's an orphan who lives with her grandfather. In The Little Princess she's an orphan who doesn't believe her father is dead while she is trapped in an unpleasant boarding school, and the list goes on. The resolution to each of these movies is dependent on her relationship with the older man/father in question, and in each of these movies she demonstrates 
great physical affection towards these gentlemen. Were the same glances, kisses, and embraces offered up by a young woman as opposed to a young girl, they would be decidedly sexual in nature, and definitely a target for Hays censorship and criticism by the viewing public. But because they were performed by a child, they were not viewed as suspicious or provocative in nature. Ultimately, unlike the flapper who represented sex without responsibility, Temple represented responsibility without sex.

Except many of the activities that she was directed to perform were sexual. The film Curly Top was a hit in the United States. But it was banned in Denmark, according to the Internet Movie Database due to "unspecified controversy." Even Temple admits in her biography that it was probably because her fantasy portrayal of cupid involved her appearing nude on screen covered in nothing but glittering body paint. In Captain January, she was originally filmed dancing the hula.

As a nubile island maiden, I wore a hula skirt and a brassiere of slippery seaweed fronds and swayed and swished until my costume seemed alive. Whatever my sin of suggestiveness, reviewers from the Mothers Clubs of America gasped in horror. The hula was immoral (Black 128).

Before the film was released, the scene was re-shot with Temple wearing "tight fitting trousers with flared bottoms" (128). Even without the hula, Graham Green referred to the movie as "a little depraved" and added that "Some of her popularity seems to rest on a coquetry quite as mature as Miss Colbert's and on an oddly precocious body as voluptuous in grey flannel trousers as miss Dietrich's" (Greene qtd in Parkinson 234). Although Graham Greene's sardonic reviews 
were eventually greeted with a lawsuit by the studio, it is clear that Temple was deliberately put in sexual situations after Hays became the law of the land.

Ann duCille points out that Temple's substitute fathers were able to supplant the patriarchal masculine sexual constructions specifically prohibited by Hays. In Little Miss Marker, quite a show is made of the little girl wearing her substitute father's pajamas to bed, and the fact that her underwear has to be removed before she sleeps in his nightshirt. Having a starlet wake up in men's pajamas was common costuming for adult actresses, and was a sort of code or ellipses for sexual behavior in a movie that could not show more for fear of Hays censors. By not showing sexual activity between two consenting adults, but by suggesting that someone had to change clothes in the night, sophisticated viewers could assume that romantic activities had occurred off screen and less worldly viewers wouldn't get any naughty ideas. But this coded behavior takes on a whole new light when a child is introduced to the mix. DuCille states that Although a man couldn't remove a woman's bra and panties on screen in 1934, he could in an act of sexual displacement, undress a little girl playing at being a woman, her flat chest purifying this otherwise risqué gesture, making it censor-proof. Titillation without tits (19).

Robert Polhemus refers to this metaphorical "attraction" or even literal attraction between older men and younger girls and women as the "Lot Complex." In his book, he bases famous literary and real-life pairings, some chaste and some sexual, on the incestuous union between the Old Testament's belabored Lot and his daughters. It is Polhemus's contention that the power base in relationships like Alice Liddell/Charles Dodgson, Jane Eyre/Mr. Rochester, Woody Allen/Mia Farrow/Soon Yi Previn, Bill Clinton/ Monica Lewinsky, Bill Clinton/Chelsea 
Clinton and Shirley Temple/her leading men develops as young girls gain power status and authority through their relationship with the older men. Meanwhile the man is charmed by the power and vitality of youth possessed by the younger woman, and rises in his societal status as a result. Clearly, as in the case of Clinton/Lewinsky and Allen/Previn, sexuality is very much a part of the equation. But in partnerships like that between Dodgson/Lidell, Clinton/Clinton, and Temple/whomever, sexuality is diffused (though sometimes barely.)

In the chapter devoted to Shirley Temple, Polhemus discusses much touted press pieces and photographs detailing the innocent relationships between Shirley Temple and J. Edgar Hoover (he put her in a make-shift jail and she deputized him as a member of her police force), her father (who is photographed literally below her as she signs a contract with MGM), W.L. Mackenzie, (the Prime Minister of Canada), scads of co-stars (like Clark Gable, Lionel Barrymore, and Bill "Bojangles" Robinson), and fictional characters (including a fictionalized Abraham Lincoln), all with whom she cuddles, sparkles, sings, and tap-dances. In each case, her youth, innocence, and gender give the man power and status while in exchange their authority gives her agency.

Through the studio's decision to build her on-screen and off-screen persona as the adorable child who can soften the gruff hearts of both real and imagined patriarchal figures (like J.Edgar Hoover, the Prime Minister of Canada, Clark Gable, and Abraham Lincoln), not only does "sexuality" get re-framed as "cute," but male to female sexual attraction becomes re-written as parental affection. Unlike Gloria Morgan Vanderbilt and Wallis Simpson, she didn't smash up families and countries and leave the mess for someone else to clean up. In fact, she did just the opposite. When she creates a family with her father figure during the plot of her movies, she's 
not only creating the idealized family situation, she is also creating the idealized national identity. A national identity that aligns itself perfectly to a heteronormative family complete with a kindly yet inspiring fatherly figure at the head encouraging the children to grow up, overcome obstacles, and become productive members of society. Really, the man who profited the most from Temple's youth, innocence, and gender was Franklin D. Roosevelt.

Make no mistake, Roosevelt was aware of Temple's positive effect on his image. When he ascended to office in 1933 during the depths of the Great Depression, his Presidency was a mash-up of perception-building, word-smithing and social reform. Likewise his predecessor Herbert Hoover had used the word "depression" to describe the economic downturn, rather than the terms like "crisis" or "panic" that had been used to describe similar economic periods, such as the "Panic of 1873" or the "Australian Banking Crisis of 1863." Roosevelt's promise of a "New Deal" offered hope to the masses, and the cultural constructions around him began to fall in line. In 1934, the president famously remarked, "When the spirit of the people is lower than at any other time during this Depression, it is a splendid thing that for just 15 cents, an American can go to a movie and look at the smiling face of a baby and forget his troubles" (Black 59).

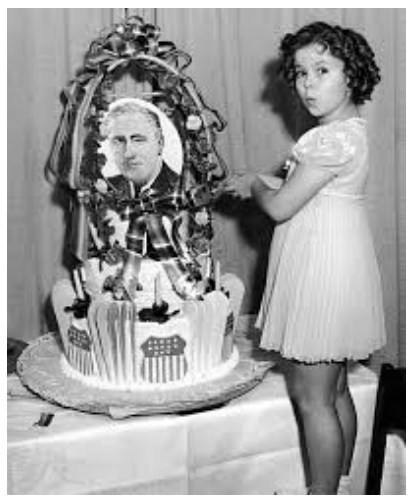

Figure 3: Shirley Temple helps celebrate Franklin Roosevelt's Birthday in 1936 by cutting the cake.

Coincidentally, 1934 is also the same year when the Hays Code went from being a a joke to becoming unilaterally enforced policy, and Shirley's image changed from that of a diminutive sex-pot to that of a small (flirtatious) cherub. Clearly, it 
was a year of cultural flux in the United States. In Temple's autobiography, she herself points out that,

In addition to using the symbolism of childhood and reborn hope as antidotes to the personal despair and disillusion of the Depression, Hollywood had also been looking to its morals. Here, too, an innocent child proved immensely useful (Black 59).

The same year that Hays went into effect, Franklin Roosevelt began promoting his domestic reform program, "The New Deal," designed to provide recovery and relief for American citizens who were suffering as a result of the financial crisis before them, and Shirley stopped wearing black lace braziers and started wearing plaid jumpers. But in her roles, she continued to dole out affection for goods and services, albeit in a much less overt and much more subtle fashion. And, much in the same way that Roosevelt's interest in making relief and recovery available to everyone in the United States, regardless of class or heritage (make that white heritage), thereby attempting to eliminate economic boundaries that had been holding people in place, the plot of Temple's movies often involved creating class mobility (for the white constituency, at least). In fact, it could be argued that where Temple's films often fall short is not at breaking barriers by portraying racial diversity (she did that), but at disallowing cultural, social, and economic flexibility for all races during the plot of her films. Although African American actors were often cast in her films (for reasons that we will discuss later), they always conformed to the "faithful and loyal servant" trope that was so prevalent in the 1930s. As Franklin Roosevelt pushed forward to make controversial changes designed to allow Americans the ability to recover from the hard times, Shirley's films were available to embody nostalgia and good will 
which would keep this new trajectory from seeming frightening or threatening to an already traumatized nation. In 1936, Roosevelt was quick to endorse her film Baby Take a Bow by publicly remarking on the future of the country, "As long as we have Shirley Temple, we'll be all right" (Kehr).

Ian Wojcik-Andrews suggests Temple's role in Bright Eyes, (as well as with many other of her "orphaned-moppet" roles) was to symbolize a way to resolve class and other social problems of the 1930s. She represents the

kind of ideal child that will take the country down the road to economic growth and emotional recovery but also the kind of ideal parents necessary to look after her. Bright Eyes shows the ideal family unit required to reproduce the ruling social order (136).

Temple wasn't scary, smelly, or threatening. Though subtly (and sometimes not-so-subtly) eroticized, she wasn't apt to break up families. In fact, she would use her pluck and charm to nostalgically champion the emergent, upwardly mobile, and hard-working American middle class. Gone are the sordid values exemplified in films and popular culture of the 1920's that led America to its decay. Instead of films like Dance Fools Dance featuring skinny dipping flappers representing the hard-partying 1920s, there were films like Bright Eyes in which the heroes like Shirley's mother and Loop work hard to bring us back to the values upon which the United States was (perceived to be) based. 
From the spectator's point of view, this ... Bright Eyes interpolates the audience to conceptualize themselves as a new and emergent class that through the institution of the nuclear family will achieve a balance between work (labor) and money (capital) and thus put the country back on the road to economic

prosperity." $\quad$ (Wojcik-Andrews 137)

Popular culture, and the art of what Walter Benjamine would refer to as "Mechanical Reproduction" -- in other words, films and still photographs -- were rapidly re-vamping the ideology of the United States during this same time period. In his book about the pop culture of the 1930s, Dancing in the Dark, Morris Dickstein suggests that the work done by photographers and journalists during The Great Depression as commissioned by the Civil Works Administration (CWA) forever altered the landscape of photojournalism and written documentary by adding increasing emphasis on the individual and the plight of the common person as relevant subject matter ripe for exploration. Since the Depression was the news, its victims were CWA subject matter. Scads of pictures of impoverished men in breadlines, women looking defeated and scared, and children in rags desperately

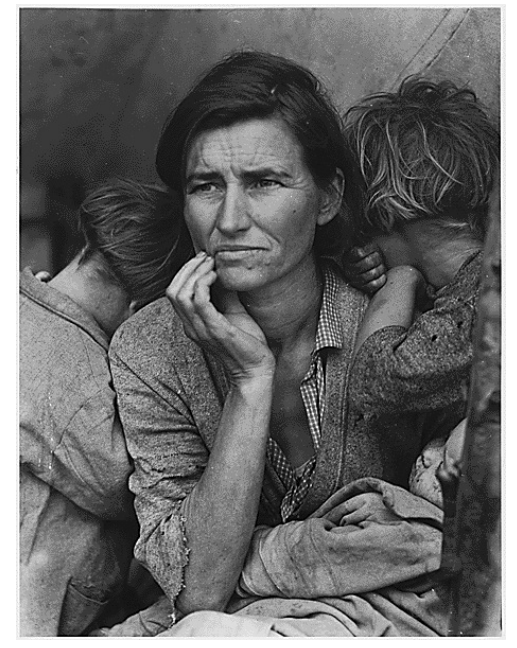

Figure 4: Dorthea Lange's 1936 "Migrant Mother" exemplifies the use of photo-journalism to represent the plight of the common person. trying to eke out an existence were published.

But it wasn't just the serious journalistic work that seemed to underscore the message that poverty was not a sin. Now that radio and film were well-established parts of the cultural 
landscape, inscribed cultural messages were immediately available to the general public. Suddenly, due to the public relations narrative of the time, it was very possible to see oneself as an "Average Joe" down on his luck, instead of just someone who was poor because he wasn't good enough, smart enough, or morally superior. Much of Roosevelt's message of hope sprang from the idea that it was possible to cross economic boundaries, and that just because you were a Southern Democrat, or part of the rank and file, or unemployed, or poor, it wasn't necessarily your fault. The rhetoric of the "New Deal" promised a better way of life for you and your family if you worked hard and persevered. . . and the brave new world of mechanically produced art, film and photography reflected this progression of attitude. Shirley Temple rode the wave of this movement.

Wojik-Andrews maintains that the work of Ms. Temple often seemed to further the liberal agenda of Roosevelt's Democratic Party. (Despite the fact that Temple herself grew up to be an avowed Republican who served in cabinet positions during the Nixon, Ford, and Bush administrations.) According to Wojik-Andrews, Temple's character shows her support in becoming part of the upwardly mobile middle class from the first scenes of Bright Eyes. As the movie begins, Shirley is hitch-hiking to the airport, and a large industrial truck lumbers past. The driver, clearly some sort of laborer, stops and offers a lift. Shirley declines because she says that his truck is too slow, and that she is in a hurry to get to the airport. The driver points out that she is the "Most particular hitchhiker" he had ever seen. Fortunately, when a nicer motor car stops by, driven by well-dressed man she takes up his offer. Once there, she spies her deceased father's aviator buddy Loop on his plane. As she cheerfully waves and yells, another pilot grins and says: "I bet you wish you were up there with him." Shirley's telling reply is, "I will be. . . 
someday!" thereby foreshadowing her social and economic growth by the end of the film.

Therefore, Shirley's rejection of the common laborer at the start of the film, and the wealthy Smythe family who fights for her custody at the end of the film belay an interest in not being part of the laboring working class or of the stale, monied upper class. Her choice is to build her own nuclear family with the metaphorical and literal upwardly mobile Loop, his fiancé, and crotchety Uncle Ned, thus eschewing traditional methods of earning money (independent wealth) and common day-labor, for the family of an educated professional aviator. Temple's characters commonly use the male female relationship to create the familial triangle of motherfather-child and choose to create a family that will sustain further growth, prosperity, and security, much like the promise of the New Deal. In this case, Shirley's character sees the more privileged classes and knows that she will be "up there with him ... someday!"

In other words, Temple managed to create her own American dream, and sutured over the anxieties presented by children and families who were fractured and disrupted by the economic downturn. She usually played an orphan, the child of servants, or a daughter of the Confederacy (in other words, a dying, bankrupt aristocracy), and always managed to use her innocence, naiveté, and positive attitude to improve not only her own character's life, but that of those around her. If cute little Shirley Temple could improve her life, then everyone could!

Lori Merish points out that Temple's charms could actually help produce parental feelings of nationality. 
Valuing cuteness entails the ritualized performance of maternal feeling, designating a model of feminine subjectivity constituted against those (ethnic, class, or national) Others who lack the maternal/ sentimental endowments (and aesthetic faculties) to fully appreciate the ‘cute.' (Merish 186)

Remember, this was a time when children had been established by the Progressive movement and the economics of previous decades as a precious and valued commodity. Most certainly, the emerging middle class of the United States, a group of people (who may well have been questioning their identity in terms of social and economic class during such a wide-spread economic panic as the Great Depression) gathering to enjoy the cult of "cute" could easily help construct (or at least further cement) their group identity by viewing and appreciating the "ritualized performance of feeling" described by Merish. In other words, by participating in the group-think that found the baby burlesque antics to be humorous and innocent, theater patrons could more firmly establish themselves within the cultural construction of the of the New Deal middle class promised by Roosevelt and even help construct more of their imagined community's infrastructure. Once linked to this particular political identity, being poor could be viewed as less of a reflection of character and more a temporary stop on the highway to prosperity, as Dickstein suggests. American Puritanical ideals could be invoked for hard workers whose ability to be part of the WPA provided much more self-satisfaction and less a source of shame than being on the dole. 
Kincaid and Merish both point out that there is a very specific "look" that our culture perceives as "cute." Often the model of "cute" involves some of the following features: a small, chubby body with an disproportionately large head, fair skin, blond hair, large eyes, wide cheeks, narrow chin and and a round mouth. (In the tradition of Mary Pickford, Betty Boop, Jackie Coogan, Lillian Gish, Precious Moments figurines, and kittens.) Shirley Temple may not have been the first young star to earn millions because she was "cute," but her films certainly raised the bar and firmly established herself as the quintessential child star.

By staging cuteness as a mini-seduction met not by sexual violence or assault, but by protective care, these films reinforce a primary mythology of patriarchal "civilization" in place since the late eighteenth century. (Merish 195)
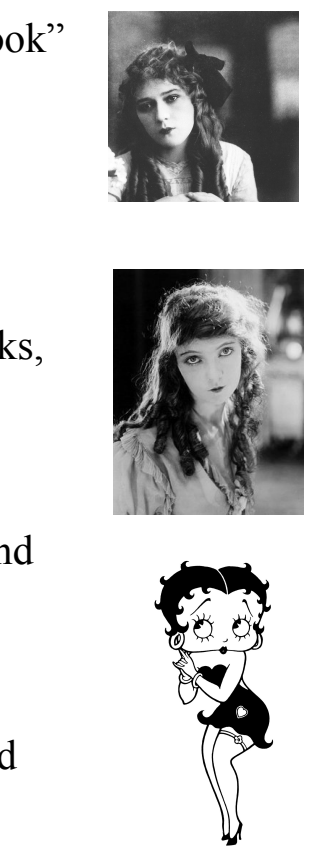

We will further discuss the implications of this imaginary "civilization" which was created, in part by American films of the 1930s, in chapter five.

But, to be sure, the 18th century ideology of father/care-

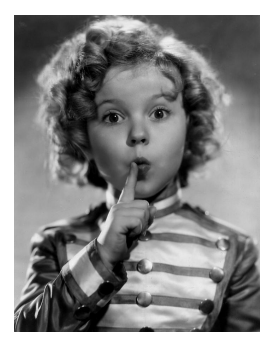

Figures 3-6: Mary Pickford, Lillian Gish, Betty Boop, Shirley Temple, Kittens, and Precious Moments figurines, and Hummels all share the same large head, large eyes, small mouth idealization of "cute." taker/master in these films didn't just extend to little girls. Like Temple, the pleasant, loyal, African-American film characters of the 1930s helped to re-affirm the social order. Temple's films often featured actors like Bill "Bojangles" Robinson, Hattie McDaniel and Steppin Fetchit. In fact, Temple-Black herself reports in her autobiography that in 
the 1930s, a popular industry joke was that it wasn't a Shirley Temple film unless it included a "darky." At face value, to the American movie-going public, these films may well have seemed egalitarian. In fact, between 1935 and 1936, she starred in three films that romanticized race relations surrounding the Civil War. In The Little Colonel, Shirley and Robinson dance up the grand staircase of a plantation mansion. In The Littlest Rebel, she and her faithful slave (again Robinson) travel to Washington and charm Abraham Lincoln into releasing her father, a Rebel Officer, from prison. In Dimples, Shirley joins Steppin Fetchit and a group of African American children for an all out minstrel show, in which most of the characters don blackface, and Temple actually mocks Fetchit's halting speech and slow gait.

The most interesting and (for my purposes, at least) inarguably significant of Temple's May/September romances was her on-screen relationships with African American adult men like Bill "Bojangles Robinson" and Steppin Fetchit in what Knight refers to as a "loose trilogy of films" set immediately before, during, and immediately after the American Civil War. According to Donald Bogle's book Toms, Coons, Mulattos, Mammies, and Bucks, the use of African American performers in film fit right into the social agenda set forth by the New Deal, or at least the spin that the Roosevelt White House was after. Although the African American performers used in film during during the late 1920s films were an extension of vaudeville performers and somewhat interchangeable, by the 1930's black characters in film were no longer portrayed simply as "jesters," they had now morphed into a sort of stereotype of the joyful and loyal domestic servant. Usually this new, less overtly insulting character type lovingly cared for their white employers. Such tender affection and loyalty was comforting to a public of white moviegoers who weren't interested in pondering the implications of a black lower class. Portraying 
loyal and happy domestic servants offered an illusion of a separate but equal existence among the races that didn't threaten to lift the veil of reality regarding the inequity and tension between races and cultures. Often a plot twist in 1930s films allowed for African American characters to show their worth when white characters were down and out, and black servants could be counted on to be there and to be the one true friend.

During this period of bread lines, of fireside chats from President Roosevelt over the radio, of labor problems of intellectual Leftist activities, and of WPA programs, blacks in films were used to reaffirm for a socially chaotic age a belief in life and the American way of living itself. Indeed, the black servants of the 1930's proved that human beings could and should endure. They seemed to say that even during the worst of times everything could be straightened out as long as people kept their chins up. (Bogle 36)

Temple's propensity for starring with African American men was not an accident, nor was it an attempt at creating a harmonious existence (albeit misguided) between the races. I would suggest that it isn't even, as Ara Osterweil would contend, simply an attempt on the end of the studio system to atone for clearly racist portrayals from the past decade, for the horrifying overtones in Birth of a Nation. It was a carefully designed situation made by the studio system to fall firmly upon the "safe" side of being intriguing and provocative. Temple recalls in her autobiography a letter written by D.W. Griffith (who himself directed Birth of a Nation) to Winfield Sheehan at Fox. The letter read: "There is nothing, absolutely nothing, calculated to raise the goose-flesh on the back of an audience more than that of a white girl in relation to Negroes (Black 90). 
The Hays Code specifically prohibited the discussion of miscegenation and interracial couples. It didn't prohibit films in which a beautiful white child interacts with black servants, though. Hollywood couldn't depict a black man and white woman touching each other for any reason. But it could depict Bill "Bojangles" Robinson tap-dancing with Temple in The Little Colonel. To be clear, though, the scenes were considered to be provocative enough that they were edited for release in Southern States so that the scenes showing Robinson and Temple touching hands

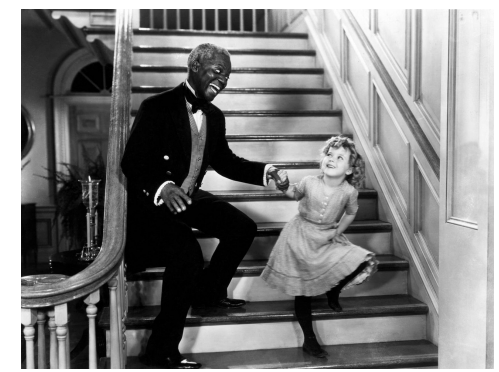

Figure 9: Robinson and Temple in a scene from The Little Colonel that was so provocative that it was edited out of copies of the film distributed to Southern audiences.

were cut. Nevertheless, Temple says that she and Robinson were the "first interracial dancing couple in movie history" (98).

The definitive authority on the American musical movie, Rick Altman, contends that when the main couple in a musical can't be lovers, then they become "conspirators" and a secondary couple falls in love. The principal character is the catalyst that makes this happen. This is almost always the case in Shirley Temple vehicles. As Ann duCill suggested earlier, Temple is at times the empty vessel that carries displaced sexuality. At other times she becomes the dance partner and conspirator to the only other character trope with little agency because she is an orphan. She partners with a black male, not only to "raise the gooseflesh on the back of the audience," but to reconstruct what the Depression has disassembled. The image of a cheerful and attractive black male slave dancing up the staircase with a beautiful white female child who more or less owns him does nothing more than illuminate the supposed superiority of white, male supremacy. 
Temple's ability to scrub floors, bat her eyelashes, and smile flirtatiously make her male co-stars give up womanizing (Stowaway), quit a life of crime (Now and Forever), release POWs (The Littlest Rebel), and uncharacteristically show empathy towards someone who is less powerful (Captain January, Little Miss Marker, and others). She is, as duCill describes her, "Every man's white dream, the perfect embodiment of the virgin-whore that patriarchy loves to look at -- simultaneously Snow White and Black Widow (albeit without the bite) (16)". And, most importantly, she is not threatening to white masculinity. Neither is the elderly slave with whom she is dancing. If the film portrays them tap-dancing up the staircase from the lowest social depths towards a higher imagined social class, then clearly the bastions of the American middle-class, white males, have already reached that summit and are way ahead of them. The existence of an upwardly mobile female child and an African American trying to climb up and out (cheerfully) does nothing more than reconstruct the image of family breadwinners who lost their jobs, status, and agency on Black Friday. Neither the little girl nor the loyal black servant are a hazard to the social order of the good old days, or the "now" of the 1930s. Neither is interested in or even considered capable of taking an adult white man's job, and both of them are so cheerful and resourceful that they aren't even a drain on the economy. Unlike flesh and blood orphans who have in many cases been in difficult situations, Temple isn't untrustworthy, dishonest, or capable of disrupting the domestic sphere with budding sexuality. Likewise, the 
devoted black servants portrayed in Temple vehicles don't necessarily serve as an open reminder of the sexual and racial politics and abuse that often took place in antebellum (or Depression era) homes that contained inequality of race, class, and economics. In other words, it was highly unlikely that a male member of the family would force sexual relations on Shirley Temple, Bill Bojangles Robinson, Steppin Fetchit, or even desexualized Hattie McDaniel (who also appeared with Temple and Robinson in The Little Colonel). In real life, domestic servants and foster daughters weren't always so fortunate.

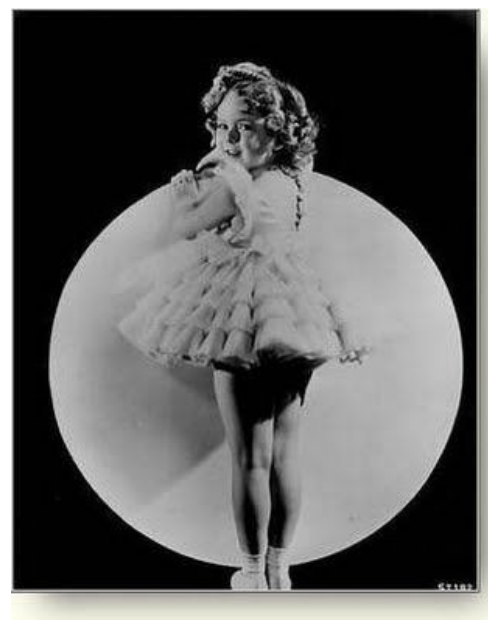

Figure 9: Twentieth Century Fox publicity still for Shirley Temple that pushes the limit of a presumed innocence of sexuality.

Ara Osterweil's 2009 article in Camera Obscura argues that Temple's films use a "pedophilic" gaze:

[the] displacement of adult sexuality onto the body of a child involved an industry wide fetishization in which Temple's infantile sexuality was both deliberately marketed and scrupulously preserved. . . it is clear that Temple's innocence -- and the signature shots of her underpants -- were crucial to her erotic appeal (2).

Osterweil contends that Temple's films utilize her sexuality and faux innocence to suture the jagged racial chasm in film history left by Griffith's 1915 violent and exploitative Birth of a Nation. However, in doing so, her cuteness exploited the "Social, emotional, economic and political consequences of inhabiting a racist society" (30). I would further the arguments of Osterweil by suggesting that Temple's charms played into the ideology of the New Deal not only 
by personifying class transgression for the American working class and the disenfranchised Southern Democrats, whose votes were so desperately needed to keep the democratic machine churning away in the 1930 's, but by also exploiting and codifying the placement of the Depression Era African American population. In other words, the use of these actors wasn't just an apology on behalf of the studio. It also significantly relieved the racial anxieties felt by a white viewing audience, while at the same time subtly feeding into their salacious interests. Karen Lury takes it all a bit further in her 2010 book length study of The Child in Film. In a chapter provocatively titled "Dirty Little White Girls," she suggests that the consistent pairing of Temple with African American characters who were almost always servants was a way to continually re-stabilize a white masculine identity that is just one of a long line of eroticized white actresses playing children opposite adult men of color who subtly, (as in Lillian Gish in Broken Blossoms and Dakota Fanning in Man on Fire) or blatantly (like Sue Lyon in Kubric's Lolita or Jodi Foster in Taxi Driver) work to establish a fantasy of white male hegemony.

Not only was this social construction of the white masculinity refracted in cultural pursuits, it was obviously and blatantly inherent in federal legislation being passed at that time. According to the Encyclopedia of American Masculinities, the effect of New Deal social policies was to institutionalize a conventional set of ideas about manhood and to implement a limited concept of social rights that granted full benefits to white men. The structuring of these obligations guaranteed higher priority on the federal level to the white male provider, but left aid to lower categories of workers to the states - thus relegating blacks, working women, poor mothers, and children to whatever benefits the states granted them. So the construction of the 
beautiful-white-non-threatening child (Temple) and the black-non-threatening-loyal-to-hisemployers servant (Robinson/Fetchett/McDaniel) serves to illuminate the white male privilege of the 1930s culturally, while the federal laws and practices in place were explicitly designed to do so economically.

Temple's role in developing a cultural framework for wavering patriarchal ideals of the day is that the groundwork is built on the illusion of nostalgia. For the 1930s American viewing audience, Temple's appearance on the silver screen harkens back to a time of an innocent childhood that couldn't be contaminated by depressions, or adult sexuality, or dust bowls. It wistfully recalls a time in which a spunky kid could move up in the world and would be safe around adults, no matter what. It calls to mind a yearning for a time in which race relations weren't complex (a subject that we will explore again in Chapter Five). It reveals a cultural longing for a time in which the bank wasn't foreclosing on your house, when you weren't going to lose your job, and when you weren't in danger of starving. Like most nostalgia, however, it reveals a sentimental pining for a time that never really existed.

The great irony of placing this nostalgia squarely on the shoulders of a little girl is that little girls don't last. Like Little Jackie Paper, they grow up and transform into something else. So as Shirley Temple careens from babyhood towards adolescence, her "innocent" sexuality becomes less and less easy to ignore. Once Temple becomes a young woman and starts playing roles in which she falls in love with the much older Cary Grant (The Bachelor and the BobbySoxer) and marries possible father-figure Ronald Reagan (That Hagan Girl), her acting career is pretty much over. The paradox of the image of childhood providing a sense of sexless (even though beneath the surface it was dripping with sex), uncomplicated comfort to the masses is that 
as the child unavoidably grows up, she (and the image of young adulthood) becomes more and more about the complexity of adult world. Those complexities include but are not limited to the sexual politics that surround young women (which is a topic that will be addressed at length in the following chapters). But for a time, the image of childhood worked. . sort of.

Under the right circumstances, popular culture really could help regular people believe that their financial losses weren't due to some sort of character flaw, or because they weren't smart enough, or good enough. Instead, it allowed the proletariat to see the hope that it really was possible to claw their way out of poverty and economic despair. And, as long as African American slaves and servants were portrayed as cheerful and complicit with the patriarchal status quo, and as long as the image of women was sexualized, infantilized, and non-threatening, Roosevelt's image of "the smiling face of a baby" really might help you "forget your troubles" for a short time.

Especially if you were a man. . .and white. 
Stella Dallas:

I don't believe there is a man in the world who can get me going again.

On May 28, 1934, in unregistered Canadian Territory, Elzire Dionne gave birth to the first known identical quintuplet daughters. The family already had five other children and lived in abject poverty. After four months, the Canadian government took custody of the quintuplets, built a nursery for them, allowed the doctor who had attended their birth to take charge of their upbringing, and began charging admission for the public to come in

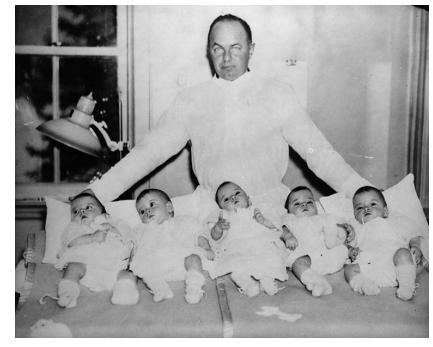
and view the girls. Their father ran a souvenir shop across the street. Cute identical quintuplets turned out to be big business for Ontario. Before it was over, the children had starred in two feature films, met movie stars and royalty, had photographs published in many major magazines, worked on many lucrative endorsements, and helped Ontario earn \$51 million in tourist revenue. They were more popular than Niagara Falls in terms of Canadian Tourism, and were pretty much credited for helping Canada make it through the Depression. Quintland, as their fenced in nursery became known, was an incredibly popular tourist destination for Americans, and

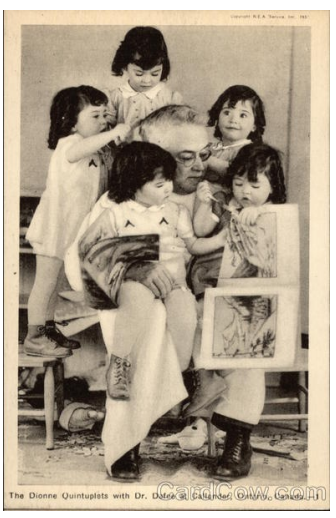

Figure 1: The Quints photographed with the Ontario Premier Mitchell Hepburn.

Figure 2: Vintage postcard of the Quints photographed with their doctor and handler, Dr. Dafoe. their popularity permeated nearly every household in the United States through various mediums of popular culture. In 1943, once their cuteness and profit margin began to wane, their parents were awarded custody of their daughters, and they moved back home. 
Meanwhile back in the United States, Eleanor Roosevelt was completely redefining the role of the First Lady in American History. Not content to simply serve as hostess for White House functions as her aunt, Edith Roosevelt, had been, she became one of the most read writers of the decade. In addition to traveling all over the country on behalf of her husband, she held weekly press conferences (for female journalists only) and wrote a daily syndicated column with over four million readers.

In these columns, she discussed laws and social concerns of importance to women, such as post-partum medical care for mothers and legislation regarding whether married women should be allowed to hold jobs. Often, as in the case of the Married Persons Clause of the Federal Economy Act, her views were highly politicized and controversial. The heart of such controversy was the issues of whether women could adequately care for their families in addition to working outside of the home, and whether married women wishing to work were doing so simply for survival, or to be able to afford luxuries. In 1937 Mrs. Roosevelt wrote: 
I have investigated a good many cases and find that on the whole, the love of work is not so great, those who are gainfully employed are usually working because of some real need. There are a few, however, who work because something in them craves the particular kind of work which they are doing, or an inner urge drives them to do a job. They are not entirely satisfied with work in the home. This does not mean that they are not good mothers and good housekeepers, but they need some other stimulus in life.

\section{(My Day)}

Although the federal rules regarding families in which both adults were employed were overturned quickly in the 1930s, state and local laws regarding the issue were prevalent throughout the country and continued some places until the 1960s.

Other issues regarding women and power within their own homes were being explored. In 1936, a clinic dedicated to assisting women in learning the rhythm method was opened in Boston, Massachusetts. In addition, birth control advocates won a Supreme Court case regarding the ability to distribute Japanese Pesseries (diaphragms) to physicians for use with their patients. Although this was considered to be a triumph among birth control advocates, this physician-prescribed

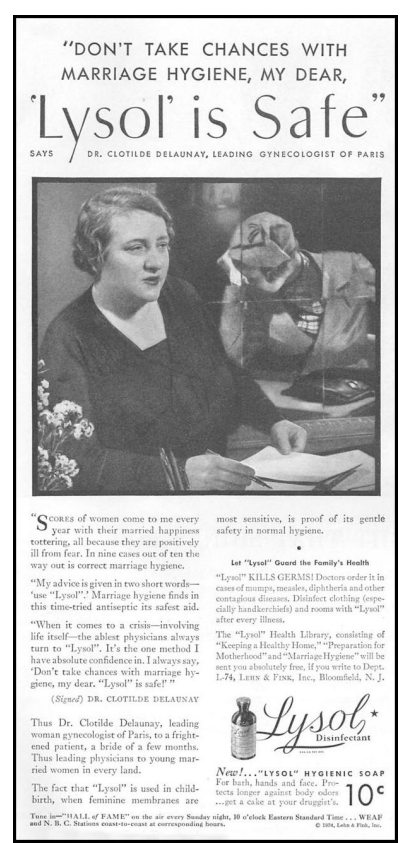

Figure 3: 1930s advertisement for Lysol, a popular douche often used for contraception. In this ad, and many of the era, the implication was that the use of lysol douche would save one's marriage by resolving feminine hygiene issues. 
contraception was expensive and difficult to obtain. The leading form of contraception among women at this time continued to be the less effective (and somewhat less safe) practice of douching with products advertised for "feminine hygiene" purposes. The advertisements for these products didn't overtly state that they were for birth control, but tended to imply that they should be used in order to save one's marriage or please one's husband.

For both the Dionne family and American families in which wives were interested in holding a paying job or controlling their fertility, the message was clear; paternalistic legislation could, and would, be a factor in the ways in which your family operated. Although taking custody of your children, making them "wards of the King," and setting them up as a tourist attraction was a rather extreme and relatively rare activity, creating legislation that decided how many children you could have, or who could have a job in your family, or who cared for the children, wasn't. It was almost as if the introduction of such paternalistic legislation was an unconscious attempt to over-compensate for a perceived lack of masculine economic agency by attempting to manipulate activity in the domestic sphere.

As we discussed in the previous chapter, attitudes towards marriage and family were changing rapidly. And even though (or possibly because) fewer children were being born during the Depression, their care and welfare had become the focus of much scrutiny. If a strong paternalistic leader like Franklin Roosevelt should lead the country, then a strong man should lead the family. Women shouldn't have to worry about issues like how many mouths there were to feed or getting an extra job for little luxuries. Furthermore, if a valuable (as in profitable) national treasure like the Quintuplets was in trouble due to the failings of the biological parents (in other words, they were poor), it was a duty for those in charge to make important decisions 
on their behalf, even if it included removing them from their home and putting a stronger, bettereducated man (like the doctor who had attended their delivery) in charge of their care. Both individual sacrifices (as in eschewing extra money for little "luxuries" and avoiding intercourse if you couldn't afford another baby) and familial sacrifices (like allowing the federal government to turn your kids into a popular tourist attraction) for the greater good of family and country were to be encouraged.

In 1937, when the Quints were toddlers and had already been the subject of their own feature film and Eleanor Roosevelt was churning out columns and holding her own press conferences, King Vidor directed a remake of the 1925 silent soap opera, Stella Dallas. The Frank S. Nugent review of Stella Dallas that appeared in the New York Times on August 6, 1937 proclaimed, "It seems unlikely that historians of the future will find Olive Higgins Prouty's 'Stella Dallas' among the imperishables of literature." Little did Nugent realize that in addition to the 1937 movie that he was reviewing, and the 1925 silent original, Prouty's novel would inspire an eighteen year radio soap opera, and a 1990 remake with Bette Midler. Imperishables of literature? Maybe not. However, the 1937 Barbara Stanwyck version of maternal love and class transgression continues to be heralded as one of the great melodramas of all time. Turner Classic Movies still plays it. Literary critics write essays about it, and most people still shed a tear or two when unconventional Stella sends her daughter packing.

At the heart of Stella's story is the dark side of class mobility during the Depression. While Shirley's "cute" and "innocent" flirtations were often used to build a nuclear family, Stella's less innocent and more aggressive flirtations show the foibles of what could happen when eroticism is used by someone who is older and more ambitious. The hegenomic message 
is clear: A child's eroticism is safe and desirable. A young woman's unbridled eroticism is most definitely not. It is my intention in the following pages to discuss the ways in which Stella is a sort of sacrificial lamb in a pathos-filled morality tale regarding the dangers of an adult woman's use of sexual manipulation as a tool to transgress economic class boundaries, the price that she must pay in order to ensure her daughter's position in an upper-class world, and the ways in which the melodramatic narrative frame manages to create a space for narrative resistance and simultaneously hamstring that resistance to patriarchal domestic control.

Stella was no Shirley. If Shirley Temple represented the 1930s idea of responsibility without sex, Stella and her double, Laurel, represented the idea of responsibility after sex. Stella's assertive behavior at trying to ensnare her future husband is clear to the film's

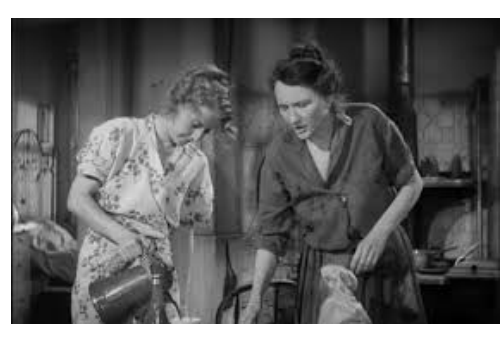
audience, if not to the clueless Mr. Dallas. Early on, in order to attract his gaze, she lingers near his path reading a provocative book titled "Indian Love Lyrics," gets dolled up to take lunch to her brother at the mill, and once they are dating treats Stephen's kisses with faux modest and demure behavior. It is immediately

Figure 4: Stella at home with her mother. Clearly, she is the younger version of what her mother once was. Who can blame her for trying to transcend class boundaries? obvious that a marriage to Stephen Dallas, much like her

enrollment in a business class and interest in better developing

diction and conversational skills, is part of her ploy to advance

from the dredges of her lower working-class family to a more

prosperous social standing. After catching a glimpse at the kitchen drudge that is her mother and presumably the symbol of what her life would become were she to marry a mill hand, one could scarcely blame her for trying to move up. 
The easiest and most straightforward reading of this 1937 "weepie" is that of class transgression. The daughter and sister of mill workers, Stella catches the eye of well-heeled Stephen, who because of family financial misfortune and a well-publicized broken heart is an easy catch for an attractive young woman. Their courtship is brief, but long enough for Stella to confide that her desire is to be like people in the movies. Stephen is quick to admonish that she should simply be herself - a sentiment that he appears to regret once they are married.

To her credit, Stella's research is impeccable. Stephen Dallas' father had recently lost the family fortune and committed suicide, forcing Dallas to flee his high society social circle and abandon his fiancé while he rebuilt his fortune. Although trying to live incognito, Stella (who spends her time reading society gossip columns, going to the movies, and attending business classes) ferrets him out and begins her pursuit of his affections. When presented with the information that his former fiancé has married someone else, Dallas hastily succumbs to Stella's many charms, despite her lack of class and breeding.

A year later, Stephen brings Stella and the new-born Laurel home from the hospital, only to discover, to his horror, that his vision of domestic bliss and Stella's vision diverge dramatically. Upper-class Stephen (who has apparently managed to rejoin polite society) pictures a lengthy, quiet, and restful post-birth confinement for his wife. Stella (who had already been forced, against her will, to a hospital convalescence) envisions going out and dancing on her first night home, finally free from pregnancy and childbirth responsibilities as the hired nursemaid cares for the baby. (One might suspect that Stella's mother would have killed for such a restorative recovery period after childbirth.) Stephen envisions a wife who will stay home and care for his child in a house with a mother who was, "serious" and "watchful," like Honoria's 
guardians in "A Babylon Revisited." Stella's post-partum behavior reflects her working class upbringing and not their upper-middle-class lifestyle. Scoffing at the upper class practice of lying abed for weeks after delivering a child, Stella cheerfully hands the care of her baby over to the African-American domestic servant (who would certainly never have been afforded the luxury of a leisurely recuperation after childbirth) and begins making social plans. But Stella's vision is that of a domestic space filled with music, entertaining, drinks, and cigars. In fact, it quickly becomes apparent that the only commonality between the couple once the honeymoon is over is their daughter, Laurel.

The price that Stella and Stephen pay for their hasty marriage and its consequences is the unhappiness that they encounter when they realize their mistake. Stephen is eventually promoted and transfers to another town, but Stella declines to bring their child and join him. Eventually he re-encounters his former fiancé (now, conveniently, widowed with sons of her own) and is unable to wed her because Stella refuses to grant him a divorce. Clearly the moral for Stephen of this particular tale is the old adage "Marry in haste, repent in leisure." As historians of the period, including Frederick Allen, are quick to point out, during the Great Depression, people had so little money that fewer people married, fewer children were born, and fewer couples divorced. The lack of money forced most families to sacrifice in some manner, even if it meant not becoming a family, not expanding the family, or not officially dissolving a problematic family. This particular melodrama furthers that domestic agenda of familial sacrifice for both men and women.

But while Stephen is prevented from marrying his true love, Stella's punishment is much worse. She continues her gaudy, lower-class, and vulgar life-style and is consistently 
confounded at why the upper classes, to which she now aspires for her daughter, ignore her overtures and invitations despite the fact that she has the means and marital connections to join them. When she finally does realize that the stumbling block holding Laurel back has to do with her unrefined ways, she makes a tremendous sacrifice by divorcing her husband and forcing her beloved daughter to be part of his upper-class family. At the end of the day, Stella is made to suffer not only for the manipulative sexual behavior she uses with Stephen, but also for her attempt to transgress from her lower-class station to a more refined society for which she has not been well-prepared, trained, or educated.

Ultimately, Stella tries to turn Laurel into what she once wanted for her herself but could never quite attain. They (Stella and Laurel) are almost two sides of one coin. In fact, in some of the shots, you can actually see that Laurel resembles the parent she is staying with at the time. Laurel is a fetish for both Stella and Stephen, because once their passion dies, she becomes the only thing holding them together. She simultaneously conceals and reveals their sins of class transgression.

Although not technically a child at the start of the film, Stella is clearly either in late adolescence or young adulthood. She still lives at home, she still fights with her brother, and her mother still calls her for dinner. But, as we have already stated, Stella is no Shirley Temple. She is blonde and attractive, and she successfully feigns sexual innocence with the men with whom she flirts. But, unlike Shirley, she isn't a child. She can't form a nuclear family for her male conspirator and his beautiful girlfriend, because she is the beautiful girlfriend. And ultimately, the domestic space that she constructs is not appropriate for Stephen Dallas's expectations or for 
his station in life. But just because she can't construct it for herself doesn't mean that she can't construct it for her daughter.

Once the passion of their fevered union has chilled, Mr. and Mrs. Dallas realize they have little in common and little interest in each other. Laurel quickly becomes the object of desire for both of her parents. She simultaneously conceals and reveals not only Stella's lack of class and Stephen's lack of warmth, but the couple's lack of interest in each other, emotionally and sexually. Stephen is embarrassed by Stella's behavior early on, but he is only moved to action once he perceives his daughter to be raised in such an unsophisticated atmosphere. Stella actually says at one point that because of her daughter, she didn't believe there was "a man in the world who could get [her] going again." Once Stephen is given a promotion and begins moving

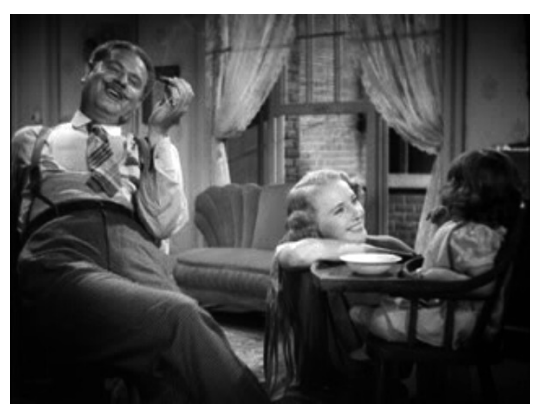

Figure 5: With Laurel in her life, Stella isn't interested in anyone or anything else. up in the world, Stella refuses to follow him up the ladder of success she was trying to climb in the first place. Ironically, the reason she won't leave is because she is so enamored with the extension of herself that is her child. Instead, Stella spends the rest of the film seeing to it that her fetish, Laurel, gets every opportunity to succeed. When she comes to the conclusion that she will hinder, rather than enhance, Laurel's

abilities to be received by the "right" people, she sacrifices herself in order to give her child the perfect nuclear family with Stephen and his new wife.

Linda Williams says that "Stella Dallas is a classic maternal melodrama played with a very straight face" (325). Clearly, a cursory viewing would lead many contemporary viewers to read it as a story complicit with patriarchal mores of the 1930s and a somewhat seductively 
dangerous view of maternal sacrifice. However, it is my assertion that Vidor uses the signifying frame of the melodrama to produce a fairly subversive statement regarding the pathology of New Deal maternal politics through the use of narrative resistance, female spectatorship, and an ultimate reflexivity of the cinematic world.

In Distinction: A Social Critique of the Judgment of Taste, Pierre Bourdieu uses quantitative evaluations to deduce that "taste" is, in fact, based ultimately on social constraints and education, both of which ultimately boil down to economic resources:

Taste is a practical mastery of distribution which makes it possible to sense or intuit what is likely (or unlikely) to befall - and therefore to befit - an individual occupying a given position in a social space. It functions as a sort of social orientation, a 'sense of one's

place', guiding the occupants of a given place in social space towards the social positions adjusted to their properties, and towards the

practices or goods which befit the occupants of

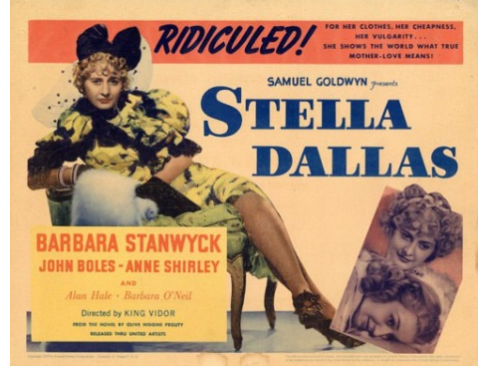
that position. (467)

Until she meets the unwitting Stephen Dallas, Stella's economic resources are clearly limited. If she stays within the class boundaries set forth by her father and brother, one look at Stella's haggard and harried mother implies a future of few choices and too much work. Nevertheless, once Vidor's heroine gains more social property through her marriage to Stephen Dallas, she is unable to move her social position towards the practices that "befit the occupants of [her] position." 
The problem is that Stella exhibits bad taste and what was considered lower-class behavior throughout the film. Vidor juxtaposes Stella's cramped apartments that are loaded full of earthly possessions against the spacious, elegant, and sparsely decorated home of the second Mrs. Dallas. Consider Stella's closet full of clothes and a dress-dummy as well as dresser-tops covered with cosmetics and cold-creams and tonics versus Helen's (and Laurel's) love of “empty closets" and no-make-up approach to life. Consider Stella's love of movies, tabloid magazines (including "Love"), and movie star pin-ups. Stella's idea of a cultural experience is a popular "show," while Laurel's well-educated teacher's idea of culture has more to do with galleries and art. In Distinction, Bourdieu states that:

The denial of lower, coarse, vulgar, venal, servile - in a word, natural enjoyment, which constitutes the sacred sphere of culture, implies an affirmation of the superiority of those who can be satisfied with the sublimated, refined disinterested, gratuitous, distinguished pleasures forever closed to the profane. That is why art and cultural consumption are predisposed, consciously and deliberately or not, to fulfill a social function of legitimating social differences. (7)

The character of Stella is, of course just that: lower, coarse, vulgar, venal, and servile. Despite marrying up, Stella is unable to define herself in a way to hale the class of which she wishes to be a member.

Bourdieu goes on to point out that the ability to differentiate between types of art is one way to assert one's taste, and to project oneself into social hierarchy. Stella yearns to be of a different class, and she makes an honorable attempt at climbing out of the one of which she is 
part. But in the long run, she is predisposed to gaudy clothes, too many bangles and frills, and too much stuff crammed into her too-small living quarters. Her sense of pleasure is based on reflection. Instead of frequenting galleries, she's taken by movies, shows, the radio, and trips to the beauty parlor. (She is apparently the woman consuming those "luxuries" that seem to be inspiring so much stress and anxiety and legislation during the depression.)

Once she has snared Stephen, she is less interested in reading Indian Love Lyrics (which one suspects to be pretty sexy stuff) and more disposed towards romances and movie magazines. In fact, one could argue that Stella's fetishistic obsession with Laurel has effectively replaced the usual object of desire in a heteronormative relationship. Clearly, Stella's interest in that "taste of reflection" extends itself to her love-life as well. She's more interested in reading trashy magazines than in cohabiting with her husband or with romancing any man, for that matter.

Taste classifies, and it classifies the classifier. Social subjects, classified by their classifications, distinguish themselves by the distinctions they make between the beautiful and the ugly, the distinguished and the vulgar, in which their position in the objective classification is expressed or betrayed. (Bourdieu 6)

Anna Simopoulos asserts that Stella's distinctions in attitude (drinking, smoking, conspicuous flirtations, ambivalent feelings about having a child, and "constant pursuit of 'good times'") characterize Stella as a flapper (8). By 1937, when this
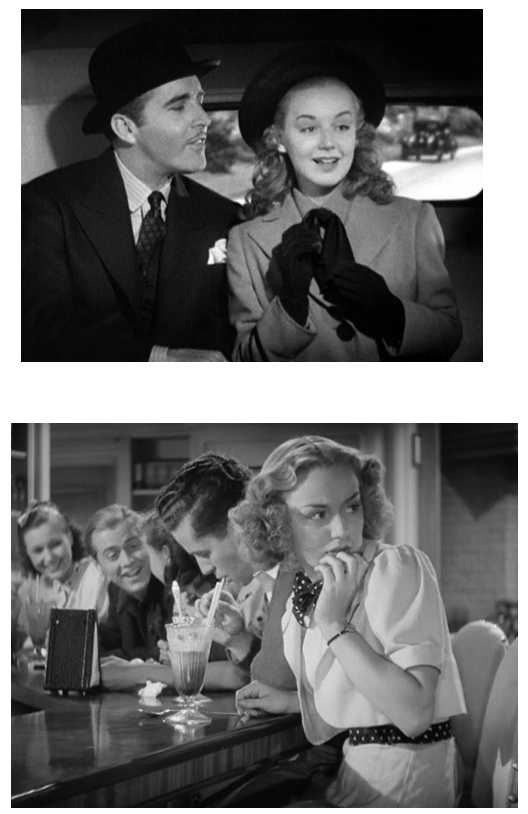
version of the movie was produced, flappers had been passé for some time, and Stella's clothing did not perpetuate that particular style. However, Siomopolous also points out that "The version of the flapper that Stella represents is not clearly distinguishable from the flapper's lower-class mirror image, the prostitute" (8). One could read into the narrative, then, that Stella was born lower class and is therefore ontologically different enough to understand the

Figure 7: When pictured with her father, it is clear that Laurel prefers clean, conservative lines and style.

Figure 8: The moment of truth when Laurel views her mother's reflection in a mirror and is humiliated by her dress and behavior. Note the strong resemblance between Laurel and Stella (when she was younger) in this scene. differences in taste and that, furthermore, Laurel's genetic

make-up is so similar to her father's that she rejects frills, and fake jewelry, and closets crammed full of consumer goods. Blood will tell.

Except, Stella does seem to know about the sexual implications of Indian Love Lyrics at the beginning of the film. She certainly uses the act of reading the book in her front yard as a signal to Stephen that she is a woman with sexual desire. And before she marries Stephen, her clothes and manner are acceptable. When she wants to impress Stephen after a period of estrangement, she clearly knows enough to rip the fringes off of her dress in an effort to make it more understated. When Laurel rejects an additional buckle on her dress, Stella says, "You are just like your father." Stella is clearly conscious of class boundaries in regards to clothing, but based on her choices of dress, it is apparent that she makes a conscious choice to wear what she likes and what she feels expresses her personality.

If the image of flapper and prostitute are, as Simopolous asserts, "mirror images," then one might wish to explore whether or not Stella's transgressions are limited to that of class. I assert that

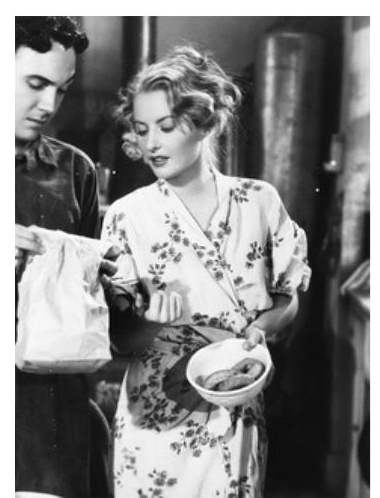


Stella's transgressions not only breach class barriers, but gender ones as well. . . and that the politics of class and gender are inexorably linked within this film. We watch Stella's gaze upon her mother, a slavish wretch played by Marjorie Maine in a rare non-comedic performance. Our image of Stella's mother is that of a woman who will do anything for her children, and when she implores Stella to be nice to her brother so that he doesn't leave for one of the local women, Stella laughs at his lack of ambition.

Figure 9: Stella packs a lunch for her brother to take to the mill. Their picture of domesticity could easily be mistaken as a young married couple, as opposed to brother and sister.

It is clear to the viewer that Stella's intent (ironically) is to not end up the selfless, crouching monument to self-sacrifice that her mother has become. Stella's brother is clearly offended by Stella's ambitiousness in attracting a husband from a different socio-economic class, and Stella's ability to use the limited amount of agency afforded her in a patriarchal system, according to its own rules, is threatening to his sense of masculinity. The scene in which he confronts her for not being interested in "mill-hands" shades sibling bickering with darker, almost incestuous overtones. Despite his joking demeanor, one is left with the unsettling impression that if Stella won't give in and become complicit with the roles prescribed to her by gender and class, that he will use any means necessary. . including sexual violence, to force her back into her place.

Stella has too much "ambition" to lean in and live according to society's expectations of her, though. Once married, she continues to foil the established norms by balking at the patriarchal medical practices of the day, pointing out that she, the patient, and not just doctors might know when it is she is feeling better after childbirth. Her suggestion that the medical establishment's only goal is to take her money (after she had already been hospitalized there for 
over a week) is met with stern disproval by an officious nurse-for-hire whose words repudiate any sense of self a young mother might possess and whose body, inscribed by white hat and uniform, serve as a complicit agent for patriarchal ideology. Later, Stella's refusal to listen to her husband's request that she recuperate from her child's birth in bed instead of going to a party, speak with certain diction, eschew loud, brash company, and avoid costume jewelry serve as examples of ways in which she refuses to allow Stephen his presumed place in the familial patriarchal norm. Clearly the behavior is threatening, especially when she does so in front of his business associates at a club dance. Stephen announces that he is leaving for New York, invites Stella to go, and is doubtless relieved when she declines. He visits to see his young daughter, but he is further threatened by his wife's choice in company, her pursuit of a "good time," and surely by his fetishistic replacement by Laurel.

Until Stella feels threatened by Helen's growing influence over Laurel, she appears to operate quite nicely outside of the established authority. Although it is clear that Laurel isn't the most popular person in her class, Stella doesn't link her brashness to her daughter's lack of birthday party attendees. Once Stella tries to show her daughter a "good time" by going on vacation with Stephen's money (rather than live frugally and sensibly) she appropriates herself into a system that she had been used to thwarting. Suddenly, not only is she a figure of fun, but an embarrassment to her daughter, and therefore a social and class liability. Stella's only choice is to sacrifice the thing she loves the most, Laurel. In forcing Laurel to stay with her father, Stella pays the ultimate price for her transgressions.

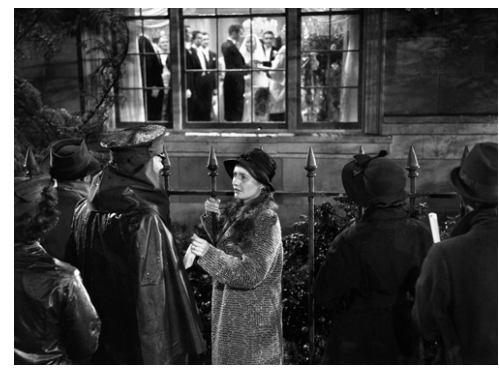

Figure 10: Stella watching her daughter marry and turning into her own type of monument to maternal sacrifice. 
Linda Williams sums up the closing scene effectively:

But the window scene at the end of the film would certainly seem to be the moment when all the above contradictions collapse into a single patriarchal vision of the mother as pure spectator (divested of her excessive bodily presence) and the daughter as the now properly fetishized object of vision.

This reading would support the idea that the film is a morality tale. Stella's economic class roots and gendered transgressions, as well as her relentless pursuit of pleasure, caused her to turn into a similar version of her own mother: a pathetic vision of maternal sacrifice.

That is, of course, if the viewer accepts maternal sacrifice as the phantasmic ideal. Linda Williams isn't convinced that most female viewers accept the moral of maternal sacrifice or any of the moralities set forth by maternal melodramas:

It is a terrible underestimation of the female viewer to presume that she is wholly seduced by a naïve belief in these masochistic images, that she has allowed these images to put her in her place the way the films themselves put their women characters in their place.' (32

Williams goes on to argue that the film is an effective melodramatic tool because the "definitive closure of its ending produces no parallel unity in its spectator" (324). Williams suggests that Stella's "near-parodic" performance makes "the female spectator unable to fetishize or overidentify with her" (52). The film ultimately acts as a subversive element in regards to women's complicity at aligning themselves within a patriarchal system. 
The melodrama's heroine "rather than raging against a fate that the audience has learned to accept, often accepts a fate that the audience at least partially questions" (Williams 325). In the Autumn and Winter 1985 issues of Cinema Journal, Anne Kaplan, Partrice Petro, and Carol Flinn join Linda Williams in a discourse of this film. Anne Kaplan argues that if we are watching the film, we are buying into it at least while we are watching it (unless we can manipulate the projector while watching) and that it is somewhat impossible for mothers who have made sacrifices (such as herself) to not identify in some fashion with Dallas. Furthermore, she indicates that "Stella Dallas makes available a series of multiple identifications specific to the experiences of a female spectator. Kaplan agrees that there are elements of resistance in the film, but he insists that "patriarchal norms" ultimately shape the picture and, therefore, the viewer (42). Petro and Flinn argue that:

Over the course of the film, she takes flight from the patriarchal tyranny that both her father and Steven come to embody. Indeed, she resists inscription in the film in any fixed position: she at once represents passivity and aggression, sensuality and vulgarity. . . It is precisely for this reason that the film is of such crucial importance for women. (52)

Not to be outdone, in the Summer 1986 issue of the same journal Christine Gledhill chimes in to point out that the "debate that Stella Dallas is currently provoking is interesting ... in its disclosure of problems in the way melodrama has entered both mainstream and feminist film studies" (44). At which point, she launches into a description of pathos and "another strategy of melodramatic rhetoric ... which involves a play around mis-and re-recognition" which open 
interpretation of the film to more complex readings ("for instance ... whether Stella was not trying to live her life through her daughter's") (47).

It seems safe to assume, then, that a viewer of the film in the 1980s, 1990s, and the $2000 \mathrm{~s}$ would debunk the premise of this film in a case of hind-sight feminism. In fact, by the time Bette Midler's remake Stella hit the screens in 1990, Pauline Kael writes of the 1937 version that "the picture is all Stanwyck's and worth seeing for her brassy, touching, all-out performance (possibly her greatest), even if pictures about maternal love and self-sacrifice give you the heebie-jeebies."

But what of the 1937 viewer? The critical reviews of Stella Dallas were never stunning. Clearly, the re-make was unapologetically intended to be a money-making tear-jerker. Roger Ebert qotes film historian Leslie Halliwell's summation of the original reception to the movie "Audiences came to sneer and stayed to weep" (Stella Dallas). The 1937 review in Time Magazine states "If the discriminating cinemaddicts find the point of view inherent in Stella Dallas somewhat irrelevant in 1937 , they are almost sure to be outnumbered by less discriminating cinemaddicts who now, as they did twelve years ago, will find it dolefully delicious." The same reviewer noted that, "Stella went out a decade or more ago. But, even that realization is no insurance against a blow to the heart." Nobody seemed to think that it was a terribly good movie, but it was worth a good cry. In the end, the curtains have been opened and the veil has been lifted - both literally and figuratively. Stella is happy but her daughter isn't, and the viewer is in tears. Stella's gift of sacrifice seems as pathetic as Stella's mother hunched over an apple butter sandwich.

Linda Williams suggests that the clues to our understanding how the signifying frame of this melodrama works is to examine self-identification in terms of the self-conscious reflexivity 
mediated by the film itself. Consider Stella's enchantment with movies and movie magazines, as well as her assertion that she wanted to "be like the people in the movies." She watches a film while courting Stephen with the same rapt attention that she watches her daughter's marriage from the street. Such reflexivity and comparison to a simulated world bodes trouble for the heroine of a melodrama. Elsaesser asserts that melodramatic characters are set upon by: 
The tensions of seeming and being, of intention and result, register as a perplexing frustration, and an ever increasing gap opens between the emotions and the reality they seek to reach. What strikes one as the true pathos is the very mediocrity of the human beings involved, putting such high demands upon themselves, trying to live up to an exalted vision of the human being, but instead living out the impossible contradictions that have turned the American dream into its proverbial nightmare. (394)

Stella's problem isn't that she was born of a lower class, and it isn't that she has transgressed class boundaries, and it isn't that she has flaunted her disregard for gender roles and behavior. It is that she is constructing herself based on the simulacra of Hollywood.

In "Art in the Age of Mechanical Reproduction" Walter Benjamine points out that:

The cult of the movie star, fostered by the money of the film industry, preserves not the unique aura of the person but the "spell of the personality," the phony spell of a commodity. (742)

Stella's lifestyle is all about commodity, and Helen's is all about sparsity. Stella's house is full of material goods. Helen's goods are elegantly spaced. As the film progresses, Stella wears more and more cosmetics and utilizes the aid of more and more cold creams. Helen wears none, yet is beautiful according to Laurel. Stella crams Laurel's suitcase full of clothes. Helen and Laurel enjoy empty closets. The watershed moment of the film's narrative occurs when, after spending hours in the salon, shopping at the upscale resort, and consuming goods at an alarming rate, Stella still manages to look like a ridiculously tarted-up lady of the evening. Despite having 
consumed the same goods and services that the other vacationers (the ones with taste) have used, she manages to look like a "Christmas tree."

Overabundance and too much stuff, embody a "lower class's desperate attempt to aspire to signs of dominant classes" (Baudrillard, 133). Stellas's overt consumerism is a symptom of her fascination with the glamour of Hollywood, causing her to not only put impossibly "high demands" on herself, but trying to, as Elsasseaur points out, live through the "impossible contradictions that make living the American dream a proverbial nightmare" (394).

Ultimately, one might read, Stella gets what she wants. The final shot is of Stella's wide smile and triumphant stride away from Laurel's fairy-tale wedding. Linda Williams maintains, though, that:

In order to justify her sacrifice, she must believe in the reality of the cinematic illusion she sees: bride and groom kneeling before the priest, proud father looking on. We, however, know that artifice and suffering behind it - Laurel's disappointment that her mother has not attended the wedding; Helen's manipulation of the scene that affords Stella her glimpse; Stella's own earlier manipulation of Laurel's view of her "bad" motherhood. So when we look at Stella looking at the glamorous and artificial "move" of her daughter's life, we cannot, like Stella, naively believe in the reality of the happy ending, any more than we believe in the reality of the silent movements and hackneyed gestures of the glamorous movie Stella once saw. (323) 
Stella, poised outside of the large picture window, watching her daughter's wedding as if it were a Saturday afternoon matinee, may think it is a happy ending. But Laurel, staged between her father, husband, and priest appears more frigid than ecstatic as she takes her place in the symbolic order.

I would assert that this lack of "suture," loosely defined by Kaja Silverman as "the means by which subjects emerge within discourse" (137) or the ability to be absorbed by the film, is part of what makes the melodrama such a subversive genre. "Suture" has been described by critics as a way to mask the technical aspects of a film in a way to make them unnoticeable. Silverman enhances the definition by discussing ways in which films "suture" over the uncomfortable parts of the narrative in order to displace the "uncomfortable" parts of the technique and story so that the spectator is able to merge with the phantasmic cinematic body

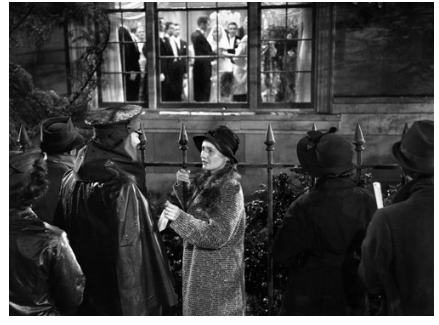

Figure 11: Stella watches the wedding as if it were a Saturday Matinee.

or, in other words the spectator becomes one with the film.

Elsaesser states that "... melodramatic effects can successfully shift explicit political themes onto a personalized plane" (370). One could surmise that the lack of suture in Stella Dallas not only illuminates feminist issues of the New Deal era, but repudiates the notion of maternal sacrifice as virtue. Court cases such as the 1936

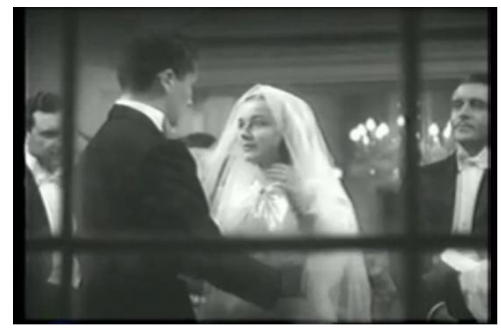

Figure 12: Laurel is situated between father and husband as she joylessly accepts her place in the symbolic order.

ruling on "United States v. One Package of Japanese

Pessaries" which won judicial approval of medicinal use of birth control and the 1937 Supreme 
Court upholding of Washington State's minimum wage for women illuminated the fact that motherhood during the depression wasn't nearly as glamorous (or even bearable) for most women as it was for Stella in the simulation of Hollywood. Even current events surrounding maternity in the late 30 s referred to the film in an effort to reflect the reflection on maternity put forth by Vidor's film, thus making it a true simulacrum. In Simulacra and Simulations, Baudrillard states that

When the real is no longer what it used to be, nostalgia assumes its full meaning ... This is how simulation appears in the phase that concerns us: a strategy of the real, neo-real, and hyperreal whose universal double is a strategy of deterrence (174).

Barbara Stanwyck's much publicized custody battle for her adopted son, which was fodder for gossip columnist, was spun as a real life "Stella Dallasesque" maternal melodrama at the time this film was released. Siomopoulos reports that Eleanor Roosevelt used press images of the film in an article she wrote for Variety encouraging the role of a "self-sacrificing mother" (17). Real life has become a reflection of a film, which is a reflection of a real-life that never really existed.

I think that despite the narrative resistance afforded by the reflexivity of the film's mechanism, this sort of melodrama is just as much about patriarchal familialism as the reassignment of the Quints to governmental control, the laws regarding whether or not married women or mothers could work, or how information about birth control could or would be distributed. Lauren Berlant writes that: 
Primarily, "women's" texts are gendering machines, locating the ideality of femininity in fantasies of conflicted subjectivity in an intimate world organized by a sense of emotional recognition, reciprocity and self-mastery, traits that are deemed the conditions for the survival of femininity if not of actual humans, whose material survival and sense of alterity represents the realist counterpoint to the modes of feminine sentimental fantasy that these works also develop. (35)

Nothing has more "conflicted subjectivity" than this film, and we have already discussed its level of reciprocity. At the end of the day, melodramas like Stella Dallas, and many of the more heartwarming Shirley Temple films do more to further a sense of femininity, and place it into a very narrowly defined space. And, as in the case of the films regarding Shirley, that narrowly defined space ultimately serves to support a very white, very patriarchal, and a very class-bound society. Stella has paid the price for transgressing boundaries that she shouldn't have, as her brother blatantly points out at the beginning of the film. And although Laurel is able to transcend the class boundaries, she seems to be doing so out of a sense of duty to her father and because she has been deposited into a family system whose class standing requires active participation in this sort of system. Besides, in losing her mother, she has lost any real example of feminine agency available to her.

In the end Stella walks away from the wedding chewing her handkerchief triumphantly, lost in a phantasmic vision of her daughter's life with the "smart crowd." Stella has sacrificed everything to give her daughter the agency she never had. But what Stella doesn't realize, or 
doesn't care to recognize, is that Laurel's trip from her father's home to her husband's home doesn't really allow for any more agency than Stella has in her life, or her that her own mother had in hers. Like her grandmother and mother, Laurel has been slotted into a very specific and narrowly prescribed role. The fantasy of the fetish, Laurel, may conceal the true tragedy for Stella, but it doesn't for everyone. As the lights come on and the film fades to the credits, the viewer is left subversively wondering if the sacrifice was really worth it after all. 


\section{The Wizard of Oz: Are you a Good Witch, or a Bad Witch?}

In Since Yesterday, published in 1939, Frederick Allen had this to say about the cultural construction of femininity in the 1930s:

She conveyed a sense of competence. This was the sort of girl who might be able to go out and get a job, help shoulder the family responsibilities when her father's or husband's income stopped; who would remind them, in her hours of ease, of the good old days before there were all-determining booms and depressions, the sentimental old days which Repeal itself reminded them of: and who would look, not hard, demanding, difficult to move deeply, but piquantly pretty, gentle amenable, thus restoring their shaken masculine pride. (137-138)

In the period between the Crash and the Bombing of Pearl Harbor, middle class American women began to take control of their environment in new and markedly different ways. Clearly women's behaviors and activities were changing. According to Vincent Tompkins, in the 1930s twice as many women as men entered the workforce. Albeit for reduced wages and poor working conditions, these women were bringing money home to their families. An additional factor in the issue of personal power among women hinged on the fact that many couples delayed marriage for economic reasons, and the birth rate dropped below the replacement rate for the first time in American history, according to the National Centers for Disease Control. The economic independence that some women experienced (especially those who were college educated) influenced them to find fulfillment through their profession, social activism, and the company of other women. Without the added responsibility of extra children, women were free 
to take jobs and earn money for a much more extended "spinster" period than once had been the case. These women, influenced by a natural outgrowth of the suffrage movement and economic necessity during the Depression, had well-publicized role-models.

One such representative of change was aviatrix Amelia Earhart. In 1928, Earhart was the first woman to fly across the Atlantic Ocean. In 1932 she became the first woman (second person, ever) to make a solo flight across the Atlantic, and the first to receive the Distinguished Flying Cross by the U.S. Congress. She subsequently became the first person to fly across the Pacific (California to Hawaii) and make the first solo flight from Mexico to Newark. The honoree of ticker tape parades in New York City, an early supporter of the Equal Rights

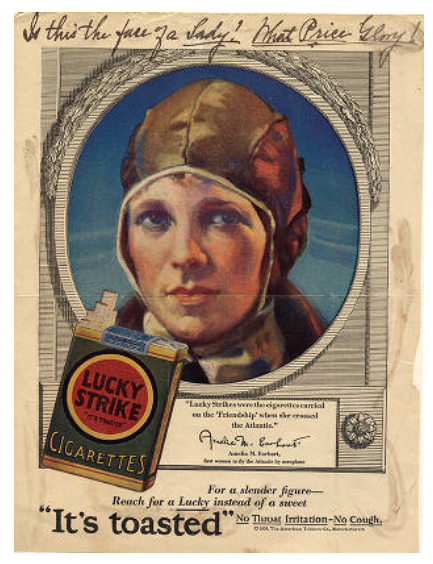

Figure 1: This Lucky Strikes advertisement featuring Amelia Earhart is from the Purdue earchives. The handwritten note at the top says "Is this the face of a Lady? What Price Glory!"
Amendment, and book author, she joined the faculty of Purdue University as a technical advisor for the Department of Aeronautics, modeled clothes for Macy's Department Store advertisements, and endorsed Lucky Strikes cigarettes. She bore a striking resemblance to superstar aviator Charles Lindburgh, and was dubbed "Lady Lindy" by the press. In 1937, just shy of her 40th birthday, she disappeared while trying to set a record for flying around the world. The U.S. government proceeded to spend $\$ 4$ million trying to find her party, but it was to no avail. The mystery of her disappearance only proved to make her more intriguing to the general public for decades after. In addition to encouraging his wife to take a leading role in public affairs as I discussed previously, Franklin Roosevelt also appointed the first woman to the U.S. Cabinet, when Frances Perkins became the first female Secretary of 
Labor. Her career was significant because she was largely responsible for the Civilian Conservation Corps, the Public Works Administration, and the labor portion of the National Industrial Recovery Act. She was also responsible for establishing unemployment benefits, social security, minimum wage laws, overtime laws, and laws against child labor.

So, despite the general media campaign discussed in the previous chapter to keep women out of the workforce during the Depression, women were not only there, but they were becoming vocal about their environment. In 1935 the "militant, communist-led" Detroit Housewives League and Detroit Black Housewives League took on the Chicago meat-packing industry (Grevatt). Before it was over, thousands had gone on strike, a meat-packing warehouse was burned down in protest, and the Detroit Housewives managed to get better physical working conditions and shorter working hours. In 1937, the Flint sit-down strike in Detroit involved a sitin of over 2,500 female cigar rollers, and in 1938, the female led Pecan Strike in San Antonio helped over 1,000 workers get a minimum wage law and access to Civil Rights. And although "Women were discouraged from taking jobs from men," according to the U.S. Department of Education's National Center for statistics, in 1938, the number of women belonging to unions had tripled since 1928 (Grevatt).

It is my assertion that the 1939 film The Wizard of $O z$ grapples with issues of female agency and its application to the emergent young woman in the 1930s who was being forced to contend with an economy that needed her skills and money making potential, but also a culture that did not know exactly what to do with that young woman's competent sustainability once it had helped construct it. The protagonist, Dorothy, is in the unenviable position of watching the interplay of gendered communications and sexual politics that surrounds a typical mid-western 
Depression Age Farm. As her coming-of-age heroine's journey unfolds, she is forced to control her own destiny in response to the sheer incompentency of her companions, and ultimately restore masculine pride to the male figures in her life. All the while, of course, she tries to figure out what she really wants, and if what she thinks she wants even exists. Is what she wants the "right thing" or the "wrong thing?" Is she, in other words, a good witch or a bad witch?

Although the film clearly sets up a dichotomy between two different paths and two different types of feminine role models, ultimately, Dorothy appears to choose a road less traveled by and determine her own path, much like this "new girl" of the 1930s to whom Allen refers. But this ambiguous choice, coupled with the Oz trip's explanation by Auntie Em ("There, there. Lie quiet now. You just had a bad dream. . .") leaves the viewer with a sense of anticlimax, as if something is missing ... as if they have been tricked all along by a cheap and manipulative plot twists.

It is my suggestion that although this film sets out to engage the issue of female empowerment in juxtaposition to a masculinity in crisis, it ultimately fails to do so by suturing together an ending that satisfies neither Dorothy nor the viewer. It attempts to address the issue of feminine action through a little girl's coming of age story, but it simply cannot effectively conceal the issues and anxieties at hand. In order to understand why it doesn't work, though, one must first examine the sexual politics at work on the Gale farm in Kansas.

Any viewing of the 1939 film will illuminate gender-charged plot points to even the most casual viewer. Women, not men, have the power in this film. Simply stated: there is no male hero. Hunk, Hickory, and Zeke are clearly as ineffective as their doubles in $\mathrm{Oz}$ (Scarecrow, the Tin Man, and Lion), and subservient to Auntie Em. Uncle Henry by virtue of his station in 
life as a poor farmer, defers to the letter of the law, and Auntie Em. And, though Professor Marvel/the Wizard/ the gatekeeper of $\mathrm{Oz}$ (all played by the same actor) seem competent and strong at first, all prove to be impotent in the face of female power. In fact, Professor Marvel is clearly revealed as a sham to the audience, if not Dorothy, as he relies on cheap tricks to "read her future" in the crystal ball. Furthermore, he is no help at saving Toto from Miss Gulch. Later, as the gatekeeper, he is tough and harsh ... until Dorothy cries. Once Dorothy sheds a few tears, he melts like spun sugar. And as the Wizard, he is revealed as a fraud by Toto. When challenged by the little girl, he is forced to admit that he isn't a bad man, per se, " . . just a very bad wizard." When he promises to get Dorothy home by hot air balloon, he blows it (no pun intended) ... proving that although his power seems to come from the manipulation of rhetoric, hot air, smoke, and mirrors, he is really not very good at manipulating any of those illusory devices.

It is very obvious who is in charge of the farm. As the film opens, Auntie Em is seen deftly and authoritatively directing Uncle Henry as they try desperately to save chicks in an incubator that has gone bad. When Dorothy interrupts their work to complain about Mrs. Gulch's vendetta against Toto, Auntie Em (who is sensibly shown counting her chickens after they hatched ... not before) breaks her bean counting long enough to tell Dorothy that she is busy. Uncle Henry tries to explain why they are so busy, but Dorothy knows where the real power is, and when she can't get Auntie Em's attention, she moves on.

In fact, it is immediately clear that Em is the backbone of the farm. She has the authority to give the three male farm-hands directives and threaten to terminate their jobs, but she also manages to keep everyone fed with freshly fried crullers in order to keep the work moving along. 
The men talk and joke, but appear to be directionless and generally ineffective. Although they manage to rescue Dorothy from a pig sty, Auntie Em shrewdly points out that they shouldn't have let a child get into such a dangerous spot in the first place.

When Dorothy turns to the men with her problems with Miss Gulch, their only solution is to suggest that Dorothy avoid her, call her names (Zeke calls her a heifer), and snigger about her marital status (Hickory calls her a "poor sour-faced old maid"). Even Uncle Henry, who appears to be genuinely fond of Dorothy, mostly just twists Gulch's words around to comic effect as his only opposition. Consider this exchange between Miss Gulch and Uncle Henry as he whitewashes the fence.

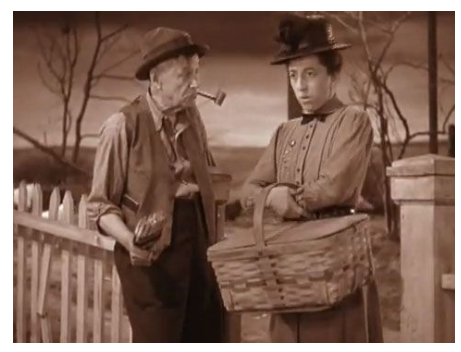

Figure 3: Unfortunately, neither Henry's paternalistic rhetorical humor nor the whitewashed fence can keep out Miss Gulch or cyclones. They can't contain a little girl on the brink of womanhood, either.

Miss Gulch: Mr. Gale

Uncle Henry: Howdy Miss Gulch.

Miss Gulch: I want to see you and your wife right away...

(Uncle Henry lets go of gate he is painting and allows

it to hit Miss Gulch on the bottom. She reacts.)

Miss Gulch: ...about Dorothy.

Uncle Henry: Dorothy? Well, what has Dorothy done?

Miss Gulch: What's she done? I'm all but lame from the bite on my leg!

Uncle Henry: You mean she bit you?

Miss Gulch: No, her dog!

Uncle Henry: Oh, she bit her dog, eh? 


\section{Miss Gulch: No!}

Uncle Henry attempts to use both rhetoric as well as non-verbal actions to keep Miss Gulch from invading the fence that, in effect, protects the domestic space of the Gale family, just as he attempts to use whitewash to protect the farm from the weather. He seems to be protecting only half-heartedly, though. For Henry, like the other men on the farm, Gulch is nothing but a figure of fun and grotesque. To him she isn't a real threat. But Gulch, like the coming storm, won't be thwarted by a picket fence and whitewash.

Dorothy and Auntie Em, recognize Elmira Gulch for what she is. When Gulch brings a written document allowing her to take and destroy Toto, the infallible Auntie Em uncharacteristically defers to her husband's judgement on the written order. The outside, paternalistic world has invaded Auntie Em's domestic space, and like many other women of the Depression, she is powerless to fight back. Uncle Henry is also stonewalled by the legal papers in Gulch's possession. Despite her obvious power and competence, Auntie Em abruptly posits herself into an economic and paternalistic system in order to, somewhat ineffectively, explain her sudden lack of agency and ability.

Elmira Gulch, just because you own half the county doesn't mean you have the power to run the rest of us. For twenty-three years I have been dying to tell you what I thought of you. And now -- well being a Christian woman, I can't say it!

It is important to note, however, that Dorothy has no problem whatsoever telling Elmira exactly what she thinks of her -- and that she thinks Elmira is a wicked witch. She fights hard and even threatens to bite Miss Gulch herself (apparently Uncle Henry wasn't so off the mark when he 
suggested this turn of events to Elmira earlier.) Obviously, though, Auntie Em's strength and power end at the white-washed picket fence, and when outside authority comes knocking on the front door, she reverts to her spot in the symbolic order by allowing her husband the final word in legal matters, and her position of class and culture by suggesting that her inability to speak her mind has to do with her status as a "Christian" woman.

But Dorothy's childish name-calling serves to expose a deeper assumption about the differences between Em and Elmira. If Elmira is either figuratively or literally a witch then she is certainly not a "Christian" woman and therefore certainly not confined by the same gender norms at work on the Gale farm. And she isn't contained by the same same rules that keep Auntie Em from protecting Toto. Dorothy buys into neither the legality that empowers Elmira and binds Uncle Henry (probably because of her age) nor the ideology that binds Auntie Em (also because of her age), so she feels empowered to flee with Toto.

She doesn't make it very far before she encounters Professor Marvel who, in taking a break from courting "the Crowned Heads of Europe" to run the fair circuit in Kansas, shares his dinner and his mystical abilities. He reads Dorothy's future in a crystal ball, only to discover through his talents (and a quick investigation of her basket) that there is a mother figure who undoubtedly misses her very much. We learn that no matter how shrewish and bossy Auntie Em seems on the farm, she is also the person who stayed with Dorothy night and day during the measles and nursed her back to health. And despite Auntie Em's ineffectuality toward Miss Gulch, if her aunt is sick, Dorothy feels that she has a duty to return to her. Dorothy returns mere minutes before the tornado, but is unable to make it to the safety of the storm cellar ... and thus begins her journey to Oz. 
Throughout the rest of film, it is abundantly clear that Dorothy is developing not only authority over her actions, but the competency and ability to be her own person and to make her own choices. Once she and her house travel to $\mathrm{Oz}$, she becomes the classic daughter of the 1930s. Her imminent transformation is foreshadowed by a dream/cyclone/travel sequence, during which she watches the giant "movie screen" of her bedroom window (not so unlike the self reflexive giant movie screen window through which Stella Dallas watches her daughter's nuptials) as a series of surreal characters and objects drift by. First the image of a roofless chicken coop, then a friendly elderly lady who is knitting and rocking in her rocking chair, then a tree, then a cow, then two men rowing a boat who lift their hats in gentlemanly courtesy, and finally Elmira Gulch herself who turns into a cackling witch before Dorothy's very eyes. Clearly they are meant to be random objects that would have been caught up in farmland twister. However, one also suspects that the elderly lady is an image of the industrious Auntie Em type of woman that Dorothy may become if she stays the course and remains on the farm. An uprooted tree comes next, not unlike orphan Dorothy who lives on someone else's farm, and is being uprooted and transported to Oz. A cow that could easily be referred to as a heifer, evokes the sniggering farm-hand's evaluation of Elmira Gulch. (A heifer on a farm is a female cow that has not yet delivered it's first calf.) Then fishermen stop their rowing to tip their hats to the young lady, surely a sign that Dorothy is more budding young woman than little girl. Finally, though, the chilling image of the cruel, wealthy Gulch appears and she shows her true colors as she turns into a wicked witch on a broom, instead of an old maid on a bicycle. All of these could certainly be construed as symbolic of Dorothy's plight, gendered fears, and feminine growth. 
The catalyst to Dorothy's choice to flee with dog in hand is her recognition that Auntie Em's "Angel in the House" persona is ineffective where the "law" can foreclose on your depression age mortgage, and kill an orphan's pet at will. And Dorothy is no bored, party girl flapper -- such a choice isn't even conceivable in her diagesis where one of the most powerful people in your world self-identifies as "a good Christian woman." But if she takes control of her destiny, and becomes a responsible, autonomous individual away from the farm in Kansas, does she become a bad witch? Does she become a Miss Gulch who owns half the county and rides around town on bicycles and broomsticks dragging domestic animals off to the death chamber and commanding a league of flying monkeys? Does she become, as Friedman calls her a "nightmare vision of feminine power" and "a grotesque of female appetite"? (24)

Or does she become Auntie Em/Glinda and remain feminine and good, but unable (or unwilling) to help people with the world outside of their own metaphorical and literal boundaries? The boundary of course, in Auntie Em's case, is the farm enclosed by a white picket fence, and in Glinda's case, is literally a pink bubble. But since Dorothy's companions in $\mathrm{Oz}$ are clearly simpletons

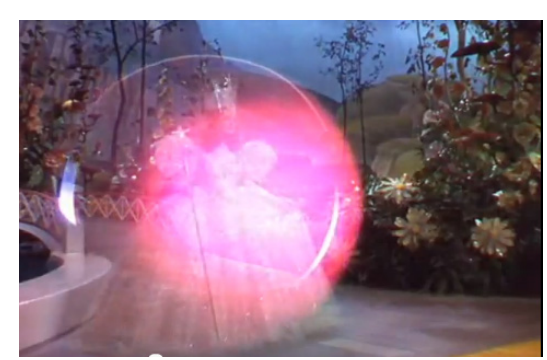
(much like their doubles back in Kansas), she has little choice but to help the Scarecrow think, the Tinman feel, and the Lion act. When they don't think they can do these things, she

Figure 4: The preferred method of travel for Glinda the Good Witch, in its corporal form is a pink domestic sphere. reassures them and tells that they can. And just like Frederick Allen's aforementioned description of the "new girl" of the 1930s, not only is she intelligent, competent, and amenable, she is able to restore "their shaken, masculine pride" by charming them, holding their hands, and 
listening to what they have to say. (138) Unlike Auntie Em, Dorothy's sphere of influence (freeing the scarecrow, oiling the tin man, smacking the lion, killing the witch, and calling the Wizard's bluff) extends not only outside of a picket fence or a pink bubble or her home, but to a whole new country. To understand the quandary over feminine roles available to her, one must first understand the origins of the film.

The film The Wizard of $\mathrm{Oz}$ was based on L. Frank Baum's wildly popular book, The Wonderful Wizard of $\mathrm{Oz}$, which was first published in 1900. Many scholars (most notably Henry M. Littlefield) have speculated that Baum's first novel was in fact a parable of the Populist Movement of the 19th Century. Specifically he conjectured that the the yellow brick road represented the gold standard, the silver slippers (in the book the slippers were silver. The ruby red sequins showed up better in technicolor, which is why they changed the color for the film) represented the Silverite movement, the scarecrow represented the farmers, the woodsman represented the common worker who was being dispossessed due to mass production methods and the wizard represented Silverite presidential candidate William Jennings Bryan. It is interesting to note that the Populist Movement came as a direct result of the financial panic of 1893 (the biggest financial depression the United States had seen to that time) and around the same time that Baum was penning his story. It does seem fitting, then, that the major motion picture version of the film came about in 1939 when the United States found itself in an even bigger economic depression. In his discussion of The Gold Standard and the Logic of Naturalism, Walter Benn Michaels discusses the economic issues at play in the stories of Naturalistic writers like Dreiser and Norris. He states that 
Defending gold or silver, the money writers end up articulating an economic theory that in its most outlandish and fetishized claims on behalf of 'real' or 'primary' money, actually stages for itself . . . the escape from a money economy (148).

Drawing those parallels to the Yellow Brick Road and the silver/ruby slippers in a time of great economic uncertainty could indeed explain why walking on the road and wearing the slippers could get a little girl out of Oz.

Evan Schwartz has more recently suggested that the book was greatly influenced by the theosophical and political leanings of Baum's own family. Baum's mother-in-law, noted feminist and suffragist of the late 19th century, Matilda Josyln Gage, was, according to Schwartz, a great inspiration to Baum. She wrote extensively about the subject of witch hunts and their use by organized religion as a method to oppress and terrorize women. There is no question that she was acquainted with well-known leaders of the suffrage movement, Susan B. Anthony, and Elizabeth Cady Stanton, and that her book Woman, Church, and State: A Historical Account of the Status of Woman through the Christian Ages: with Reminiscences of Matriarchate is considered a classic of first wave feminist theory. According to Schwartz, Gage encouraged Baum to write down his clever stories and enter writing contests for magazines like The Youth's Companion. If Gage could influence Baum to publish literature for children, it isn't a far stretch to imagine that her views and focus on feminism didn't, at least on some level, influence his subject matter when it came to the use of women, women's imagery, and symbolism in his novels. The use of dual natured girls, women, and witches in the novel (and consequently the 
film) was no happy accident. Baum was well-acquainted with the use of witches as symbols for power and feminist threat to masculinity.

The book and film have been categorized by many critics as a classic hero (ine)'s journey; a young person sets out on a physical journey, is significantly altered by the course of the events on the journey and returns home as a full-fledged adult who has transcended paternalistic and cultural domination. Not only is it a heroine's journey, though. Baum has been much lauded for creating the first original American fairytale, and one that influences (if not creates) the secular myth of America. ${ }^{1}$

Clearly this story of a little girl going on a journey to seek a better place and figuring out who she is and growing up in the process is transcendent. Like Huck Finn, Holden Caulfield, Harry Potter, and Luke Skywalker, Dorothy makes a physical journey that serves as a metaphor for her psychological and emotional development. But for the purposes of this reading, instead of discussing $\mathrm{Oz}$ as a metaphor for the Hero's Journey, a bildungsroman, forbidden love, sexuality, spirituality, Buddhism, populism, or Organizational leadership, I am interested in looking at the psychoanalytical aspects of Dorothy's feminist Oedipal journey and the reflexivity within the text of the movie and within the context of feminist film theory.

I posit that although the film wrestles with and confronts the changing image of girlhood and femininity in the 1930s, the actual 1939 movie ultimately fails at its attempt to resolve the

\footnotetext{
${ }^{1}$ The basic plot of both book and film have been used not only as an allegory regarding Populism (as mentioned before), but also an allegory regarding repressed homosexuality (Alexander Doty's My Beautiful Wickedness: The Wizard of Oz as Lesbian Fantasy), of business management (Craig Hickman, Tom Smith and Roger Connors' book The Oz Principal: Getting Results through Individual and Organizational Accountability), of spirituality and Buddhist Philosophy (Joey Green's The Zen of Oz: Ten Spiritual Lessons from over the Rainbow ), of many explanations of Christianity
} 
issues it puts forth: Dorothy desires to grow up. In Freudian terms, she desires to be desired. But what does growing up mean for a girl in the 1930s? What does it mean for the women who have come of age during the Great Depression? What does it mean for a country still licking its wounds from a great economic collapse, with no relief in sight? These are the questions that the film seems to wrestle with, and, in my opinion, never satisfactorily resolve.

Teresa DeLauretis contends that when examining the story of the women's version of the Oedipal/Hero's Journey, it is important to remember that "women must either consent or be seduced into consenting to femininity" (134). I would project that Dorothy, spends her time during this film being seduced into femininity, and that we, the viewer/voyeurs who are identifying with Dorothy enter into the seduction of

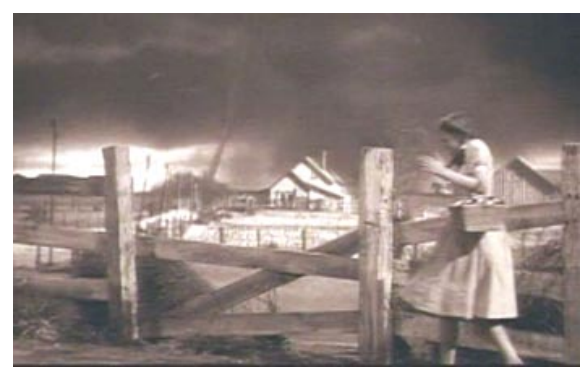
femininity with her. Unfortunately, the film's mixed messages and "dream sequence" trick keep many viewers from being completely taken in, and forces them to find the film's ending unsatisfactory and empty.

Figure 5: As Dorothy contends with the fences and boundaries that contain her, the long, tall, and powerful image of a twister looms in the background. Much like the promises of sexuality and adulthood will forever alter her boundaries and the course of her life, this twister will change the appearance of the Kansas landscape forever.

Dorothy, who is clearly burgeoning on adolescence in the film, encounters many metaphorical signals that hail a procession towards emotional, developmental, and sexual maturity. Joey Green's reading of the film suggests that as the at the beginning of the film

Auntie Em and Uncle Henry's desperate attempt to contain chicks in a new incubator is a foreshadowing of the realization that what the Gales are sure to lose is Dorothy, who is so clearly at the brink of womanhood. "The incubator has gone bad all right, and the chick Aunt [sic] Em 
and Uncle Henry are about to lose is their niece, Dorothy" (22). She will be the chick who flies from the nest, not the ones they are counting because, as Bonnie Friedman puts it, "The ashen menopausal farm cannot sustain its eggs" (4). As they deal with trying desperately to artificially nurture the motherless baby chickens that will keep their farm afloat, one is moved to wonder how well they have nurtured their ward, Dorothy. Will she one day keep their farm afloat as well?

The cyclone totally disrupts the pastoral life in which Dorothy is part of a nuclear family, and casts her into a world where she is forced to take charge of her destiny. In both Kansas and Oz, Dorothy cavorts with grown men, but in $\mathrm{Oz}$ she has lost the watchful and authoritative eye of Auntie Em. Despite Dorothy's gingham, girlish dress, Dorothy dons the red sequined pumps with heels, and follows her ambition. The story about the life of an adolescent girl wearing high heels and in the company of grown men and away from the watchful eye of her guardians managing to disrupt her nuclear family and being forced to take charge of her destiny isn't unique and it isn't new. Usually, however, the object of the story ends up being a mother or wife (or if Shirley

Temple is involved, the newly adopted orphan/daughter who has craftily and adorably created her own nuclear family.) But by the end of the film Dorothy is neither married, a (1) Figure 6-- Glinda imparts a hard truth to the Wicked Witch when she points to the Ruby Slippers on Dorothy's feet and declares, "There they are, and there they'll stay." Dorothy is the one with the power in $\mathrm{Oz}$, even if she doesn't know it yet. mother, or even a daughter. She is still an orphan who has seen what lies beyond the rainbow, but has been forced to return to the grey world of Kansas. 
In his full-length study of the film, Paul Nathanson points out that the slippers are probably the most obvious signal that Dorothy is in the process of becoming a woman. Like the blood from pricked fingers and severed toes in Grimm's Fairytales, these red slippers lend themselves well to a discussion of blood, menstruation, and sexuality. After all, he points out, one does not cause menstruation oneself, nor does one stop it oneself. It just happens one day when you are old enough. Dorothy "does not seek" the slippers, Glinda transfers them to her feet and points out that they have "powerful magic." Her urging to "Never let these slippers off of your feet for a moment, or you will be at the mercy of the Wicked Witch of the West" does not sound unlike urging and advice that women share with each other regarding casual sexuality and unplanned pregnancy. Sexuality and reproduction are, indeed, "powerful magic" but one must be vigilant about its use, or bad things could happen. When the Witch tells Dorothy, "I'm the only one that knows how to use them. They're of no use to you," Glinda insists that "Their magic must be very powerful or she wouldn't want them so badly" (75).

It is almost as if the women in $\mathrm{Oz}$ are giving pre-adolescent Dorothy advice about sex and sexuality in another language, or in code. Nathanson points out that bodily changes can be frightening for adolescents, and that being thrown into a new, confusing world, having these magical shoes placed upon her feet, and being trapped in the witch's castle are all symbolic of an adolescent who is dependent on forces that she doesn't understand and can't control. In Oz, magic becomes an alternate feminine knowledge that is parallel to the patriarchal legal system back in Kansas. Back home, the law can help an unpleasant and unattractive spinster take your dog and destroy it. In the seeming gynocracy of $\mathrm{Oz}$, a pretty little girl can kill the nasty witch with a bucket of water, and the Wizard is a fraud. 
Clearly in Oz, Dorothy is no passive object. At the beginning of the film she may not understand and be unable to control the world around her, but by the time she awakens again in Kansas, she has a much better understanding of the world she has been left with. In Oz she makes clear choices and follows through with them. Dorothy is the savior to her three companions (all of whom are adult anthropomorphic males). Despite the lack of knowledge about her red shoes, Dorothy manages to capture the respect and affection of everyone in $\mathrm{Oz}$, except the Wicked Witch of the West/Gulch (who Auntie Em apparently had no power over either in their "Mirror/Mirror Universe"), and Dorothy calls out the Wizard for being a "humbug" and "a very bad man."

The triangle of female power in this film revolves around the adolescent Dorothy, the

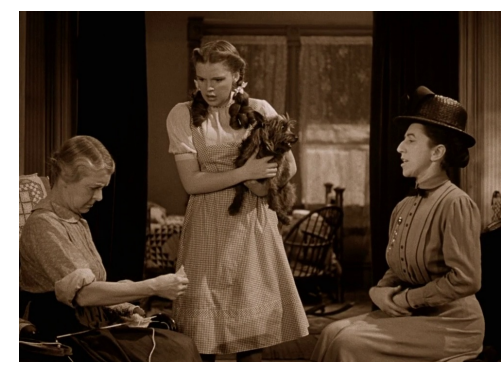
mother figure Auntie Em/Glinda, and the "sour-faced old maid" Elmira/Wicked Witch of the West: the virgin, the mother, and the crone. Normally when these patriarchal assignments of womanhood are present, they are considered to be a progression:

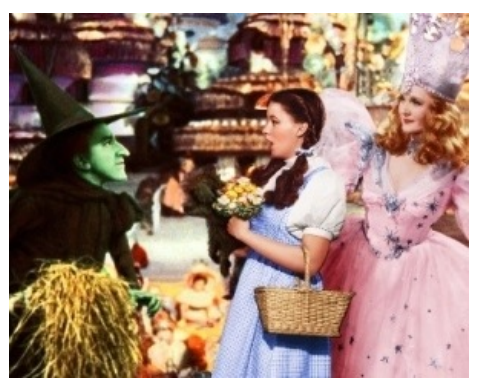

Figures 7 \& 8: The triangle of feminine power in the film is laid out clearly during the Kansas scenes and continues with Glinda and the Wicked Witch once in $\mathrm{Oz}$. first a woman plays the role of the virgin, then a mother, then a crone. But in the case of MGM's Kansas the options available to Dorothy don't necessarily revolve around physical motherhood. In fact, the mother figures (Em and Glinda) may seem motherly and control their own spheres, but neither seems to have children. The Crones (Gulch and the Wicked Witch) aren't simply wise mothers past their childbearing years. They are threatening, controlling, castrating women who wield fire, broomsticks, 
written documents, and power. In fact, NO ONE in this film appears to be having children in a conventional manner. Dorothy is an orphan who has been fostered with Em and Henry, the chickens in Kansas are being fostered in an incubator instead of with the hen who laid them, and in Munchkinland munchkins appear to be hatching out of eggs in a large nest and following Glinda around like baby chicks follow a hen.

During the 1930s when the birth rate in the United States was lower than it had ever been, Motherhood and the physical act of giving birth definitely didn't have the same capital as it once did. For Dorothy, there were powerful options available that didn't include birthing babies. But instead of being an aviatrix like Amelia Earhart, or writing weekly columns and holding press conferences for women journalists like Eleanor Roosevelt, they included unappealing and undesirable roles like "owning half the county," killing dogs, riding broomsticks, and controlling

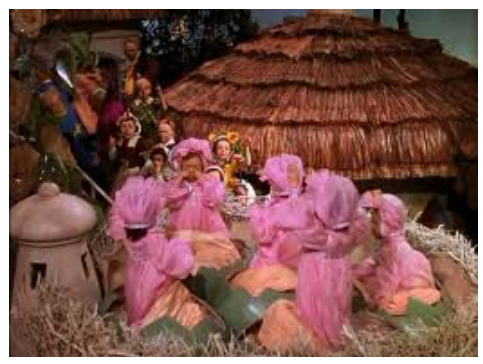
Figure 9: Munchkins hatch out of eggs in $\mathrm{Oz}$. perverted and grotesque creatures like the Winkie Guards and the winged monkeys. Having agency outside of one's domestic sphere meant being referred to by men as "sour" and never marrying and therefore never exploring your sexuality. Having options to do be something other than a mother (even a foster one) meant being surrounded by guards who were quite delighted (and happy to give away your stuff) when some brat killed you with a bucket of water. But more importantly, it didn't help you contend with the crisis that the men around you were facing.

It is my assertion that the agency Dorothy attains, her strength in The Wizard of $O z$, is a reaction to the crisis of masculinity that men were experiencing because of the economic 
instability of the Great Depression. Men were humiliated by unemployment which was "previously thought to be a working class problem but was now increasingly experienced by the middle class." According to the Encyclopedia of Masculinities, since working class families were already depending on women and children to help support the family income, workingclass men didn't seemed to be challenged as much as middle-class men who had always assumed that they would be the traditional family breadwinner and that their family would adhere to strict gender roles. But once the Depression hit, all bets were off, and children, mothers, and daughters were all needed to help keep the wolves at bay. So, although twice as many women as men entered the workforce in the 1930, it was because employers could hire them at reduced wages.

It is with a symbol of domestic work, a scrub-bucket, that Dorothy actually manages to use to defeat the witch (or bad mother) on her own terms, a behavior not usually tolerated in good little girls, and not usually considered to be a desirable feminine trait. All things considered, by the time she leaves $\mathrm{Oz}$, she is a triumphant adult. She has control of her environment, autonomy to do as she pleases, and influence over those around her. She, who had once desired to be desired, is, indeed, desired. Her companions in Oz want her to stay, the Wizard wants to travel with her, and when she wakes up in her old room, all of the Kansas characters (save Elmira Gulch) are gathered around her bed to form a circle of perfection.

The great debate is not, though, whether or not she should grow up. Dorothy's growth is inevitable. The question is, what kind of a grown up woman will Dorothy be? In Kansas we see two types of feminine role models at play. There is the long suffering, worn-out, economically disadvantaged, snappish Auntie Em who doesn't have the power (or courage, or intelligence, or heart) to resolve the Toto issue to Dorothy's satisfaction, who threatens the farm hands with their 
jobs, and who scolds everyone for allowing Dorothy to go near a pig-pen. The other example of feminine power is the hard-hearted Miss Gulch who is unkind, unmarried, and because she knows the law and is wealthy is planning to euthanize an innocent animal. Finding neither character inspirational, or even particularly likable, Dorothy (and the viewer in her phantasmic self) decides to run away. But once out on the road and visiting with her new friend, Professor Marvel, Dorothy is prompted to remember who took care of her when she was ill. Determined to go back home to Auntie Em and comfort, Dorothy returns, only to be sent off to Oz.

In Oz there are two more images of adult womanhood, but these characters are flattened archetypes. There is Glinda the Good Witch, adorned in a pink puffy dress, crown, and carrying a beautiful wand who helps Dorothy gain control of the the slippers and who is beloved by the child-like munchkins, and The Wicked Witch of the West who is green, wears black, and brandishes a broom. Making the choice to become a "good witch" like Glinda is an obvious goal. But neither Auntie Em or Glinda have agency outside of their prescribed domestic boundaries. They can only, in the case of Auntie Em, control the activities generated within their own space, and in the case of Glinda, give ambiguous advice as she makes the munchkins giggle. Miss Gulch can work within the patriarchy to terrorize neighbors in Kansas while the Wicked Witch can terrorize the residents of Oz. When seen through the eyes of a little girl, one must conclude that neither role would be enviable to Dorothy. But looking through Dorothy's eyes actually sheds light on her (our) situation.

Although the issue of the gaze at first glance may seem somewhat dated, it is my supposition that an understanding of this conversation can and will provide valuable insight to the discourse at hand. The discussion of women's representation in film by Laura Mulvey begins 
with the presumption that in classic Hollywood cinema women are always the object of the male gaze. This objectification makes them purely passive, thereby causing the audience of viewers to identify with the man who is watching her. So, when Uncle Ed looks and the field hands sympathize with Dorothy's plight in opposition to Miss Gulch, the audience, too, sees poor little Dorothy as an object of pity and wishes it could help.

Mary Anne Doane's work on women's films of the 1930s and 1940s argues that these films simultaneously assert and deny female desire and and the anxiety of that period about women performing as active subjects. She suggests that these films "provide us with an image repertoire of [classical feminine]poses . . . that document a crisis in subjectivity around the figure of the women ... although it is not always clear whose subjectivity is at stake" (4). In other words, we know that little girls and young women have been given more economic independence and agency during the Depression as a survival mechanism for families, but to depend on that sort of personal power and influence in the future is unrealistic. Therefore, we will show the classical pose of a little girl who wants adventure and excitement, finds it, and is ultimately happy to return to "her own back yard." But as Doane also suggests, when societal issues are represented in these women's films, quite often the use of sentimentality in relation to the film's subject become so inflated that they deconstruct their own position. So, if the movie's premise is that a little girl who wants to go on an exciting adventure, does so, and sentimentally realizes that if she should ever "go chasing [her] heart's desire" she shouldn't look further than her "own back yard," then perhaps the real issue is that it would be impossible for the little girl to sustain a livelihood outside of her own back yard. 
Later in the field of feminist cinematic criticism, Teresa De Lauretis points out that the gaze is not absolute, and that it becomes fractured in many ways. She states that the female viewer becomes split and develops a sort of "bisexual," passive identification that fluctuates between subject and object of the gaze, but that ultimately ends with a female whose desire is to be desired, rather than have her own desires. Indeed, Dorothy's desire at the beginning of the film is to have her guardians, the farm hands, and even Miss Gulch pay attention to her, instead of the chicks, the impending storm, or her little dog. Her desire is, indeed, to be desired. Once she kills the witch (or bad mother), she returns to Kansas, everyone is waiting to pay attention her, and she gets her "heart's desire."

\section{Tania Modleski, in her discussion of classic}

Hitchcock films, further develops the conversation about the gaze by pointing out that in order for these films to work, the male spectator has to gain mastery over the woman before she can become objectified and that (at least in the Hitchcock films she discusses) the women
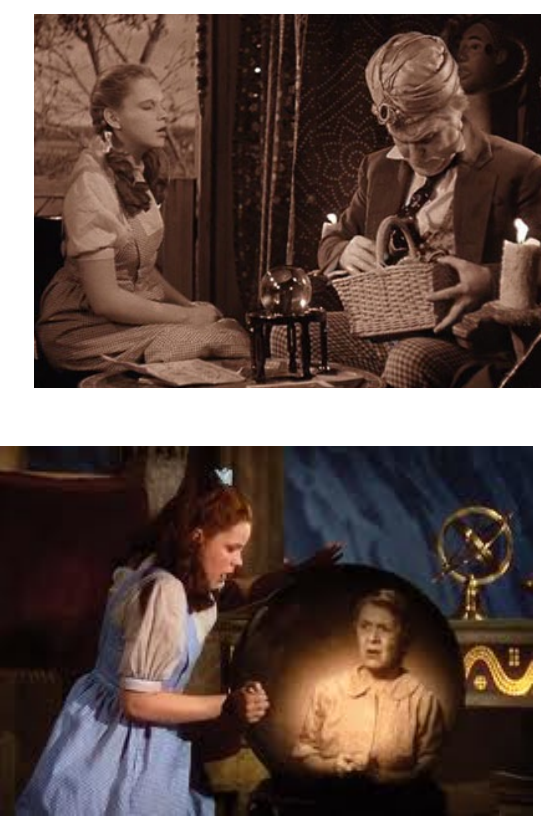

Figures 9 \& 10: In the alternate feminine knowledge of magic as opposed to law, Marvel/Wizard's crystal ball is no competition for the one owned by the Wicked Witch. continue to exert subversive behavior and they "remain resistant to patriarchal assimilation." So despite the fact the Wizard is supposed to be the allpowerful entity who can get Dorothy home and make everything right with the world, it is Dorothy who actually gets Dorothy home. Modleski also points out that one way that women show their resistance to the patriarchy is by "uncovering men's secrets" (as in literally uncovering 
the "man behind the curtain" and finding out that the Wizard is a "Humbug") and "that which knows the kind of pleasure unique to women's relationships with other women" (13). In other words, Dorothy is desperate to get back to her pleasurable relationship with Auntie Em, and Glinda is the only one who can tell her how to do that.

Like Professor Marvel, the Witch has a crystal ball, but hers is larger, is more terrifying, and works. In it, Dorothy sees what is often considered to be the most heartbreaking and terrifying scene of the movie. As Dorothy is locked in the tower of her castle, awaiting her execution, like a modern day Anne Boleyn, her Auntie Em really appears in this crystal ball calling for Dorothy.

What makes this film unique and worth discussing, is that although Dorothy may start out as the classic object of the male gaze, she ultimately assumes subjectivity over objectivity. Once she is locked in the castle, Dorothy is left alone with a much larger, more elaborate, and more ornate version of the Professor Marvel's crystal ball. With Professor Marvel, Dorothy is told to close her eyes, and suddenly Dorothy becomes the classic mark for a kindly con-man's game. We watch him watch her as he manipulates her behavior and encourages to return home. At no point do we see anything in the crystal ball, nor does Dorothy. But when the witch leaves Dorothy alone with the crystal ball, we watch Dorothy watch Auntie Em appear. 
Auntie Em: Dorothy . . . where are you? Please, it's

Auntie Em, we're trying to find you...

Dorothy: I'm here in Oz, Auntie Em -- I'm locked up

in the Witch's castle. . (the crystal ball turns black) and

I'm trying to get home to you, Auntie Em. Oh Auntie Em, don't go

away. I'm frightened. Come back!

And then we watch Dorothy's resolute terror as Auntie Em's image in the crystal ball morphs into that of the Wicked Witch, "Come back, Auntie Em, come back! I'll give you my Auntie Em, my pretty...Ah, ha, ha, ha, ha, ha, ha, hah!" Auntie Em and the Witch, the two diametric forms of womanhood in this film, become one before Dorothy's eyes. Dorothy begins to realize that Auntie Em and the Wicked Witch aren't that diametrically opposed, and that in fact, they are two parts of one self: the self that Dorothy will grow up to be.

I would posit that one of the reasons that this is such a frightening scene isn't just that Dorothy and the viewer are startled by the transformation from nurturing mother figure/ to a castrating, perverse version of womanhood such as the witch. Instead, the horror is due to the sneaking realization that Dorothy doesn't really have a choice between being a "good" witch or a "bad" witch. On some level, the Wicked Witch may be Auntie Em (who could just as easily fire the farm hands as feed them) viewed from a different perspective. The actual unsettling horror hinges on the realization that it isn't a good witch in opposition to a bad witch. Instead, they represent the two sides of feminine agency available to the "new girl" of the 1930s. In other words, Dorothy doesn't get a choice. In order to be a grown up woman in the world of the 1930s 
Depression (which is inevitable), she will have to be both a nurturing and pretty Dorothy as well as a smart, and powerful Dorothy who not only possesses Elmira Gulch-like confidence, but Auntie Em-like skills necessary to support the men, and the patriarchy, around her. The terror comes from the realization that the new girl of the 1930s might have glimpses of a world in which agency is possible, but in which there is no authentic, practical way of attaining it. Although a wealthy and attractive socialite like Amelia Earhart might come close, or the less attractive but even higher-born niece of President Theodore Roosevelt like Eleanor might marry into it, and a highly educated woman with good connections like Francis Perkens might even be appointed into it, a poor orphan from Kansas, played by a child actress who was considered to be unattractive by industry standards didn't stand a chance (Frank). And neither did the audience who was watching (and identifying with) Judy as she/they watched her/their future play out in front of her/them.

Despite the strides towards independence and agency that some women and unions were making, the deck was still stacked against the New Girl of the 1930s. Even though twice as many women were joining the work force as men, and even though more women had jobs, and even though Eleanor Roosevelt thought that married women should work if they want to, women were still not making enough to live on, support their families with, or qualify for federal relief, should they choose to do so. Women were entering the workforce in droves, but there were no laws to protect their interests, they were being hired at rates that many men refused for themselves, and relief jobs were next to impossible for women to get (Tompkins).

As the witch melts away, her last words are inarguably the most provocative lines of the movie: 
Ohhh -- you cursed brat! Look what you've done! I'm melting! Melting! Oh -- what a world -- what a world! Who would have thought a good little girl like you could destroy my beautiful wickedness!? Ohhh! Look out! Look out! I'm going. Ohhh! Ohhh. ...

This, of course, is the climax of the film. As Dorothy enters Oz trying to figure out who she should emulate, her days as a child are already numbered. But instead of being passive object of the gaze and letting them kill off her childhood (or innocence), she herself actively kills off the adult roles that she finds threatening. The "good little girl" of the 1930s, the motley yet spunky, orphan effectively eliminates the rich, bluestocking crone who is asexual and controls men, women, and munchkins, and emasculates anyone else in her path. In effect, Dorothy has taken revenge on the wealthy landowners who own half the county, squandered away the 1920s, and got the country into a depression in the first place. Dorothy Gale and Shirley Temple, have destroyed the beautiful wickedness. What a world, indeed! Dorothy wanted agency, and in Oz, she has it. But, and this assumption bears emphasis, Dorothy's real world doesn't have a real plan for Dorothy. In the 1930s, women were working, but they weren't being paid nearly enough, they were facing external societal criticism for doing so, and they were facing anxieties about gender-role changes from within their own domestic spheres.

In addition to attempting to deal with this anxiety regarding economic instability for women, the film also illuminates the fact that depending on women and children to help with the bills meant that the boundaries between working class and middle-class were no longer well defined. It had never been unusual for the women and children in working-class families to 
contribute to the families' economic bottom line. But before the Depression, it was rare for middle class women and children to help make ends meet. In other words, men who don't control the cash flow not only have less personal power within the domestic space (Uncle Henry vs. Auntie Em), but are vulnerable to "the law" that can appear in the form of a rich neighbor who can come over and bully your dog or foreclose on a mortgage, or whatever she wants to do. It takes the generally accepted middle class masculinity, dashes it against the floor, and makes the cartoonish munchkins from the Lollipop Gild the toughest guys in the film. In fact, the stark contrast between the highly gendered stereotypes of the munchkins (especially The Lullaby League, and the Lollipop Guild) contrasts with the gendered confusion of the tall (adult) characters in the film.

Ruth Feldstein states that "Resolving a perceived crisis in the family required resolving a perceived crisis of masculinity, and both of these moves were necessary to bolster liberal democracy" of the Great Depression in the United States. Basically, if families were perceived to be in crisis during the 1930s (and evidence presented in the previous chapters would support that they were, indeed, perceived to be in crisis) then resolving masculine identity should have been at the forefront of any espoused ideology.

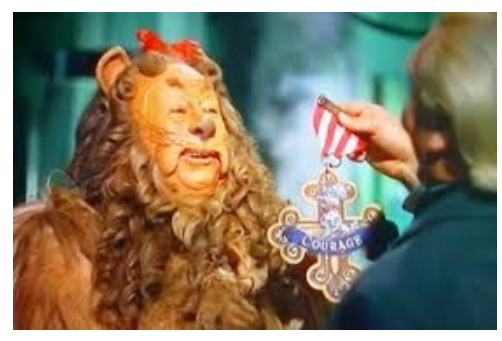

Figure 10: None of the "adult" or "tall" male characters in the film met the normative image of masculinity for the 1930s.

Unfortunately, although this film did much to bolster a young women's search for agency, it did nothing to resolve the masculine identity crisis careening around it. 
As Dorothy travels through the very merry land of $\mathrm{Oz}$, we see example after example of failed masculinity. First the scarecrow questions his intelligence, then the rusty Tin Man has no heart, then the lion has no courage, and finally the Wizard turns out to be a Hum Bug. Fortunately, because of Dorothy's entrapment in the Witch's castle, the Scarecrow is forced to devise a plan, the Tin Man is forced to feel emotion for Dorothy and act on it, and the Lion is forced to do something courageous. Until that point, Dorothy had been the smart, empathetic, and brave member of the party. Even the old blow-hard of a wizard is forced to actually get himself back to Kansas with the use of a hot air balloon, because Dorothy has inspired him.

As the 1939 passage by Frederic Allen at the beginning of this chapter states, the new girl of the 1930s, "conveyed a sense of competence," and "restored ... shaken masculine pride." By the time she left Oz, everyone's pride was up to speed, but only because Dorothy actively helped them by appealing to their emotions, intellect, and sense of courage. And when she was locked in the castle, they were forced to demonstrate their intelligence, empathy, and bravery by hatching a plan to get her out of there. And Dorothy didn't just "convey a sense of competence." She was competent. When the Scarecrow catches on fire in the witch's castle, Dorothy competently dampens it by throwing water on him and manages to successfully kill the witch in the process. She didn't hide behind her the prescribed boundaries set forth by patriarchy like Christianity, picket fences, pink bubbles, money, or orders from the sheriff. And more importantly, she didn't just threaten to "bite" the Wicked 'Ol Witch this time. She actually kills her.

For a while, it seems as if everything is going to work out well for Dorothy after all. After the wizard has managed to let the balloon get away without Dorothy or Toto, motherly Glinda 
shows up to point out that Dorothy always had the power to get home. When asked by the Tin Man (now proven to have a heart) what she has learned, she reflects:

Well, I - I think that it - it wasn't enough to just want to see Uncle Henry and Auntie Em - and it's that - if I ever go looking for my heart's desire again, I won't look any further than my own back yard. Because if it isn't there, I never really lost it to begin with! Is that right?

Indeed, she now has the agency to get back home by tapping her feet together and uttering the famous lines "There's no place like home." Once there, she get's her heart's desire. She who, for DeLauretis' purposes, "desired to be desired," is desired. All of the adults who didn't have time for her previously gather to care for her (including Professor Marvel). Auntie Em is clearly worried about her, and everything is right with the universe.

Except, it isn't really. Because when Dorothy tells them about Oz, no one believes her. They are happy of course that she is alive and well, but they assure her that her fantastical dream was the product of a bump to the head, and it never existed. Dorothy protests that "It wasn't a dream, it was a place, " but then gently and amenably agrees to stop arguing and proclaim her relief at returning home, like a "good little girl."

So we are left with an unresolved situation. Although in the movie, Oz isn't real, on some level for the American audience, Oz was real for Dorothy. And if Dorothy's family in Kansas didn't believe that Oz was real and that Dorothy's ability to control her own environment was real, what does that say about the audience who has spent that last 60 minutes believing in $\mathrm{Oz}$, and in a place where the protagonist has control? What does it say about the world outside of the movie theater, and their own place in it? And if Dorothy's ability, (and, therefore the ability of the 
New Girl of the 1930s) to control her environment is really only a child's fantasy, then the audience's ability to control their environment during the 1930's was also a fantasy.

Much like the self-reflexivity inherent in Stella Dallas, the use of color in this film sets up a duality between the dreary real world of Dust Bowls, Depressions, and foreclosures, and good witches wearing pink, munchkins who are either very masculine or very feminine, and a yellow brick road. It is the comparison of a world where someone can come onto your own land to kill your dog (or take your farm) as opposed to a world where a little girl can get angry and finish off the wicked witch with a bucket of water. It is a world of limited agency for a little girl (and the woman she will soon become) against the limitless agency of a good little girl who can "destroy ... beautiful wickedness." And if we believe De Lauretis, that we are all identifying with the female protagonist in this instance (even males in the audience) it becomes bigger than a little girl. It becomes everyone in the theater. The film, in effect, tries to inscribe the problems of the Depression onto the body of a little girl, but because the problems are too big for her shoulders, the narrative fails as an entertaining piece of storytelling that will
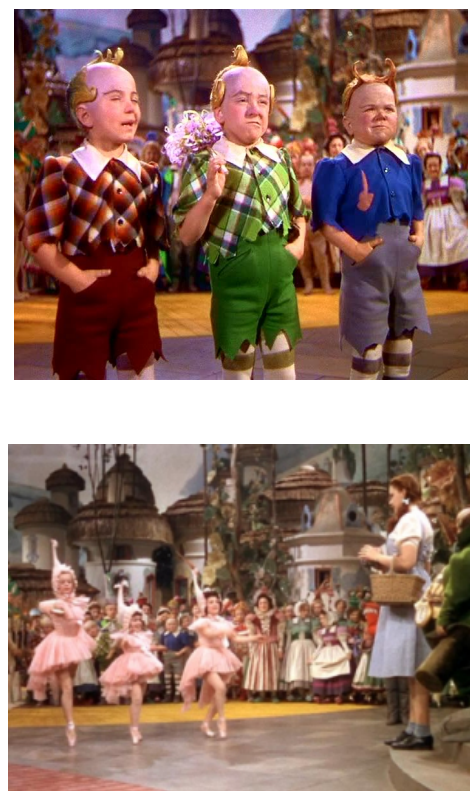

Figures 11 \& 12: The Lollipop Guild and the Lullaby League represent the most extreme portrayals of male and female gender stereotyping, which is fitting for the the fantasy of a child.

resonate with the masses. Kansas is the real world, but $\mathrm{Oz}$ is

Hollywood. Just as Dorothy has to leave Technicolor Oz to return to Sepia Kansas, the spectator has to leave the piece of Hollywood that is the theater for the Depression waiting just outside the door. 
Oh, but anyway, Toto, we're home. Home! And

this is my room, and you're all here. And I'm not gonna leave

here ever, ever again, because I love you all, and - oh, Auntie Em

- there's no place like home

Just like it is fun to believe we can stay in the dreamworld that Hollywood has set forth for us, it is fun to believe that Dorothy is home and that everything will go back to normal. Except it won't be normal, and Dorothy's growth and development is suddenly contracted down to her room -- a domestic space even smaller than that of Auntie Em's. Dorothy (and her doppelganger New Girls) might be able to go out in the world and get a job, but the working conditions will be poor, most of the jobs available to her will be jobs that pay so little that men refuse them, and very few women qualified for relief or CWA jobs (Tompkins). Though the spirit on behalf of the women was willing and competent, the infrastructure simply did not exist to assure parity.

The ending of the film ties up everything nicely, but ultimately, this time the suture is incapable of containing the energies unleashed in the film. Although her friends and family think that $\mathrm{Oz}$ is the product of a fanciful dream, the character of Dorothy thinks Oz is real. The audience, who has spent the last hour living in the world of $\mathrm{Oz}$ thought it was real, too. Based on her opening solo, we know Dorothy wants to get out of Kansas, and the audience wants Dorothy to get out of Kansas. The probability of competent Dorothy repressing her desire and staying put in order to fulfill the somewhat dated expectations of what sorts of behaviors were appropriate for "good little girls," seems low in a world where Earhart can fly and Eleanor can control the media. Maybe a small child like Shirley Temple could create her own nuclear family, and maybe Stella Dallas could give up her daughter and watch it all play out on the big screen 
like a depression era weepie. But the dreams of Dorothy (and the American people) were simply too big to be contained on a sepia colored farm in Kansas.

I posit that the unresolved nature of the anxieties addressed in this film contribute to the lack of popularity upon its release. At the end we are forced to leave the theater and Dorothy is stuck on the farm raising pigs and chickens. We want things to get better economically, and Dorothy wants to see the world and have agency. The film unleashes these energies: a young girl's burgeoning womanhood and path in life, threatened masculinity due to economic changes, and our wish to be part of a fantasy world that is much better and much more colorful. The Wizard of $\mathrm{Oz}$ never really captures, sutures, or contains these energies. Instead we are left with "it was all a dream."

These failings didn't do a whole lot for the film when it was released, either. The Wizard of $O z$ wasn't a really big box office hit in 1939. Sure, it was nominated for six academy awards, and it was the second highest box office film of the year. But it was in a very distant second behind Gone with the Wind (Gone). The Wizard of $\mathrm{Oz}$ made $\$ 3,017,000$ at the box office, while Gone With the Wind made \$77,641,106 (What's Wrong). Now, to be clear, Gone With the Wind is still supposed to be the highest grossing film of all time (if you adjust for inflation), but a couple of years earlier, in 1937, Snow White made $\$ 7,846,000$ (Jewel 44). In other words, another children's film that came out two years earlier made almost twice as much money as The Wizard of $\mathrm{Oz}$ did in roughly the same economy.

During the Great Depression, Dorothy's agency really could be threatening. Depicting men who look like bumbling fools, showing grown women who could nourish your body one minute and eliminate your job the next, and depicting the patriarchy as a spinstery, emasculating, 
bicycle/broomstick driving crone who has winged monkeys and green armed guards with deep voices indebted to her, wouldn't necessarily comfort the average American middle class man trying to keep body and soul together. Although the Great Depression was in its last gasps before the War Boom, a film that infantilizes masculinity to the point that it is laughable and uncomfortable isn't apt to be a runaway hit. The only normative gendered roles in the film were left to the munchkins, who were clearly costumed and created to be silly, cartoon-like, and freakish.

To make matters worse, the images of womanhood represented aren't viable options for Dorothy. She isn't going to grow up to be an evil bluestocking crone like Miss Gulch, and she probably isn't going to stay on the farm and play the domesticated wife or fairy princess. Like Earhart and Roosevelt, she wants to have agency far outside the parameters that have been assigned to her. Unfortunately, by 1939, when the film was released, Amelia Earhart was dead. There would be no more record-breaking flights for Lady Lindy. And although her presence heralded change for women everywhere, there was no disputing the fact that Mrs. Roosevelt's identity as a stateswoman and journalist was developed not because of her oratory talents or prodigiousness in public policy, but because she was Mrs. Franklin Roosevelt. Despite her decidedly feminist agenda, her championing of working women, and her egalitarian personal values, ultimately in 1939 she was still a woman whose identity was constructed because of who she was married to, not because of her own gifts and talents, wondrous as they may have been. Basically, the film attempts to deal with this anxiety regarding economic instability and the fact that depending on women and children to help with the bills meant that the boundaries between working class and middle-class were no longer well defined. Despite the fact that wives 
and daughters going to work and bringing in money to help the family bottom line was

theoretically possible and desirable, the practice ended up economically castrating the image of middle-class masculinity. In other words, men who didn't control the cash flow not only have less personal power within the domestic space (like the power relationship between Uncle Henry and Auntie Em), but are vulnerable to "the law." It takes the generally accepted middle class masculinity, dashes it, and makes the cartoonish munchkins the toughest guys in the film.

So at the end, Dorothy is back where she started, in Kansas, and the audience has to leave the darkness and warmth of the theater for the harshness of the outside world. What will she do now? The answer is part of the larger context. She can't get back to the very real fantasy land of Oz where she lived for "days and days," and she can't stay on the farm. She has agency -- she knows too much. She killed a witch -- she has done too much. She is no longer a child. America can't get back to the promise of America in the 1920s any easier than Dorothy can go back to Oz. . . but the 1930s and Kansas is not going to work for either the audience or for Dorothy. The film unleashes too much, and is then unable to fit the genie back into the bottle. It doesn't know how to help women find agency without disenfranchising an already tattered version of masculinity. The audience has no idea what will happen to Dorothy back in Kansas, or to them when they leave. They had technicolor, fantasy, and agency for a short time, but now it is the time to return to Kansas, the real world, shades of sepia, a paternalistic ideology, and an uncertain economic future.

Gone With the With the Wind: Before War and Poverty Had Done Things to You 
In March of 1931, several young people were hopping freight trains on the Southern Railway Line in in Tennessee and Alabama. A fight broke out between the white and African American males on the train, and the white youths jumped off the train to report that they had been set upon by the black teens. A sheriff's posse stopped the train and were told that the African American males had raped two white girls. As a result, nine African American adolescents (popularly referred to in the press as the "Scottsboro Boys") between the ages of 13-19 were arrested, very nearly lynched by a mob, rushed through trials with all-white juries and inadequate representation, and spent the next several decades on re-trials, appeals, and trying to survive the most substandard prisons in the country.

The story of the two alleged victims (Ruby Bates and Victoria Price, ages 16 and 21) was later recanted. Although at the time of the arrest a doctor had examined both young women and had testified that there was some bodily evidence of recent sexual activity, some time later Ruby Bates actually admitted that Price (who had already been married three times at the time of the incident) had encouraged her to participate in the story so that the two could avoid arrest for vagrancy and adultery. The last of the Scottsboro Boys was released from prison in 1950, but their case stands as a landmark example of stereotypical racial injustice.

Meanwhile, as the narrative of the story changed from a gang rape of innocent white women by barbaric and uncivilized black men to one of sexually experienced Jezebels lying about their promiscuity in order to whip the passengers on the train into a violent and racially charged frenzy, little attention has been paid to the other atrocities of the story. First, all of the people riding the train were hobos. In effect, they were homeless drifters who had not paid a fare and were stowaways using an illegal and incredibly dangerous mode of travel. Secondly, Bates 
and all but one of the African American males were all technically minors. That's a large group of children to be traveling alone looking for work under such dangerous circumstances. And even though Price and one of the males were not minors, much was made of the fact that Price had clearly been sexually active with at least three men (to whom she was married, admittedly) before the age of 21. Although the most heinous acts of wrongdoing and abuse seem to occur at the hands of middle-aged white male judges, middle-aged white male attorneys, and a lynch mob that was made up of members of the white community, black and female children were the only participants in the story who are consistently punished, vilified, or whose motives were questioned. In fact, after closer examination, it could easily be read as the narrative of white masculinity under siege by economic and social forces (i.e. you can't afford to feed your family) lashing out at the physical manifestation of these perceived failings (children are forced to do dangerous things in order to survive) and the imagined fantasies (racial insurgence and racial miscegenation) that fan the flames of the era's anxiety.

While the Scottsboro Boys case was capturing headlines in the 1930s, and the Great Depression continued to churn on, something else happened in the American South. In 1936, a former Atlanta debutante who was known for scandalous flapper behavior in the 1920s among the Georgia gentry, Margaret Mitchell, published what would be one of the most popular and well-known novels of the English language. The next year Mitchell was awarded the Pulitzer Prize for Fiction for Gone With the Wind. In 1939, the book was transformed into a Technicolor epic that not only garnered multiple awards, but has become one of the top grossing films of all time. 
Though the film is set immediately before, during, and after the Civil War, it isn't difficult to identify themes relevant to Depression-era audiences peeking out behind hoop skirts, columned mansions, and Confederate flags. Concerns about a crumbling social order, a redefinition of white manliness, and a triumph over poverty in times of adversity would all have been of interest to most moviegoers in 1939. The fact that it has sustained its popularity to the present day is a testament to its ability to engage these issues in a way that continues to satisfy and seem relevant to many viewers. That, throughout the most popular film in American history, the heroine is able to maintain a completely self-absorbed and psychologically immature perspective through Civil War, near starvation, and three husbands (not unlike Victoria Price) speaks to the deep seated discomfort and trepidation many audiences have felt regarding the redefinition of women's roles in the United States during uncertain times. It is my assertion that, since the heroine begins the film as a spunky and rebellious adolescent who never really manages to grow up emotionally until the very last moments of the film, once again the spunky little lass, the child, the "New Girl," has managed to deflect and suture over anxieties revolving around the changing status of white American men. But unlike the aforementioned girls, she fulfills all of the requirements desired by her culture. She is sexual, she can be depended on in a crisis, she can survive adversity, she can make money, and when you get tired of her, you can tell her to go to Hell. In fact, I would propose that by the end of the decade, the sullen sexuality of the 1920's flapper, the flirtatiousness of the Shirley Temple's Lollipop Licking Tease, the fetishization of Stella's Lolly, and the hard-working and attractive "New Girl" of the 1930s combine to create a whole new category of child. Scarlett becomes, in effect, the inverse of 
Shirley Temple. Instead of being a woman presented to us as a child, Scarlett is a child presented as a woman. She is a teenager.

As I have stated in previous chapters, I attribute the eroticization of female children in 1930s film to the destabilized masculinity brought on by the Great Depression and the subsequent reconstructed, decidedly white, decidedly adult, and decidedly upwardly mobile male identity. The anxieties produced by any threat to this new American male, including racial (in)equality, shifting gender roles for women, and the disintegration of patriarchal agrarian family values were neatly contained in films that featured little girls as heroines, fetishes, and metaphors for the American Spirit. Selznick's Scarlett accomplishes what Shirley, Stella, and Dorothy could not -- the portrayal of a girl's journey to womanhood that successfully finds upwardly mobile agency and power, while remaining complicit with patriarchal norms. Scarlett and Rhett's bad behavior becomes a metaphor for a new type of woman, a transformed male gender role, and a new cultural definition of the American Spirit as it moved towards a new decade and a World War. Molly Haskell refers to Scarlett as a heroine who never quite outgrows adolescence ... transfigured into something much larger, something profoundly American, a canvas that contains if not Walt Whitman's multitudes, at least multiple perspectives. (Haskell 53) The lollipop-licking tease may have gotten older, it seems, but she never truly grew up.

But who, exactly, is the lollipop licking tease in this film? There are many children and child-like characters in the story. In the novel, Prissy was noted to be around the age of eleven and Scarlett is 16 years old. Bonnie Blue Butler, of course is a young child when she dies, and one could make a convincing argument that Melly's innocence and purity makes her child-like in 
nature. And even with her wrinkles and age, virginal spinster Aunt Pittypat wears her hair in a style as reminiscent of Shirley Temple in a freakish parody of 1930s Southern-Gothic innocence.

Although Pittypat's portrayal and costuming seems to be almost tongue-in-cheek, it is important to note that due to her marital status and presumed lack of sexual experience, she is never shown caring for the young men in the Civil War

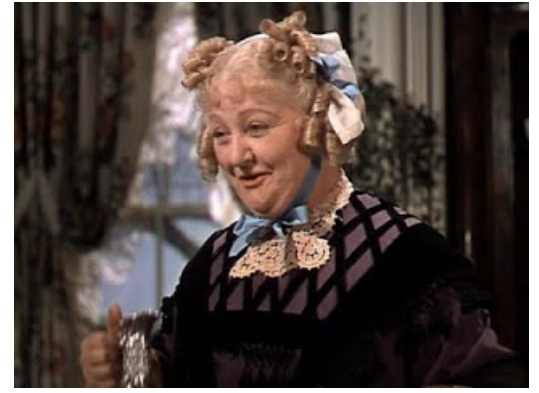
hospital, unlike the very young Melly and Scarlett who, despite their tender ages, had indulged in one night of sexual experience before their adolescent grooms headed off to war. Thanks to their one quick sexual encounter, they are deemed suitable for
Figure 1: Aunt Pittypat's curls and immature behavior seem to be coded as"childlike" and "virginal," despite its caricature-like quality. nursing wounded Confederate soldiers and, worse, witnessing the aftermath and horror of wounded and dying soldiers for whom there is no relief.

But it is Scarlett, not Melly, Prissy, Pittypat or even Bonnie that is the most child-like character in the film. When we first encounter her, 27 year old Vivian Leigh portrays a prim adolescent playing naive flirtatious games with beaus as she sports high-necked, ruffled dresses and bows in her hair. Shortly thereafter we witness a scolding by her Papa, and a forced feeding by her Mammy, as all the while she pouts, whines, and throws temper tantrums like an over-tired toddler in order to get her way.

Throughout the film, Scarlett's childish status is constantly reaffirmed. Immediately after the opening, Scarlett's behavior as a spoiled child is established as she flirts and spars with the Tarleton Twins who bribe her with gossip. When they change the subject to something as pedestrian as the looming civil unrest she exclaims that "this war talk is spoiling all the fun at 
every party this spring," and threatens to "go in the house and slam the door" if it is discussed again. Although the roles are all played by actors who are well beyond the age of majority, the posturing of adolescent boys hoping to be tough men who play at battle, and of the little girl testing her coquetry and feminine whims on her playmates echoes the Shirley Temple Baby Burlesque shorts. But, instead of the comical incongruity of childish bodies using adult language to describe grown-up issues, these characters have adult bodies using childish language to describe grown-up issues. The Tarleton Twins manage to keep Scarlett from leaving by promising to tell her a secret, at which point they divulge the news that Ashley plans to announce his engagement to his cousin Melanie. Scarlett, horrified, races out to find her father (who is indulging in the guilty pleasure of reckless horsemanship that his wife wouldn't approve of) and get more information. Once she

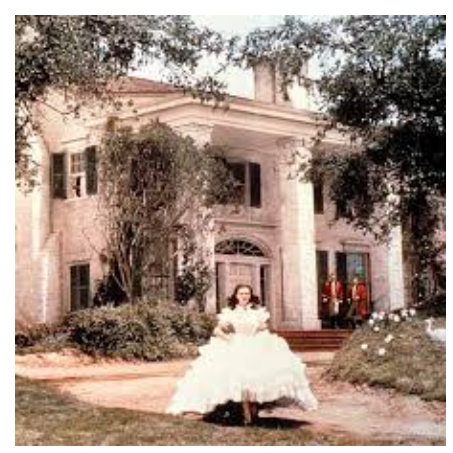

Figure 2: High necks, ruffles, ribbons, virginal white and hoop skirts turn 27-year-old Vivian Leigh into 16 year old Katie Scarlett. engages him in conversation, he immediately establishes her place in his Irish/Southern American patriarchal order. After waxing nostalgically about how important land is to the Irish, he looks at her fondly and relents, "Oh, but there, there now, you're just a child. It'll come to you, this love of the land." When faced with the possibility that he may be chastised by Mrs. O'Hara, the one person with more authority than he within the domestic space of Tara, Scarlett's father is quick to construct his own sense of masculinity by deconstructing his daughter's ego with loving, albeit patronizing, sentiment.

The references to Scarlett's childishness don't end there. When Scarlett professes her love and interest in marrying to Ashley at Twelve Oaks, as a defense he immediately counters with, 
"How can I make you understand? You're so young and unthinking, you don't know what marriage means." A few lines later, Rhett, mocks the aforementioned conversation by teasing Scarlett about the shallowness of her profession of love to Ashley. "He doesn't strike me as half good enough for a girl of your ... what was it?. . Your passion for living?" Scarlett, characteristically, responds by throwing another short tantrum regarding the magnificence of Ashley, to which Rhett responds wryly, "And you were going to hate him for the rest of your life." While old guard Southern gentlemen like Gerald and Ashley gently and indulgently patronize Scarlett by calling her a child, Rhett smirks and mocks both Scarlett and the social conventions that clear a space for such condescending behavior on the part of these men.

Nevertheless, Scarlett is clearly a young girl who rushes into a war wedding to spite Ashley. Scarlett's young and nervous (and equally childish) husband manages to die immediately (of illness, not even a war wound), leaving Scarlett a widow, and sister-in-law to Melanie. At this point, Scarlett accepts the call to adventure in her own heroine's journey, and innocently heads to Atlanta to have a good time.

Like Dorothy (and Ulysses, and countless heroes of other great epics), she will never return to the same home again. Before she sets foot back at Tara, she nurses sick and dying Civil War soldiers, witnesses the siege of Atlanta, single-handedly delivers a baby, watches a city burn, and even manages to get a postpartum woman and her newborn back home with next to no help from those around her.

The first act of the film depicts Scarlett's transformation from little girl to Southern Lady. This transformation first becomes obvious when Scarlett heads out to find Dr. Meade to help deliver Melanie's and Ashley's child in the middle of the of the Atlanta Campaign. She is furious 
at being obligated to stay and care for Melanie, and furious at Prissy who has failed to fetch the doctor. Scarlett, who is sweating and angry, and probably terrified dons her sun hat from the Wilkes Barbecue at Twelve Oaks (inverted, now, for practicality's sake. ...much like Scarlett's life) and heads off to the railway station to find Dr. Meade so that he can deliver Ashley's son. As Scarlett walks towards the rail yard to fetch the doctor herself, the camera focuses in on her, and the audience feels her claustrophobic point of view as she is jostled by horses and carts. Then Scarlett spies a wounded soldier on a stretcher, then two, then three, then ten or twenty, and then the camera zooms back to reveal to the audience and to Scarlett for the first time, that hundreds -- no, thousands-- of wounded and dying soldiers surround her under a tattered Confederate flag. The scene is stunning and horrifying and powerful. As Scarlett shifts from being the object of the gaze to the holder of the gaze, the audience realizes that her problems are dwarfed by the thousands

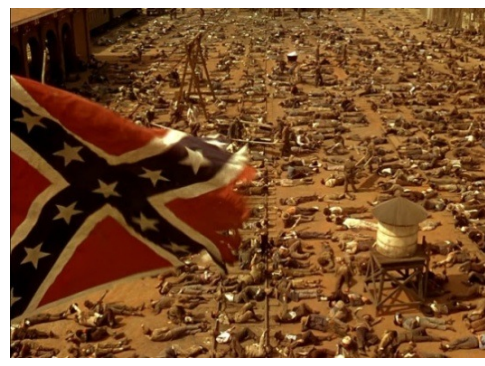

Figure 3: As the camera zooms back, the audience, and Scarlett, begin to realize that her problem is one of thousands in a horrific situation.

in Atlanta. This observation is punctuated by Dr. Meade, as he swiftly and abruptly dashes any adolescent feelings of self-absorption Scarlett may have been harboring. When she asks him to come help with Melanie's travail by expressing fear that her sister-in-law might die in childbirth, his response reveals his feelings towards Scarlett's maturity, or lack there of, and compassion for the thousands of wounded soldiers in their midst.

Die? Look at them. Bleeding to death in front of my eyes! No chloroform, no bandages. Nothin! Nothing to ease their pain. Now run along and don't bother me. Now don't worry, child. There's nothing to bringing a baby. 
What is interesting about this exchange, is that although Dr. Meade clearly expects Scarlett to nurse sick and dying men in a thankless situation, or alternatively manage to singlehandedly deliver a baby with presumably very little working knowledge, and no practical experience of how to do so, he refers to her as child twice, tells her to find "some" (not "another") "woman to help you" and admonishes her to run along. In Dr. Meade's eyes, Scarlett, though old enough to marry, tend to wounded soldiers, deliver babies and presumably have them herself, is not yet a woman.

As Dr. Meade tries desperately (and in vain) to save the soldiers who have fought for the Old South, in the face of horror he continues the charade of paternalistic benevolence in regards to Scarlett. Although she was

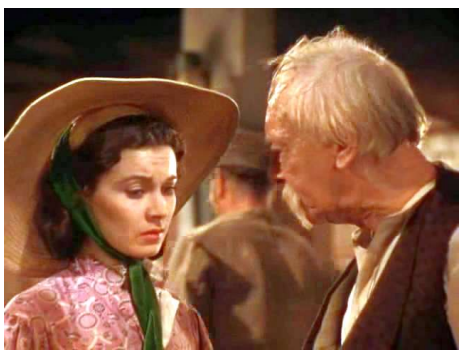

Figures 4 and 5: Scarlett O'Hara: same hat, different day. Clearly like her hat, Scarlett's circumstances and purpose in life, have changed. Both are looking a bit older, and a bit worse for the wear.

obviously as aware of the horrors of war as he was, and

although he was the one who encouraged her to stay in Atlanta with Melly because he feared a difficult labor, and although he was perfectly aware that there were no other women around to help Scarlett, he offers no helpful advice or comfort. Instead, in the face of the powerlessness and defeat of not being able to do more for thousands of dying men in agony, his only response is to tell this "child" to "run along." In the face of his own ineffectiveness, Meade can at least mask the erosion of his authority and agency by firmly placing Scarlett back into her spot in the symbolic order. 
In fact, Meade's tactic of undermining Scarlett's age and experience in the light of his own masculine failings is reminiscent of Gerald O'Hara who is quick to dismiss his daughter as a child who knows nothing of the land as soon as soon as he thinks he might get in trouble with his wife for taking risky chances jumping his horse. Although we barely see her, Mrs. O'Hara is clearly one female character who wields authority within her domestic realm, much like Dorothy's Auntie Em. Her participatory scenes in the film (other than suggesting that her bored daughter head off to Atlanta) include her return from having delivered Emmy Slattery's illegitimate baby and leading the family in the rosary. Not only are Gerald and his daughter forced to conspire to help avoid her wrath, when she returns from delivering the Slattery baby, Scarlett's mother tells her husband to fire the overseer who sired the child.

By the end of the first act, the narrative establishes that Scarlett has returned to Tara not to be with her mother (she died right before Scarlett gets home), but to become her mother. With Mrs. O'Hara dead, Gerald obviously suffering from dementia, and the sisters ill, it falls on Scarlett to take control. Indeed, by the time the intermission appears on screen, Scarlett, too, has delivered a baby, has taken charge of Tara, and although she didn't lead the saying of the rosary, she has certainly invoked "God as her Witness." Scarlett has come home. She may be the mistress of Tara, and she is clearly not the same child who left. But, as we shall discuss later, she isn't quite an adult, yet. She isn't alone, either.

Often described as lazy, annoying, lying, and deceitful, Butterfly McQueen's Prissy rarely invokes positive emotions from the film's audience. Between assuring everyone that she knows how to deliver babies, and dawdling along humming Stephen Foster's "My Old Kentucky Home" in the face of Melly's maternal crisis, Prissy's behavior is atrocious. In fact, the only 
character who seems to be on to Prissy's proclivity to stretch the truth is Rhett Butler, who is also impressed to hear that Scarlett managed to deliver the baby single-handedly.

Which begs the question of why on earth anyone would think that Prissy could have delivered a baby in the first place. Although her age in the film is ambiguous (remember, she was supposed to be around 11 in the novel, and more people in the United States had read the novel than had voted for Herbert Hoover), Butterfly McQueen's character is clearly a child at some level. Her lilting voice, her short stature, and her immature behavior indicate that she is is young, and her character is clearly added as comic relief. She is, in fact, one of the many African American tropes so prevalent in film and popular media of the era. Instead of being the coon or the mammy, she's a slightly cleaned up version of the pickaninny.

Although in the 1860 s and in the 1930 s, it was still quite common for women to labour at home with the help of a midwife or other women, expecting a child (especially one as young as 11 or 12) to take charge of the situation was a bit of a stretch under any circumstance. Yet, as an audience, as we watch Scarlett gaze upon Prissy ambling along singing, "We must tote the weary load. . ." we are outraged and ready to leap upon her from our seats in the audience. For those in the audience who were white, (and for the time being, at least, identifying with Scarlett), the moment during which Scarlett strikes Prissy was (almost) justified. Since maternal and infant mortality numbers were much higher in the 1930s, much less the 1860s, Prissy's obstinance becomes doubly frustrating and horrifying. ${ }^{2}$

2 I hasten to add that critic bell hooks would suggest that Prissy's participation in the scene provides a focal point for the "Oppositional Gaze" felt by many African American and otherwise marginalized viewers. Those viewers would not necessarily find themselves rooting for Scarlett. 
Molly Haskell makes an excellent point in regards to our frustration with, and Scarlett's rage against, Prissy.

Prissy, in her whining, lying way is a stumbling point for most viewers, yet the humor and wild individuality she brings to the movie is a vital, idiosyncratic force. No one is like her unless. . . it is Scarlett herself. Prissy is a comic grotesque, the dark mirror image of her devious lying mistress (location 1878).

Prissy is the double of Scarlett with whom neither we, nor Scarlett, wish to identify.

If we are already secretly rooting for whiny, lying Scarlett, it is painful to watch her twisted double manipulate her using the very same tactics. It seems as if the purpose of Prissy of the film is to portray some of the undesirable aspects of childhood that we can't (or won't) tolerate in our heroine, Scarlett. Children, even the most lovely and angelic, are prone to whining, crying, boasting, and lying. Often their undesirable traits are a result of the same thing that makes them cheerful, playful, innocent, and painfully honest: vast inexperience, unsophistication, and naiveté.

It is my assertion that, just as in the case of the Scottsboro Boys, African American and female children are being made to pay for the sins of the white adults in their world. Scarlett (who had been guilted by Meade into staying with Melly) is forced to deliver a baby even though he considers her a child who should "run along." Instead of being annoyed with Meade, or Pittypat (who was an adult, and was supposed to be chaperoning Melly and Scarlett, but who left them flat in Atlanta at the first sign of approaching Yankees), or the white male politicians and landowners who started a Civil War in the first place, the audience generally blames the character with the lowest social standing and the least agency in the whole film: Prissy. 
Like the elastic social narrative of the Scottsboro Boys incident, the narrative of the South seemed to be constructed based on fear and guilt regarding what Eric Lott refers to as "sexual anarchy" resulting from a world in which slaves and women must be contained lest things get out of control (126). "Specifically, there were the twin threats of insurrection and intermixture, the consequences, to white men's minds, of black men's place in the slave economy" (Lott 123). So, in the 1930s, a time not so very removed from slavery, there was still a constant anxiety in regards to containing the other. And in a time of political and economic disorder such as the Great Depression, this anxiety could (and did) easily bubble to the surface.

The fact of the matter is that with the exception of Prissy (whom the film has made sure we feel justified in hating), the portrayal of all of the African American characters in the film, and the portrayal of the interactions between them and their white owners consistently paints a nostalgic picture of a harmonious, and if not equitable at least justifiable, interracial relations. Scarlett was clearly thrilled to see Big Sam in Atlanta upon his conscription, and shows practically more emotion for the other slaves from home than she does for anyone in the film, save Ashley. "Goodbye Big Sam, goodbye boys. If any of you get sick or hurt, let me know!" Later, when he saves her from robbery and defilement at the Hoovervillesque shantytown, Scarlett is genuinely appreciative.

Once in his dotage, Gerald O'Hara actually articulates his philosophy in dealing with slaves, and it isn't so very different than the prevailing white philosophy for dealing with non-white people in the Jim Crow South of the 1930s. 
Gerald O'Hara: I've been talking to Prissy and Mammy and I don't like the way you are treating them. You must be firm with inferiors, but you must be gentle with them.

Scarlett: Yes, Pa, I know. But I'm not asking them to do anything I'm not doing myself.

And it is true. Scarlett is forcing everyone in the household to pull their own weight. She isn't giving preferential treatment to the white people. Everyone is working hard and hungry.

After Gerald's death, Scarlett even offers Pork his pocket-watch. When he suggests that she instead sell it to pay the taxes on Tara, she refuses, "You take it, it's for you. Pa'd want you to have it...You think I'd sell Pa's watch? And don't cry. I can stand everybody's tears but yours." In fact, one might even argue that Scarlett is somewhat subversive (in 1860s terms) in her treatment of African Americans. Tim Ryan, in his book Calls and Responses, suggests that Mitchell's novel is less about racial tension and more about tension between classes. He points out that Mitchell's African American characters have layers of complication and construction.

Again and again, Gone with the Wind distinguishes between decent, threedimensional, elite African Americans -- who play a positive and constructive role in southern society -- and brutish, anonymous, lower-class blacks who are ill equipped for the responsibilities of freedom and who threaten social stability.

Although the Scarlett of the film is clearly not the kindest mistress to work for, her behavior and words definitely suggest some knowledge of the incongruous behaviors of the people around her in regards to race and class. When she is using slave labor to run her sawmill, business partner 
Ashley objects. He doesn't want her to mistreat the white prisoners, and Scarlett doesn't want to pay for expensive freed slaves.

Ashley: I will not make money out of the enforced labor and misery of others.

Scarlett: You weren't so particular about owning slaves.

Ashley: That was different. We didn't treat them that way. Besides, I'd have freed them all when father died if the war hadn't already freed them.

Scarlett certainly points out the fallacy of Ashley's whole argument. Ashley who, along with the lovely Melly, constitutes the metaphor for the "Old South" can't easily argue with Scarlett's point. He can claim that he would have released the slaves after his father's death, but based on the fact that Ashley has spent the entire film up until this point pussyfooting around every issue and not taking a firm ideological stand on much of anything concrete, it doesn't seem very likely. Ashley's form of "old South" equivocation isn't the only traditional metaphor at play in regards to the complicated relationships between the white hegemonic structure in the film, and the African American slave characters. Hattie McDaniel's academy award winning portrayal of Mammy is layered and surrounded by complex relationships. Clearly Mammy appears to have power over Miss Scarlett, and clearly she feels very much a part of the O'Hara family. In addition to taking pride in the way that she had raised Scarlett (making sure that she ate like a bird at the Wilkes barbecue, even if it violated the custom of showing her bosom before 4:00, and making sure that Scarlett had flawless skin by helping her bathe in buttermilk) she isn't shy about showing her disdain for poor white trash like the Slattery family. She even intervenes several times when Scarlett is about to make a fool of herself over Ashley. 
Her relationship with Captain Butler is very agreeable, too. He brings Mammy a red taffeta petticoat from his honeymoon, and the night that Scarlett labors with Bonnie, the two of them cheerfully spend the evening tossing back drinks.

Rhett: Have another glass, Mammy. What is that rustling noise I hear?

Mammy: Lordsy, Mr. Rhett. That ain't nothing but my red silk petticoat you done give me.

Rhett: Nothing but your petticoat? I don't believe it. Let me see. Pull up your skirt.

Mammy: Mr. Rhett, you is bad. Yeah, oh, Lord!

And later, when little Bonnie Blue dies, Mammy is as broken up as the rest of the family, and her hushed conversation with Melly regarding Rhett's state of mental heath reveals affection and concern.

By making the African American men in the film into paternal, harmless protectors of white virtue (as in the case of Big Sam in the Shanty Town), the film can, to a certain extent, alleviate the anxiety related to "intermixture." By making Mammy and Pork docile, and most of the other interracial relationships positive and productive, the film can easily suture over these worries regarding a social uprising related to African Americans. And by finding Prissy to be annoying, we can allow her to carry the burden of Scarlett's bad behavior as well as the mitigating circumstances that put children like Scarlett and Melly and Ashley's baby (and eleven year old Prissy, for that matter) in incredibly dangerous circumstances. So even though the Depression was a failing of the system (patriarchy) that allowed for thousands of children to be forced to ride the rails under unbelievably dangerous conditions, and the Civil War was a failing 
of the system (patriarchy) that allowed for children with no training to deliver a baby in the middle of city under siege, it is easier to shift the blame to the children who were victimized, instead of the adults that allowed these things to happen.

I would propose that Prissy sticks out in our mind for another reason, though. While Mammy, Pork, and Sam follow the trajectory of the happy-to-serve-the-master-loyal-blackservant role, Prissy never seems to be on the same page. Mammy is desexualized, while Pork and Sam are gentle and loyal. All are happy to serve and feel a place within the white Patriarchy around them. But Prissy takes this docility and converts it to something else, something that undermines the whole system: Passive Resistance. Scarlett tells Prissy to go get the doctor; Prissy doesn't go. Scarlett tells Prissy to go or she will sell her "down south;" Prissy slowly wanders back singing about how much longer she must "tote the weary load." Scarlett tells Prissy that they must deliver the baby themselves; Prissy points out that she doesn't know how to deliver a baby. Scarlett slaps Prissy; Prissy continues to do whatever she wants (including telling Rhett that she delivered the baby herself.)

Prissy continually plays the part of the "bad child" who also does whatever she wants, and subverts the entire system upon which the institution of slavery is built. The relationships between white slave-holders and servants like Mammy, Pork, and Sam may ultimately cover over and conceal the racial and economic anxieties felt by 1930s audiences who were watching a film about the Civil War. But Prissy isn't easily concealed. She doesn't participate in the narrative agreement that the slaves at Tara were happy to be part of the family and were loyal to the bitter end. Like Scarlett, she does what she wants in the way that she wants. And because the film was designed to be shown to a white viewing audience, her inability to participate in that 
agreement makes her more bothersome. She disrupts the narrative. Not only is she a bad child, but in the narrative of the Old South where slaves were a little less than human, her subversiveness and passive resistance make her worse than Scarlett. And her behavior makes her a sticking point in the otherwise illusory and aesthetic version of pre-emancipated Georgia.

The 1939 film viewer was otherwise certainly treated to a vision of the ante-bellum south that was honorable, beautiful, and well-designed. In Margaret Mitchell's novel, Tara wasn't a beautiful mansion with pillars, and Gerald O'Hara wasn't a member of the Aristocracy. Tara was, instead, a square brick house, and Gerald O'Hara was an Irish immigrant who had managed to make a lot of money and had married a woman who was from a good family and was a very good manager. In fact, as I mentioned previously, much has been made by some critics who felt that Mitchell's book was, in many ways, subversive and critical of the antebellum world.

Not so much in the Selznick film. In fact, the opening lines about cavaliers, cotton fields, knights, and ladies fair illustrate a fantasy land that, though appealing, never existed. The pillared mansions, the image in our mind of plantations and magnolia trees that we have of the South were pretty much manufactured by machinery of Hollywood. Helen Taylor points out that this pattern of setting up an idealized version of the "Old South" in film certainly didn't begin with Selznick's picture. Films like Dixiana, Dixie Days, and of course the Shirley Temple vehicles like The Little Colonel, The Littlest Rebel, and Dimples, along with Gone with the Wind presented to Depression-era audiences nostalgic and idealized images of a feudal 'paradise lost' of large plantations, white-columned mansions, beautiful Southern belles and their chivalrous beaux, against a backdrop of loyal and humorous slaves (14-15). 
In fact, many critics suggest that this film actually re-invented the image of "The South" for the twentieth century.

Tara stands positioned as a kind of ur-simulacrum, at the threshold of the South's entrance into the cultural industry and its subsidiaries -- the heritage industry, the nostalgia industry, the tourist industry, and so forth -- by distinctively mixing memory and desire. More specifically, Gone with the Wind enacts -- and in enacting, constitutes - the commodification of southern culture, reproducing the South not as home (inhabited place), but as homesickness, as an object of nostalgia in both the spatial and temporal senses of the word. (Romain 28-29)

In other words, the film evokes comforting feelings for country traumatized by financial collapse. They become, in effect, homesick for the good old days that never really were.

To take it a step further, if one applies a New Historicist lens to the the film, the subject matter isn't just about creating an imaginary heritage that is a sense of comfort to a group of people in the midst of trauma. And it isn't just about providing an idealized cultural touchstone to a people in the midst of adversity. Instead, a more insidious agenda begins to emerge. Alice Randall, author of the notorious 2001 parody of the story provides an intertextual reference not to what was explicit about the south in the original story, but what was unsaid. 
I think Gone with the Wind in fact is more significantly understood as propaganda for the perpetuation of Jim Crow segregation that existed in the 1930s. It's more about that than it is about the Civil War. It's as much about what the future should be, than what the past is. (qt.. in Wallace-Sanders 136)

And if the past was gone anyway, why not, as Kimberly Wallace-Sanders points out, "replace the negative image of slavery as an institution of dominance with a nostalgic fictional representation of interracial harmony" (97).

Except there were plenty of people alive in 1939 who could, if they chose, remember the implications of the Civil War. In 1936, Life magazine featured an article about houses in Georgia that survived the Battle of Atlanta. Margaret Mitchell would have been aware of these houses as she wrote her novel. Accompanying the piece was an interview with octogenarian Lucinda

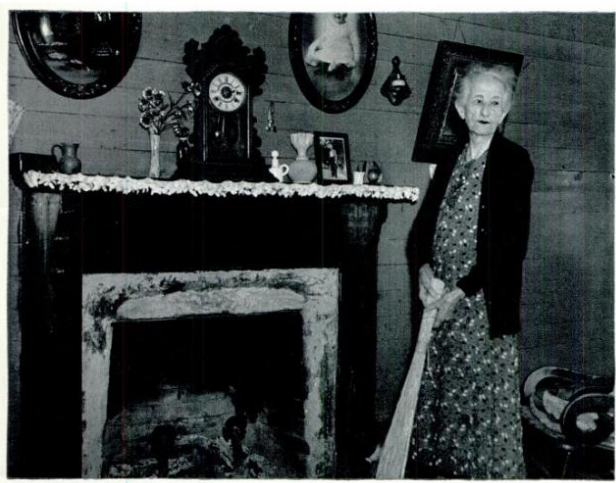

Figure 7: Lucinda Hardage was 16 during the Battle of Atlanta. In 1936 she remembered that she was picking beans for supper when Confederate General Loring rode across her family farm. It stands to reason that she could remember many of the atrocities of slavery as well.
Hardage, who remembered the battle quite well, as she was a young teenager living outside of Atlanta who could hear the cannon fire as she picked beans. Many African American people who were born into slavery were still alive, and certainly their children were. In fact, Roosevelt's WPA workers were dispatched to do oral histories with former slaves. Inarguably, the events that had occurred in Atlanta during the Civil War were just as relevant and fresh in the collective consciousness of 1936 Southerners, as the events of December 7, 1941 (the 
bombing of Pearl Harbor) would be in the minds of many Americans in the year 2013. Even if you yourself didn't remember the event, it was a watershed moment in the lives of your parents or grandparents, and therefore the topic of conversation and public and domestic narrative.

As Deborah Gray White's book, Aren't I a Woman (which was based in large part on those WPA interviews conducted with former slaves) explains, the life of a slave wasn't like the ones depicted in Selznick's film. It wasn't unusual for women who were slaves to be used for sex and regularly assaulted. It wasn't unusual for slaves to serve masters that were at the very least half brothers and sisters. One had only to look at the proliferation of light-skinned slaves in the 19th century and their descendants in the 1930s to be painfully, shockingly, and constantly aware that miscegenation had been an issue for African Americans somewhere along the line. In her book Southern Horrors, Crystal Feimster points out that during the Civil War, white women were far less worried about being raped by black slaves than they were by Union soldiers (hence Scarlett and Melly's willingness to shoot the Union soldier that had invaded Tara.)

Despite these attitudes, the narrative of oversexed black brutes violently lusting after virtuous white southern women continued to be in effect during reconstruction, and clearly well into the 1930s based on the reaction to the Scottsboro Boys debacle. In fact, one could easily argue that the racial fantasy that imprisoned the Scottsboro Boys was, in fact, partially based on the fear of childhood sexuality and the inability for patriarchal values, ideals, and practices to contain it. Because people were out of

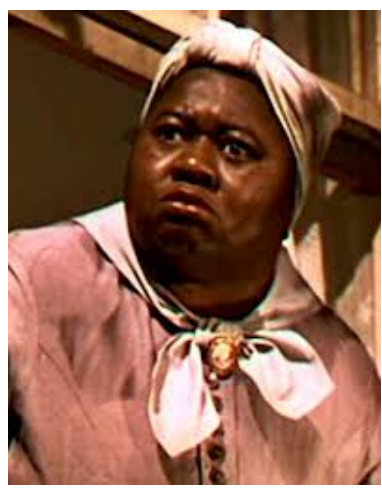

Figure 8: Making sure that Mammy was morbidly obese was one way of desexualizing the destabilizing influence of female slaves on plantations who were used as sexual entertainment and as breeding stock. 
work and times were hard and fathers couldn't provide for their families, minors were forced to ride the rails, and look for work and consort with other young people -- many of whom were lower-class and even black. But most importantly, with limited agency due to low economic status, what was once the hegonomic authority was hobbled in its attempt to control the sexuality of women and children. .. and its minorities.

Therefore, instead of overtly being more accurately portrayed as possible (probable) sexual partners to Gerald O'Hara, Ashley, and Rhett, African American women like Mammy and Prissy are desexualized. Mammy is morbidly obese and obviously elderly, while Prissy is painted as a grotesque, comical, and unappealing child. In reality, a Southern man of Rhett's station would have had more interest in bringing lingerie home to his wife's servant than just hearing a red taffeta petticoat rustle. In light of that knowledge, the scene of Mammy drinking and coyly teasing, "Mr. Butler, you is bad" after he directs her to lift up her skirt take on a whole new meaning. Molly Haskell points out,

For white upper-class women, accepting their own idealization means a conspiracy of silence and denial where brutality and the philandery of their husbands, often with slaves, is concerned.

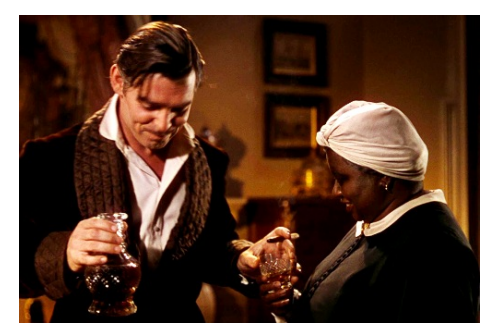

Figure 9: Despite the good cheer pictured here, historical evidence suggests that when a master offered a female slave a few drinks, his motives were probably not as pure as Captain Butler's seemed to be on the night of Bonnie's birth.

The logic of female dependence, the

enforced sense of vulnerability rests on the idealizing and, more important, protective services provided by men. But with the war there is a crack in the facade. The absence of husbands opens up a chasm. (location 1950) 
The desexualization of the female slaves, as well as the unsympathetic and hostile portrayal of characters like Prissy and Reconstruction-era African American men comically rolling their eyes at the suggestion of 40 acres and a plow had the distinct effect of alienating white viewers from the plight of human trafficking, and aligning them with the "noble" and "chivalrous" white southerners. When Prissy sings the words, "We must tote the weary load" from Stephen Foster's nostalgic ballad, the juxtaposition of a stupid and stubborn child who is not appropriately alarmed by the seriousness of dear Melly's situation evokes frustration and anger from the audience. When Prissy complains about having to do field-hand type chores once they have returned to Tara when everyone is half-dead and she says she can't do the work, it isn't difficult to have sympathy with Scarlett, Melly, Ashley and Rhett. Who wouldn't want to be in a world in which you can physically abuse stupid and unreliable people? By the end of the film, Selznick has done a lovely job of whitewashing an ugly situation. It isn't hard to imagine the antebellum south as a place where everyone got along well, and Mammy was happy to take care of the O'Haras and get drunk with Rhett (and accept his innocent gift of a red taffeta petticoat). After all, this is the world in which faithful manservant Pork was honored to have his master's watch, and when Prissy was scolded into place, she clearly deserved it.

But, just as importantly, as Haskell has pointed out, there is a crack in the foundation of the whole system. Men were unable to be gallant protectors because they were off at war in the 1860s. And in the 1930s, men were often unable to find work. Not only were they not able to provide for their own families, but their own self-sufficiency was in question. In both eras, women were forced to (or had the opportunity to) to step up and lean in and fight for survival. If Scarlett could make it while Atlanta was burning around her, then the average housewife could 
stand a chance in the face of her husband's unemployment, soup lines, and economic collapse. It was bad, but at least the Yankees weren't coming to get you!

In his work on blackface minstrels of the eighteenth Century, Eric Lott suggests that blackface is used as a "distorted mirror" of the values and issues that faced the white working class members of their typical audience, and that this form of entertainment used both sympathy and derision along with sentimentality and ridicule to play upon the audiences fascination and fear of African Americans (8). Much of the same could be said of Selznick's use of the black characters in Gone with the Wind. Prissy, Mammy and Pork become distorted reflections of white characters. Mammy reflects Mrs. O'Hara's authority and maternal instinct, yet is sexless and grotesque. She is more a mother to Scarlett than Mrs. O'Hara, and a better mother to Bonnie than Scarlett could ever be. As Wallace-Sanders points out, Mammy's force-feeding of Scarlett (and in the novel, Scarlett's mother) is really a metaphorical breast-feeding that infantilizes white women in the South (138).

Furthermore, when Pork takes the pocket watch from Scarlett, he metaphorically becomes Gerald. (She could stand anyone's tears, but his.) And Prissy is, of course, the site upon which we can heap the negative aspects of childhood. She lies, is lazy, and makes up ridiculous stories. She does what we hate Scarlett for doing. But she isn't as pretty, as white, or as rich.

The viewing audience can have sympathy for, and be sentimental about, the slaves of long ago who had to put up with the spoiled and pampered Scarletts of the world, but who were loyal and knew their place in the class order of the plantation. At the same time they can ignore Mammy's sexuality, scoff at Prissy's idiocy, and roll their eyes at a slave who thinks that a 
carpetbagger's promises of 40 acres and a mule are anything more than a new type of slavery.

For as the working class citizens of the 1930s knew all too well, having land and a mule didn't mean that the dust bowl wouldn't ruin you, or that that the crops wouldn't fail, or that a twister wouldn't destroy your house (if you had one), or the bank wouldn't foreclose on your land, or your rich neighbor wouldn't have your dog destroyed, or you wouldn't be able to provide for your family. The white working-class members in the audience could feel superior in the knowledge that even if they were poor, they were vastly superior to the black rubes on the screen who were simply being released from one type of servitude into another hideous economic situation in which there were no guarantees.

It is for just these reasons that the film has often been considered a rallying cry for the poverty stricken of the Great Depression. As Scarlett returns to Tara and announces that she will do whatever it takes never to go hungry again, so go the Okies and desperate and hungry victims of economic collapse of the 1930s. It was almost as if Scarlett was speaking directly to an audience who had vowed never, ever to be caught unprepared again.

Well, make that a white audience who had vowed never to be unprepared again. Because, clearly, the trope of the happy-to-be-here-loyal black servant of the 1930s wasn't an issue to be tackled by this women's film, at least overtly. The nostalgic representation of interracial harmony was simply too intertwined with the construction of fantastical white womanhood being celebrated in the 1930s. The closest we get to exposing the issues of race is our dislike for Prissy, but she's such an unappealing character on so many levels, that although every time she appears on screen she disrupts the narrative a little bit more, it isn't enough to pull the curtain back and 
reveal the whole, sordid, foundation. Instead, it is just enough to make the audience feel uncomfortable and resentful towards the child.

What does happen in this film, is that the white heroine completely and repeatedly manipulates the patriarchal behaviors, customs, and ideals of world in order to get what she wants. In "Film and the Masquerade," Mary Anne Doane appropriates Joan Riviere's concept of feminine flirtation as a sort of Masquerade used by women to create a distance between the woman as object and the woman herself (82). It is almost as if Scarlett uses her whole "fiddledee-dee" routine along with the ruffles, bows, and hoopskirts as a masquerade to divert the rest of the characters in the film from understanding exactly how determined she is to accomplished what she wanted to accomplish.

The over-use of feminine-wiles to gain agency is consistent with both the life of the person who created Scarlett and the original novel itself. Much has been made by Mitchell biographers about the fact that Mitchell, herself a 1920s party girl, never managed to fit in to the white southern aristocracy around whom she was raised in Atlanta. She scandalized the Junior Women's League with her racy version of the apache dance, she left Smith after only one year, and she was a career journalist until she managed to break her ankle and write Gone With the Wind out of boredom (or so the legend goes). Throughout the novel, Scarlett questions hegemonic issues for women of her time, including war, the wisdom of having babies, and the social structure of plantations where the women are complicit in creating an illusion of competency among their husbands as they themselves manage the operations.

In The Female Complaint, Lauren Berlant states that, "For a woman committed to romantic fantasies of love as reciprocity to break with the normative emotional bargains is to 
threaten her participation in the good life that seems to unfold from desire and to be maintained by ordinary emotional labor." (19)

In other words, if women maintain and believe the phantasmic version of heteronormanative relationships, then everything should work out well. If you believe and work toward the fantasy, then good things will happen. If you stop believing, though, it won't work out too well. Except that, save her infatuation for Ashley, Scarlett stopped believing romantic fantasies about the time she returned to Tara to find her mother dead, her father deranged, no food, and a bunch of mouths to feed. In the "Old South," the Melanies and the Ashleys had believed in fantasy and romance, of "cavaliers and cotton fields," of "knights and their maidens fair," and of course of gallantry. Scarlett started believing in true grit, in doing whatever it takes to put one step in front of the other, of lying, cheating, stealing, or killing (all of which she manages to do in the second act) in the name of putting bread on the table, and hoping that nobody notices -- or maybe not caring if anyone notices. And if it meant that she had to use her looks to steal her sister's boyfriend, or whimper in order to get Ashley to stay in town, or flirt to get information, or get dressed up in drapes in order to seduce a man into giving her the money to save Tara, she was more than willing to do it.

But because she still clung desperately to the romantic notion of what true love with Ashley would mean, she never quite matured. And as long as she was in this "in-between" spot, between childhood and womanhood, she could be manipulated by the likes of Dr. Meade who wanted her to stay in Atlanta to save Ashley's child (as opposed to saving her sister-in-law and companion, Melly), and could be a child who Rhett could pamper and spoil. As long as she 
performed the role of the beautiful southern belle, her bad behavior could be overlooked and excused and she could always be written off as a child.

Scarlett continually gains material resources, not in a mature way, but in a way not so different from the girl who had to be goaded by her mammy into eating before a party. Scarlett continues her immature and egocentric ways. When she attends a dance dressed in mourning attire, she dances the Virginia Reel with Rhett anyway, despite the impropriety (and rather bad taste) of dancing at a party immediately after her husband dies at war. When she wants money, she goes to Rhett and tries to use her flirtatious charms to get it. When that doesn't work, she marries her sister's boyfriend. When she doesn't want Ashley to leave, she manipulates Melly into cajoling him to stay. When she is worried that the baby has caused her to gain weight, she tells her husband that she will no longer share his bed. She uses prisoners as laborers, even though her comment to Ashley regarding his willingness to own slaves reveals her rather sophisticated understanding of human rights issues. And she continually puts herself in dangerous situations that ultimately lead to the death of one of her husbands. Although Scarlett may be playing a child, it is a role that the patriarchal South was all too happy to have her play. In fact, the character who most seemed interested in infantilizing Scarlett was none other than everyone's favorite, charming scalawag: the dashing Captain Butler.

The Encyclopedia of American Masculinities suggests that as the Great Depression dragged on, men were forced to "reconsider their notion of masculinity in light of the now more limited prospects for success." (Great Depression) During the 1920s a "modern" masculinity had begun to develop that privileged "personality over character and flexibility over determination and pride." A man who could make a fortune running blockades, explain the 
foolishness and self-defeatism the war could bring, yet join the glorious cause anyway, make friends and join a regular poker game with his warden while a POW, and get the old-guard of post-war Southern ladies establishment to approve of him (and his progeny) despite his checkered past and associations with carpetbaggers and vulgar nouveau rich was just this sort of person. In 1936, Dale Carnegie published the infamous How to Win Friends and Influence People, but had Captain Butler not been a fictitious character, he could have written it. "Carnegie argued that if male success is no longer preordained but precarious, then modern men had to advertise themselves in order to gain status and income."(American Masculinities)

In other words, good old puritanical values were no longer enough. It wasn't just a matter of being hard working and honest. You needed to be charming and interesting, too. In his book, Manhood in America, Michael Kimmel says that different visions of manhood competed for dominance during the early part of the 19th century, including the concept of the "Genteel Patriarch" and that of the "Self-Made Man."

On one hand there was the chivalrous Ashley whose dedication and loyalty was both noble and effete and on the other there was Rhett Butler who was both a rogue and a scoundrel who thinks of no one but himself, a model selfmade man whose individualism prevents any connection with lofty noble contrivances such as country and honor. (220)

Undoubtedly, Rhett was a self-made man who didn't care about anything other than control over his own body and own life. He makes that clear from the outset when he meets Scarlett at Twelve Oaks. 
Scarlett: Are you tryin' to tell me you don't believe in the cause?

Rhett: I believe in Rhett Butler. He's the only cause I know. The rest doesn't mean much to me.

Kimmel points out that the "contrast between Rhett and Ashley represented the fantasy of the triumph of the self-made man as hero" (221). And that once their "competitive individualism" and "callous indifference both to other people and political cause" won out over the other images of masculinity, those characters were guaranteed to seduce the woman (221). When Rhett (like Bogart's Rick would in Casablanca in the 1940s) finally "finds himself putting aside his selfcenteredness and taking a moral or political stand for good," (the Glorious Cause for Rhett, and the Resistance for Rick), the audience, by extension, is seduced (221).

It seems, then, apparent that virtuous Melanie and chivalrous Ashley represent the "Old South" and gender codes, while engaging Rhett and scheming Scarlett represent a new symbolic order. One thing is for sure, though. Scarlett may well have represented the image of a new sort of girl, but no one in the film wants her to be a woman --least of all, Rhett. When he sees her after he has been released from jail, he taunts her for her immature gendered games.

You still think you're the belle of the county don't you? That you're the cutest little trick in shoe leather. Every man you meet is dying of love for you.

It is later in the film, that his true feelings in regards to Scarlett's immaturity become obvious. It is once Melly dies, and Scarlett realizes that she isn't much interested in Ashley after all, that Rhett reveals his true feelings for the relationship he wanted with Scarlett. 
As long as there was Bonnie, there was a chance we might be happy. I liked to think that Bonnie was you. A little girl again, before the war and poverty had done things to you. She was so like you, and I could pet her and spoil her as I wanted to spoil you. But when she went, she took everything ... My darling, you're such a child ... Here, take my handkerchief. Never at any crisis of your life have I known you to have a handkerchief.

The problem is, Scarlett hasn't been a child for a long time. Scarlett goes from being a child to being someone with the body of an adult and the psyche of ... not an adult. She isn't a child and she isn't an adult for nearly all of the movie. She is, in fact, a teenager. Her egocentric and immature behavior is pretty much what is commonly considered to be standard issue for an adolescent.

This observation is somewhat significant because up until the early 1940s, there was no word in the vernacular to describe the concept of a teenager. The 1920s had flirted with the Flapper, but ultimately the word became more associated with a style than of chronological age. According to Steve Mintz, record numbers of adolescents were staying in school longer during the Depression (twice as many graduated from high school in 1940 as had in 1929) which pretty much solidified the teenage years as being a distinct period of life. Film stars like Lana Turner, Mickey Rooney, and our "New Girl" Judy Garland, brought the concept to new heights as they starred in films featuring young people with their own culture frequenting soda shops. So, as Rhett falls in love with a young, egocentric, narcissistic, child-in-a-woman's body, we begin to 
realize that he wasn't falling in love with an actual woman. He was falling in love with the idea of a perpetual teenage girl.

It is my supposition that the masculine anxiety that is being sutured in this film revolves around the fear of unbridled childhood (or teenage) sexuality, and the inability of the patriarchal cultural customs to contain it. Because of the economic prolapse, and because of the lack of jobs, and because so many children were doing what ever it took (including catching a box car and riding the rails, like Price, Bates, and the Scottsboro Boys) to survive, the whole underpinning of the traditional concept of "family" seemed to be eroding. Unbridled sexuality was dangerous, and to a hegemony already ill at ease due to threats of insurgency (remember, the Civil War was in living memory and the population that had been enslaved now had the right to vote) and racial intermixture (which is what could have happened if Ms. Price or Ms. Bates had gotten pregnant on that boxcar) was very troubling indeed. Furthermore, the lack of boundaries represented by young adults (who were too young to be traveling alone in the first place) hopping boxcars (instead of buying tickets for passenger trains), which enabled black and white passengers to ride together (instead of being segregated) represented a society out-of-control.

When compared to the perceived chaos of the Depression, with its destabilized families, out of work fathers, mothers supporting the family bottom line, and white young women possibly engaging in sexual intercourse with black young men, the nostalgia of Scarlett and Tara would have been very appealing to the anxiety-ridden status quo. A world in which men and women knew their place, and in which people of another race were cheerful, helpful, and understood that they were a subordinate part of the family would have been a welcome relief. A family in which the head of the household never asked the slaves to do more than they asked of other members of 
the family, and in which the women weren't sexual hostages and plantations weren't an incestuous intermixture of half-brothers and half-sisters separated by a caste system based on breeding and skin color, wouldn't have seemed so terrible. Instead it depicts the re-containment of the entire African-American population within the idealized structure of the nation itself as a (white) family, with the black population participating in the agreement of subservience.

A film like Gone With the Wind helped ease fears by establishing a sense of nostalgia and affirmation that if a country can survive the societal collapse and poverty of the American Civil War, it can survive the collapse and poverty brought on by the Great Depression. It also mostly affirmed the hegemonic belief (denial) that racial issues on plantations were mostly positive, and that black people were so ontologically different that there was little chance of intermixture between the two groups. Finally, it suggested that unruly teenage girls who don't subscribe to societal norms in regards to femininity may well be successful in some arenas and may have some agency (Scarlett does survive and have Tara, after all), but ultimately will never find true love and happiness which they have been conditioned to desire.

But in the south, or at least the cultural memory of the "Old South" that maybe never was held by the movie-goers in the 1930s, teenage girls could be sexy, and it was acceptable for Rhett Butler, Ashley Wilkes, Charles Hamilton, and Frank Kennedy to marry them and to impregnate them. Melanie's naivety and Scarlett's reckless and unrestrained behavior could be overlooked, or considered charming. But once these women reach some emotional maturity, the romance, and the narrative, simply no longer work. Melanie's selflessness manages to get her pregnant for a second time, which is her death sentence. And once Scarlett becomes emotionally evolved, self-aware, and sensible, she is no longer of interest to Captain Butler. 
When Melanie (the last beautiful vestige of the old South) dies and leaves Ashley looking flaccid and pathetic, Scarlett realizes that her feelings for Ashley were childish and immature. But as Scarlett finally comes into her true womanhood, Rhett can't stand it. As long as Bonnie was able to serve as her fetishistic stand-in, it might have worked. But now that Scarlett has grown up emotionally, he isn't interested. The new American Masculinity knows what it wants, and what it wants is a girl who can be "spoiled and petted," and never has a handkerchief "at any crisis of [her] life," and who thinks she is "the cutest trick in shoe leather." According to David Gaillard, "He's got to go as long as he feels that Scarlett should have remained a child. His leaving is not a mark of strength, but of weakness and of blindness, the blindness that tradition has produced." (18) Scarlett can grow up and take on the world. And the audience can secretly root for her. But, in order to alleviate the anxiety of transition, we can never allow Rhett to approve of such a thing. So he must leave, to keep the turmoil of change from bursting the narrative apart.

I would propose that the film would never be as popular if Rhett had said, "Gee, you are right, Scarlett. I'm glad you have grown up a bit. Let's live the rest of our lives and be happy" at the end. Likewise, had Scarlett not looked us in the face and announced that she would get him back and that "Tomorrow is another day," it wouldn't have been popular. But by allowing Rhett to curse Scarlett, and allowing Scarlett to lift her chin and begin formulating a plan, the bourgeois American public could hate Scarlett and root for her at the same time. Rhett's denunciation of Scarlett is cathartic for the viewer, but it is a complex catharsis. The American viewing audience, with whom the film was so popular, is never in the position of approving of 
Scarlett's behavior, but they are in the position of hoping that "true love" will win out at some point in the not-too-distant future.

What Selznick does with this film is, on every single level, a masterpiece. He creates a world in which there was a harmonious relationship of shared happiness between people of color and people who were white, and he creates a world in which, although everything is falling apart, hard work and determination and nerves of steel could keep everyone moving forward in the face of adversity. In the 1930s, relations between white people and black people were in no way harmonious. In Calls and Responses, Tim Ryan Points out that Gone With the Wind records how the Civil War violently eradicated the social order of the slaveholding South -- but its narrative conceals the degree to which the white power structure of the region subsequently restored its traditional plantation system and all but reinstituted slavery through an exploitative feudal agricultural system and racist Jim Crow legislation. (66)

Legislation, I might add, that was still going strong in the 1930s. He creates a South that is more Southern than the South ever was, thereby searing a nostalgic image of happiness and harmony into the brains of a nation's people who could, collectively, still vaguely remember a world in which it was perfectly legal and common to sexually exploit black women for sport and pleasure, kill black men, and try to pull a country apart through a long, bloody, and destructive Civil War.

Scarlett becomes, in this film, the unrepressed, unrestrained, looks-good, can-do American Spirit to take the United States out of a Depression and into a war that would support the economy for the next few decades, make them a world power, and depend on the women of 
the household to keep things going in a crisis. And instead of using melodrama and the "sentimental bargain of femininity," she manages to plow ahead and avoid allowing emotional cache to "be proximate to this story of emotional centrality" (Berlant 19).

Ultimately, this film is able to alleviate anxieties of economic uncertainty and racial integration being felt by the viewing audience. But the interaction between Scarlett and Rhett in the final scene indicates Rhett's rejection of Scarlett's true maturity and empowerment. It lays bare the tensions between their two genders in a way that becomes a complex catharsis for all of the New Girls in the audience. Scarlett becomes both a true vessel of the American Spirit, and the dire warning to a generation. The audience wants to see them together, but knows that Scarlett's behavior has not been conducive to keeping the relationship afloat; no one is surprised that Rhett has reached his limit. (The audience has been buying into the patriarchal myth of the Old South for the past three hours, after all.)

Throughout this dissertation, I have attributed the eroticization of female children in 1930s film to the destabilized masculinity brought on by the Great Depression and the subsequent reconstructed, decidedly white, decidedly adult, and decidedly upwardly mobile male identity. The anxieties produced by any threat to this new American male, including racial (in)equality, shifting gender roles for women, and the disintegration of patriarchal agrarian family values were neatly sutured over in films that featured little girls as heroines, fetishes, and metaphors. But Selznick's work stands out due to its fabulous popularity from the time that it was released to the present day.

It is my supposition that this work has endured because it doesn't effectively suture all of the issues of race, class, and gender that were of such distress during the Depression. Although 
the nostalgic image of the Old South and its ability to reconstruct itself from its own ashes would have been of comfort to the masses in the late 1930s, and although the image of racial harmony illuminated by the idealistic, revisionist vision of plantation life would have eased much of angst in regards to race relations, there is no resolution for the gender issues. Scarlett does remain complicit with patriarchal norms for nearly all of the film. By painting her as a character who possesses the flirtatiousness of Shirley Temple, the fetishization of Laurel Dallas, and the competent industrialism of Dorothy, Scarlett becomes the ur-woman-child. Her sexuality and abilities combined with her inexperience and lack of maturity create the ultimate white American Masculine Fantasy: the teenage girl.

In the end, it is clear that Scarlett can't and won't be contained. Once she moves past the fantasy of Ashley, the last vestiges of adolescence are gone. Unlike her mother and Melly who grew to adulthood and allowed their selflessness to claim their lives, Scarlett grows into a woman that sees the world and has agency. Rhett can't live with that.

But maybe much of the film's popularity had to do with an America that was more ready and accepting of a woman with agency. The 1930s were coming to an end, the Depression wasn't as severe, and bad things were happening in Europe. Softening the tensions related to financial hardships and a country's failed emancipation were still necessary, but allowing a space for a woman who could save everyone seems appropriate for the time immediately leading up to World War II.

Before there was Rosie the Riveter who could keep things going till Johnny came marching home again, there was Scarlett O'Hara. Scarlett, who like the moppets, the new girls, 
the former flappers, and lollipop licking teases would do whatever it took to make sure that neither she nor her "folk" would ever "be hungry again!"

As God is my witness, as God is my witness they're not going to lick me. I'm going to live through this and when it's all over, I'll never be hungry again. No, nor any of my folk. If I have to lie, steal, cheat or kill. As God is my witness, I'll never be hungry again! 


\section{FIGURES CITED: CHAPTER 1}

Figure 1: "Smart Fashions for Limited Incomes: Economies which the Spring Mode Proposes and the Clever Woman Disposes-A Shop Where the High Cost of Dressing is Reduced to its Lowest Terms without Sacrificing One Jot of Individuality." March 15, 1913. The Vogue Archive. Web.

Figure .2: Louise Brooks, photograph 1920s, (Motion Picture and Television Photo Archive, Image Collection.) Accession Number imh206048. Web.

Figure 3: Fitzgerald, Zelda. "Looking Back Eight Years." Article. College Humor. January 6, 1928. Web.

Figure 4: "Fashions: Helen Hayes, White Organdy Sister." May 15, 1933. The Vogue Archive. Web.

Figure 5: Mae West. Sentinel Archive Photo. "Controversial Mae West Play 'The Drag' Get's Reading." January 25, 2011. Orlando Sentinel Online. Web.

Figure 6: Dance, Fools, Dance, VHS Video Cover, original film 1931. amazon.com. Web.

Figure 7: Time. Magazine cover. 04 January, 1937. Web.

Figure 8 Duke and Duchess of Windsor Wedding Party. Photograph. Bridgeman Education Database. June 3, 1937. Image \#STC 340890. Web.

Figure 9: Duccio, Rucellai Madonna, tempera on panel, begun 1285, (Florence, Galleria degli Uffizi,) Web.

Figure 10: -- Raphael: Madonna of the Meadow, oil on panel, 1505, (Vienna, Kunsthistorisches Museum) Web. 
Figure 11 -- Homer, Winslow: Snap the Whip, oil on canvas, 1872, (New York, Metropolitan Museum of Art) Accession ID: 50,41. Web.

Figure 12 -- Norman Rockwell. Rosie the Riveter. Saturday Evening Post, Cover. May 29, 1943. Web. 


\section{FIGURES CITED: CHAPTER 2}

Figure 1: War Babies. Dir. Charles Lamont. Perf. Shirley Temple. Educational Film Exchange, 1932. Film.

Figure 2: "Shirley Temple Sets." Sears and Roebucks 1935 Catalogue. Blum, 77. Print.

Figure 3: "Shirley Temple Cuts the President's Birthday Cake." Los Angeles Times. Jan 30, 1937. Web.

Figure 4: Lange, Dorthea. The Migrant Mother. 1936. Prints and Photographs Div., Lib. of Cong., Washington DC. Dorthea Lange: Photographer of the People. Web.

Figure 5: Mary Pickford. 1922. Publicity Still from Tess of the Storm Country. 24 May 2013. IMDB. Web.

Figure 6: Lillian Gish. 1921. Publicity still from Orphans of the Storm. 2. 24 May 2013. IMDB. Web.

Figure 7: Fleischer, Dave. Betty Boop. N.d. Stock Photo. 24 May 2013. IMDB. Web. Figure 8: Temple, Shirley. 20th Century Fox Publicity still. N.d. May 2013 IMDB. Web.

Figure 9: The Little Colonel. Dir David Butler. Per. Shirley Temple. 1935. IMDB. Web.

Figure 10: Baby Take a Bow. Dir Harry Lachman. Perf Shirley Temple. Twentieth Century Fox, 1934. 


\section{FIGURES CITED: CHAPTER 3}

Figure 1: The Dionne Quintuplets photographed with Mitchell Hepburn. Library and Archives, Canada. Web.

Figure 2: The Dionne Quintuplets with Dr. Dafoe at Callandar. cardcow.com. Web.

Figure 3: Lysol Advertisement. Good Housekeeping. Page 128. December 1, 1934. Web.

Figure 4-12: Stella Dallas. Dir. King Vidor. Per. Barbara Stanwyck, Anne Shirley, MGM. 1937. Film. 


\section{FIGURES CITED: CHAPTER 4}

Figure 1: Amelia Earhart from the Purdue e-archives. Web.

Figures 3-11: The Wizard of Oz. Dir. Victor Fleming. Perf. Judy Garland, Ray Bolger, Bert Lar, and Jack Haley, Frank Morgan, Billy Burke, Margaret Hamilton, Charley Grapewin and the Munchkins. 1939. MGM/UA Home Video, 1989. DVD. 


\section{FIGURES CITED: CHAPTER 5}

Figure 1-6: $\quad$ Gone With the Wind. Dir. Sam Wood. Perf. Vivien Leigh, Clark Gable. Warner: 1939. Film.

Figure 7: "Gone With the Wind: Passes the Million Mark and Attracts Thousands of Readers to Scenes Like These.” Life. 28 December 1936: 18-21. August 2013. Web.

Figuress 8\&9: Gone With the Wind. Dir. Sam Wood. Perf. Vivien Leigh, Clark Gable. Warner: 1939. Film. 


\section{Works Cited}

Allen, Frederick Lewis. Only Yesterday: An Informal History of the 1920's. New York: Wiley, 1931. Print.

---. Since Yesterday: The Nineteen-Thirties in America, September 3, 1929 - September 3, 1939.

New York: Harper, 1940. Print.

Altman, Rick. The American Film Musical. Bloomington: Indiana UP, 1988. Print.

Aries, Phillipe. Centuries of Childhood. New York: Random House, 1962. Print.

Baby Take a Bow. Dir. Harry Lachman. Perf. Shirley Temple. Twentieth Century Fox, 1934.

Film.

The Bachelor and the Bobby-Soxer. Dir Irving Reis. Perf. Shirley Temple, Cary Grant. 1947.

Film.

Baudrillard, Jean. Selected Writings. Stanford: Stanford UP. 2001. Print.

Bazin, Andre. "The Evolution of the Language of Cinema." Film Theory and Criticism. Ed. Leo

Braudy and Marshall Cohen. 6th edition. New York: Oxford USA UP, 1999.41-53 Print.

Benjamine, Walter. "Art in the Age of Mechanical Reproduction." Film Theory and

Criticism. Ed. Leo Braudy, and Marshall Cohen. New York: Oxford University Press, 1999. 137-147. Print.

Berlant, Lauren. The Female Complaint: The Unfinished Business of Sentimentality in American Culture. Durham: Duke UP, 2008. Print.

Berman, Donald. "The Great Gatsby and the Twenties." The Cambridge Companion to F. Scott Fitzgerald. Ed Ruth Prigozy. Cambridge: Cambridge UP, 2002. 79-95. Print.

Berton, Pierre. The Dionne Years: A Thirties Melodrama. New York: Norton, 1978 
Blum, Stella, ed. Everyday Fashions of the Thirties as Pictured in Sears Catalogs. New York:

Dover, 1986. Print.

Bogle, Donald. Toms, Coons, Mulattoes, Mammies, and Bucks: An Interpretive History of Blacks in American Films. 3rd edition. New York: Continuum, 2006. Print.

Bourdieu, Pierre. Distinction: A Social Critique of the Judgment of Taste. Trans. Richard Nice. Cambridge: Harvard UP. 1984. Print.

Bright Eyes. Dir. David Butler. Perf. Shirley Temple, James Dunn, Jane Darwell, and Jane Withers. Fox Film Corporation, 1934. Film.

Broken Blossoms, or the Yellow Man and the Girl. Dir. D.W. Griffith. Perf. Lillian Gish, Richard Barthelmess. D.W. Griffith Productions, 1919. Film.

Captain January. Dir. David Butler. Perf. Shirley Temple. Twentieth Century Fox. 1936. Film.

Corliss, Richard. "That Old Feeling: A Stellar Astaire." Time. 22 June, 2002. Web.

"Cold War." American Masculinities: A Historical Encyclopedia. Thousand Oaks: Sage, 2003. Credo Reference. 2 Aug. 2010. Web.

Curnutt, Kirk. "F. Scott Fitzgerald, Age Consciousness, and the Rise of American Youth Culture." The Cambridge Companion to F. Scott Fitzgerald. Ed. Ruth Prigozy. Cambridge: Cambridge UP. 2001. Print.

Dance, Fools, Dance. Dir. Harry Beaumont. Per Joan Crawford. 1931. Film.

De Lauretis, Teresa. Alice Doesn't: Feminism, Semiotics, Cinema. Bloomington: Indiana UP, 1984. Print. 
D'Emilio, John. "Capitalism and Gay Identity." Powers of Desire: Politics of Sexual Identity. Ed. Anne Snitow, Christine Stansell, and Sharon Thompson. New York: Monthly Review P, 1983. Web.

Dickstein, Morris. Dancing in the Dark: A Cultural History of the Great Depression. London: W.W. Norton \& Company, 2009. Print.

Dimples. Dir. William A. Seiter. Perf. Shirley Temple, Frank Morgan, and Robert Kent. Twentieth Century Fox, 1936. Film.

Doane, Mary Ann. The Desire to Desire: Women's Film in the 1940s. Bloomington: Indiana UP. 1987. Print.

---. "Film and the Masquerade: Theories of the Female Spectator." Screen 23.3 (1982): 74-88. Print.

DuCill, Ann. "The Shirley Temple of My Familiar." Transition 73 (1997): 10-32. Web. Doherty, Thomas. Pre-Code Hollywood: Sex, Immorality, and Insurrection in American Cinema: 1930-1934. New York: Columbia UP, 1999. Print.

Doty, Alexander. "My Beautiful Wickedness: The Wizard of Oz as Lesbian Fantasy." Flaming Classics: Queering the Film Canon. New York: Routledge, 2000, 49-69. Print.

Ebert, Roger. "Stella.” Chicago Sun Times. 2 Feb. 1990. Web.

Elsaesser, Thomas. "Tales of Sound and Fury: Observations on the Family." The Genre Film Reader IV. Ed. Barry Keith Grant. Austin: Texas UP. 2012. Print.

Emblidge, David, ed. My Day: The Best Of Eleanor Roosevelt's Acclaimed Newspaper Columns, 1936-1962. Cambridge: Da Capo, 2001. Print. 
Farrell-Beck, Jane, and Jean Parson. 20th-Century Dress in the United States. New York: Fairchild, 2007. Print.

Feldstein, Ruth. Motherhood in Black and White. Ithaca: Cornell UP, 2000. Print.

Feimster, Crystal N. Southern Horrors: Women and the Politics of Rape and Lynching. Cambridge: Harvard UP, 2011. Print.

Finch, Christopher. Rainbow: The Stormy Life of Judy Garland. New York: Grosset \& Dunlap, 1975. Print.

Fitzgerald, F. Scott. Babylon Revisited and Other Stories. New York: Scribner, 1960. Print.

---. Flappers and Philosophers. New York: Cambridge UP. 2000. Print.

Fitzgerald, F. Scott and Zelda Fitzgerald. "Looking Back Eight Years." College Humor. June 1928, 36-37. Web.

Frank, Gerald. Judy. Cambridge: Da Capo, 1999. Print.

Friedman, Bonnie. "Relinquishing Oz: Every Girl's Anti-Adventure Story." Michigan Quarterly Review. 35. (1996): 1-28. Web.

Gage, Matilda Joslyn. Woman, Church and State: A Historical Account of the Status of Woman Through the Christian Ages: with Reminiscences of Matriarchate. Chicago: Kerr, 1893.

Google Book Search. Web.

Gaillard, David. "Gone with the Wind as Bildungsroman or Why Did Rhett Butler Really leave Scarlett O'Hara?" The Georgia Review, 28.1 (1974): 9-18. Print.

Gallagher, Tag. “Tag Gallagher Responds to Tania Modleski's 'Time and Desire in the Woman's Film' ("Cinema Journal," Spring 1984) and Linda Williams's ، "Something Else besides a 
Mother": "Stella Dallas" and the Maternal Melodrama' ("Cinema Journal," Fall 1984)"

Cinema Journal. 25 (1986): 65-66. Web.

Gledhill, Christine. "Christine Gledhill on 'Stella Dallas' and Feminist Film Theory."

Cinema Journal 25, (1986): 44-48. Web.

"Gloria Vanderbilt is a Ward of the Court." Lewiston Daily Sun 21 Nov 1934: 1. Web.

Gone With the Wind. Dir. Sam Wood. Perf. Vivien Leigh, Clark Gable, Warner: 1939. Film.

"Gone With the Wind Back: Film Will Return to Broadway for third Time on March 31." New

York Times. 23 March, 1942: 25. Print.

"Gone With the Wind: Passes the Million Mark and Attracts Thousands of Readers to Scenes

Like These." Life 28 Dec 1936: 18-21. Print

"Great Depression." American Masculinities: A Historical Encyclopedia. Thousand

Oaks: Sage, 2003. Credo Reference. Web. 18 July 2012. Web.

Greene, Graham. "Wee Willie Winkie. The Life of Emile Zola." Night and Day Magazine 28

Oct, 1937. Print.

Green, Joey. The Zen of Oz: Ten Spiritual Lessons from Over the Rainbow. Carson City: Renaissance Books, 1998. Print.

Grevatt, Martha. "1930s: The Women Were Fearless." Workers World 27 Mar, 2008. Web.

Haskell, Molly. Frankly My Dear: Gone with the Wind Revisited. New Haven: Yale UP, 2009. Ebook.

-- "Mae West's Bawdy Spirit Spans the Gay 90's." The New York Times on the Web. 15 Aug. 1993. Web.

-- From Reverence to Rape: The Treatment of Women in the Movies. Chicago: UP, 1987. Print. 
Heidi. Dir Allen Dwan. Perf. Shirley Temple. Twentieth Century Fox, 1937. Film hooks, bell. Black Looks: Race and Representation. New York: Routledge. 1992. Print.

Hart, Hornell. "Changing Social Attitudes and Interests." The President's Research Commission on Social Trends. New York: McGraw. 1933. Web.

IMDB. "Mini Biography -- Shirley Temple." IMDB. IMBD, Web. 24 May, 2013. Web.

Jewel, Richard. "RKO Film Grosses: 1931-1951." Historical Journal of Film, Radio, and Television Volume 14. Issue no 1 (1994): 33. Web.

Kael, Pauline. "Stella Dallas." The New Yorker. 66 June 18, 1990: 23. Print.

Kaplan, Ann. "Ann Kaplan Replies to Linda Williams's '”Something Else besides a Mother: 'Stella Dallas' and the Maternal Melodrama”' ('Cinema Journal,' Fall 1984)” Cinema Journal 24 Winter, 1985: 40-43. Web.

Kehr, Dave. "New DVDs: Shirley Temple." New York Times. 22 April, 2008. Web.

KeKimmel, Michael. Manhood in America: A Cultural History. New York: Oxford, UP. 1996. Print.

Kincaid, James. Child-Loving: The Erotic Child and Victorian Culture. New York: Routledge, 1994. Print.

---. Erotic Innocence: The Culture of Child Molesting. Durham: Duke UP, 1998. Print.

Knight, Arthur. Disintegrating the Musical: Black Performance and American Musical Film. Duke UP: Durham. 2002. Print.

The Little Colonel. Dir. David Butler. Perf. Shirley Temple, Lionel Barrymore. Fox Film Corporation, 1935. Film.

The Little Princess. Dir. Walter Lang. Perf. Shirley Temple. Twentieth Century Fox, 1939. Film. 
The Littlest Rebel. Dir. David Butler. Perf. Shirley Temple, John Boles. Twentieth Century Fox. 1935. Film.

Little Miss Marker. Dir. Alexandar Hall. Perf. Shirley Temple, Cary Grant. Paramount. 1934.

Film.

Littlefield, Henry M. "The Wizard of Allegory." The Baum Bugle. Spring, 1992. Web.

---."The Wizard of Oz: A Parable on Populism." American Quarterly 16.1 (1964): 47-53. Web.

Lott, Eric. Love and Theft: Blackface Minstrelsy and the American Working Class. New York: Oxford UP. 1993. Print.

Lolita. Dir. Stanley Kubrick. Perf. James Mason, Shelley Winters, Sue Lyon. Metro-GoldwynMayer (MGM), 1962. Film.

Lury, Karen. The Child in Film: Tears, Fears, and Fairy Tales. London: Taurus, 2010.

Print.

Man on Fire. Dir. Tony Scott. Perf. Denzel Washington, Christopher Walken, Dakota Fanning. Fox 2000 Pictures, 2004. Film

Monroe, Marilyn. "Diamonds are a Girl's Best Friend." From Gentlemen Prefer Blondes. Dir Howard Hawks. Twentieth Century Fox.1953. Film.

Merish, Lori. "Cuteness and Commodity Aesthetics: Tom Thumb and Shirley Temple." Freakery: Cultural Spectacles of the Extraordinary Body. Ed. Rosemarie Garland Thomson. New York: New York UP, 1996. 185-203. Print.

"A New Kind of College Graduate." The Milwaukee Journal. 31 May, 1936: 23. Web.

Michaels, Walter Benn. The Gold Standard and the Logic of Naturalism: American Literature at the Turn of the Century. Oakland: University of California UP, 1988. Print. 
Mintz, Steven. Huck's Raft: A History of American Childhood. Cambridge: $\quad$ Harvard UP, 2004. Print.

Nathanson, Paul. Over the Rainbow: The Wizard of Oz as a Secular Myth of America. State University of New York UP: 1991. Print.

Now and Forever. Dir Henry Hathaway. Perf. Gary Cooper, Shirley Temple, Co., 1934. Film.

Nugent, Frank S. "Stella Dallas.” New York Times. 6 August 1937: 21. Print.

Orphans on the Storm. Dir D.W. Griffith, dir. Griffith Productions, 1921. Film.

Ostrweil, Ara. "Reconstructing Shirley: Pedophilia and Interracial Romance in Hollywood's Age of Innocence." Camera Obscura: 24 (2009), 1-39. Web.

Petro, Patrice, and Carol Flinn. "Patrice Petro and Carol Flinn on Feminist Film Theory." Cinema Journal 25 Autumn, 1985 50-52. Web.

Michaels, Walter Benn. The Gold Standard and the Logic of Naturalism. Berkley: California UP, 1987. Print.

Modleski, Tania. The Women Who Knew Too Much: Hitchcock and Feminist Theory, 2nd Ed. New York: Rouledge, 2005. Print.

Mulvey, Laura. Visual and Other Pleasures, 2cd Edition. New York: Palgrave Macmillan, 2009. Print.

Phillips, Cabell. From the Crash to the Blitz: 1929-1939. New York: Macmillan, 1969. Print. Polhemus, Robert. Lot's Daughters: Sex, Redemption and Women's Quest for Authority. Palo Alto: Stanford UP, 2005. Print.

Polly Tix in Washington. Dir. Charles Lamont. Perf. Shirley Temple. Jack Hays Productions, 1933. Film. 
"Possible Formula for Screen Hit." New York Times 23 March1942. Print.

Riley, James Whitcomb. The Complete Works. Indianapolis: Bobbs-Merrill, 1916. Print.

Robertson, John S. Tess of the Storm Country. Perf. Mary Pickford. Mary Pickford Co., 1922.

Film.

Roosevelt, Eleanor. "My Day" United Features Syndicate. July 24, 1937. Web.

Roosevelt, Mrs. Franklin D. Roosevelt. It's Up to the Women. New York: Stokes, 1933. Print.

Rose, Jacqueline. The Case of Peter Pan, or the Impossibility of Children's Fiction.Philadelphia: University of Pennsylvania UP, 1994. Print.

Romine, Scott. The Real South: Southern Narrative in the Age of Cultural Reproduction. Baton Rouge: Louisiana State UP, 2008. Print.

Rushdi, Salman. BFI Film Classics: The Wizard of Oz. Worcester: Trinity Press, 1992. Print.

Ryan, Tim A. Calls and Responses: the American Novel of Slavery Since Gone With the Wind.

Baton Rouge: Louisiana State UP. Print.

Sanderson, Rena. "Women in Fitzgerald's Fiction." The Cambridge Companion to F. Scott Fitzgerald. Ed Ruth Prigozy. Cambridge: Cambridge UP, 2002. 145-162. Print.

Schwartz, Evan I. Finding Oz: How L. Frank Baum Discovered the Great American Story. New York: Houghton Mifflin Harcourt: 2009. Print.

Schwartz, Evan I. "Matilda Joslyn Gage -- the Unlikely Inspiration for the Wizard of Oz." American History Magazine. 24 September, 2009. Web. 13 September, 2012. Web. Sebba, Anne. That Woman: The Life of Wallis Simpson, the Duchess of Windsor. New York: St. Martin's Press, 2012. Ebook. 
Silverman, Kaja. "On Suture." Film Theory and Criticism. Ed. Braudy, Leo, and Cohen, Marshall. New York: Oxford University Press, 1999. 137-147. Print.

Siomopoulos, Anna. "'I Didn't Know Anyone Could Be so Unselfish': Liberal Empathy, the Welfare State, and King Vidor's 'Stella Dallas'"Cinema Journal 38 Summer, 1999: 3-23. Web.

Blum, Stella, ed. Everyday Fashions of the Thirties as Pictured in Sears Catalogs. New York: Dover Publications 1986. Print.

Stella Dallas. Dir. King Vidor. Perf. Barbara Stanwyck, Anne Shirley, MGM. 1937. Film. "Stella Dallas" Time 30 Aug, 1937: 36. Print.

Stowaway. Dir, William Seiter. Perf. Shirley Temple, Robert Young Co., 1936. Film.

Taxi Driver. Dir. Martin Scorsese. Perf. Robert De Niro, Jodie Foster. Columbia Pictures, 1976. Film.

"Table 1-1. Live Births, Birth Rates, and Fertility Rates, by Race: United States, 1909-2000." Centers for Disease Control, National Center for Health Statistics, Vital Statistics. Web. 2 Feb, 2012.

Taylor, Helen. Scarlett's Women: Gone With the Wind and its Female Fans. Rutgers UP: New Brunswick, 1989. Print.

That Hagan Girl. Dir. Peter Godfey. Perf. Shirley Temple, Ronald Regan. 1947. Film.

Thornton, Michael. "Shirley Temple: The Superstar Who Had her Childhood Destroyed by Hollywood." UK Daily Mail Online 18 April 2008. Web.

Thornton, Edie. "Fashion, Visibility, and Class Mobility in Stella Dallas." American Literary History. 11 (1999): 426-47. Web. 
Tompkins, Vincent, ed. "Working Women in the 1930s. " American Decades. 4. 4. Detroit: Gale, 2001. CRSN. Web 17 Nov.2010. Web.

Uys, Errol Lincoln. Riding the Rails: Teenagers on the Move in the Great Depression. New York: Routledge. 2003. Print.

Wallace-Sanders, Kimberly. Mammy: A Century of Race, Gender, and Southern Memory. Ann Arbor: U of Michigan Press. 2008. Print.

Walkerdine, Valerie. Daddy's Girl: Young Girls and Popular Culture. Cambridge: Harvard UP, 1998. Print.

War Babies. Dir. Charles Lamont. Perf. Shirley Temple. Jack Hayes Productions, 1932. Film.

Ware, Susan. Holding Their Own: American Women in the 1930s. Boston: Twayne, 1982. Print.

"What's Wrong with the Movies" New York Times. 13 Nov. 1938. Print.

White, Debra Gray. Ar'n't I a Woman?: Female Slaves in the Plantation South (revised edition) . New York: W.W. Norton and Company. 1999. Print.

Williams, Linda "'Something Else besides a Mother': 'Stella Dallas' and the Maternal Melodrama.” Cinema Journal 24 (1984):27. Web.

The Wizard of Oz. Dir. Victor Fleming. Perf. Judy Garland, Ray Bolger, Bert Lar, and Jack Haley, Frank Morgan, Billy Burke, Margaret Hamilton, Charley Grapewin and the Munchkins. 1939. MGM/UA Home Video, 1989. Film.

Wojcik-Andrews, Ian. Children's Films: History, Ideology, Pedagogy, Theory. New York: Garland, 2000. Print.

Wullschlager, Jackie. Inventing Wonderland: the Lives and Fantasies of Lewis Carroll, Edward Lear, J.M. Barrie, Kenneth Grahame, and A.A. Milne. Free Press: New York, 1995. Print. 
Yarro, Peter, and Leanord Lipton. "Puff the Magic Dragon." Perf. Peter, Paul, and Mary. Warner Bros, 1962. Musical recording.

Zeitz, Joshua. Flapper: A Madcap Story of Sex, Style, Celebrity, and the Woman Who Made America Modern. Three Rivers: New York, 2006. Print. 